\title{
DANIELLE AYUMI NISHIMURA
}

Análise de ressonância magnética com baixo campo para mensuração da porosidade óssea alveolar

São Paulo 



\section{DANIELLE AYUMI NISHIMURA}

Análise de ressonância magnética com baixo campo para mensuração da porosidade óssea alveolar

\section{Versão Corrigida}

Dissertação apresentada à Faculdade de Odontologia da Universidade de São Paulo, pelo Programa de Pós-Graduação em Diagnóstico Bucal, Radiologia Odontológica e Imaginologia, para obter o título de Mestre em Ciências.

Orientador: Profa. Dra. Emiko Saito Arita 
Autorizo a reprodução e divulgação total ou parcial deste trabalho, por qualquer meio convencional ou eletrônico, para fins de estudo e pesquisa, desde que citada a fonte.

Catalogação da Publicação

Serviço de Documentação Odontológica

Faculdade de Odontologia da Universidade de São Paulo

Nishimura, Danielle Ayumi.

Análise de ressonância magnética com baixo campo para mensuração da porosidade óssea alveolar / Danielle Ayumi Nishimura; orientador Emiko Saito Arita. -- São Paulo, 2020.

94 p. : fig., tab., graf. ; $30 \mathrm{~cm}$.

Dissertação (Mestrado) -- Programa de Pós-Graduação em Diagnóstico Bucal, Radiologia Odontológica e Imaginologia. -- Faculdade de Odontologia da Universidade de São Paulo.

Versão corrigida.

1. Imagem por ressonância magnética. 2. Osteoporose. 3. Porosidade. 4. Densidade óssea. I. Arita, Emiko Saito. II. Título. 
Nishimura DA. Análise de ressonância magnética com baixo campo para mensuração da porosidade óssea alveolar. Dissertação apresentada à Faculdade de Odontologia da Universidade de São Paulo para obtenção do título de Mestre em Ciências.

Aprovado em: 22/05/2020

\section{Banca Examinadora}

Prof(a). $\operatorname{Dr}(\mathrm{a})$. Thasia Luiz Dias Ferreira

Instituição: Universidade de Guarulhos (UNG) Julgamento: Aprovada

Prof(a). Dr(a). Marcelo Eduardo Pereira Dutra

Instituição: Universidade Nove de Julho (UNINOVE) Julgamento: Aprovada

Prof(a). Dr(a). Claudio Costa

Instituição: Universidade de São Paulo (USP) Julgamento: Aprovada 

À minha família, que sempre me apoiaram e ficaram ao meu lado. 



\section{AGRADECIMENTOS}

À minha mãe, Sandra Marly Nishimura, meu maior apoio e admiração. Por toda ajuda e compreensão em todos os momentos. Se não fosse por ela, eu não teria chegado até aqui e terminado essa etapa importante na minha vida.

Ao meu irmão, Robson Toshio Nishimura, por ter me ajudado nos momentos difíceis, por toda sua paciência e companhia.

Ao meu tio, batian e tias, por todo carinho, atenção e apoio.

À minha orientadora, Professora Dra. Emiko Saito Arita, por ter sido uma mãe na pós graduação, por todos os conselhos e conhecimentos. Graças a ela, consegui seguir em frente.

Aos meus professores da graduação e pós graduação, por sempre ajudar e compartilhar todos os seus conhecimentos e experiências.

Aos meus amigos da pós graduação, por toda ajuda sempre, deixando o dia dia da pós muito mais feliz.

Aos meus amigos, que sempre me acompanharam em todos os momentos, me dando todo apoio.

À secretária do departamento de radiologia, Cidinha, que é a salvação de todos na pós graduação, sempre tratando todo mundo bem, muito paciente e gentil.

Ao Professor Dr. Arthur Rodriguez Gonzalez Cortes, por disponibilizar os dados dos pacientes, ajudando na metodologia e resultado desse estudo.

Ao Martinos Center - Massachusetts General Hospital - Universidade de Harvard, pela aprovação de uso das imagens de ressonância magnética. 
À Universidade de McGill - Canadá, por analisar as imagens de micro-ct.

O presente trabalho foi realizado com apoio da Coordenação de Aperfeiçoamento de Pessoal de Nível Superior - Brasil (CAPES) - Código de Financiamento 001. 


\section{RESUMO}

Nishimura D.A. Análise de ressonância magnética com baixo campo para mensuração da porosidade óssea alveolar [dissertação]. São Paulo: Universidade de São Paulo, Faculdade de Odontologia; 2020. Versão Corrigida.

A porosidade possui grande influência na resistência óssea, conforme as pessoas vão envelhecendo, a porosidade tende a aumentar, diminuindo a densidade mineral óssea. O objetivo principal desse trabalho foi a avaliação da porosidade óssea com a utilização da técnica de ressonância magnética de baixo campo, comparando com os dados do paciente como a idade e como objetivo secundário consiste em comparar os dados de ressonância magnética com os dados de micro-ct e tomografia computadorizada de feixe cônico (TCFC). Foram incluídos 14 casos de paciente que haviam sido diagnosticados para colocação de ao menos um implante. Os pacientes foram submetidos a um exame de TCFC, onde foi medido as regiões de interesse (ROIs) de $6 \mathrm{~mm}$ de comprimento e $3 \mathrm{~mm}$ de largura, coincidindo com o local de colocação do implante. Com o software Osirix, foi medido os valores de pixel (densidade óssea). Os sítios implantares foram preparados com uma trefina, obtendo amostras ósseas de 3,0 milímetros de diâmetro e 7,0 milímetros de comprimento. As amostras de osso foram fixadas e armazenadas em solução tampão de formaldeído a 10\%, para depois serem escaneados no aparelho de ressonância magnética. Das 14 amostras, as 8 primeiras amostras ósseas foram analisadas com uma máquina de micro-CT, onde analisamos quanto ao número (Tb.N), espessura (Tb.Th), espaçamento trabecular (Tb.Sp) e a fração volumétrica óssea (BV/TV). Os escaneamentos de RM (Ressonância Magnética) foram realizados em um aparelho de 0,3T para amostras (NMI20, Niumag Corporation, Shanghai, China). Os dados das curvas de T2 foram convertidos em porosidade da amostra óssea, isso é possível devido aos diferentes tempos T2 que as moléculas de água de cada poro possuem, uma vez que cada poro tem tamanhos diferentes, ou seja, a água dentro deles tem diferentes tempos T2. Assim, T2 é proporcional ao tamanho do poro. Nos gráficos da $\mathrm{RM}$, conseguimos analisar a relação de quantidade de poros grandes e pequenos, uniformidade e tamanho médio dos poros. $\mathrm{Na}$ análise estatística, a normalidade foi avaliada para as variáveis contínuas (idade, porosidade com RM) através do teste de 
Shapiro-Wilk. Análises de correlação foram realizadas entre todas as variáveis analisadas no estudo. Para teste de correlação foi utilizado os testes de correlação de Pearson e o teste de correlação de Spearman. Todas as análises estatísticas foram realizadas utilizando o software IBM SPSS Statistics 24 . Os resultados dos testes foram considerados estatisticamente significativos quando $p<0,05$. Como resultado achamos correlações positivas entre a fração volumétrica óssea (BV/TV) e espessura trabecular, e correlação negativa entre a fração volumétrica óssea (BV/TV) e raio médio dos poros; e entre a espessura trabecular e o espaçamento trabecular. Diante dos resultados encontrados, conseguimos achar uma correlação na paciente mais idosa de 70 anos, com os achados dos gráficos de RM, micro-ct e TCFC e nos pacientes mais novos, de 35 e 37 anos, tiveram os dois maiores valores de pixel em TCFC, ou seja, foram o que tiveram maior densidade.

Palavras-chave: Imagem por ressonância magnética. Osteoporose. Porosidade. Densidade óssea. 


\begin{abstract}
Nishimura DA. Magnetic resonance analysis with low field to measure alveolar bone porosity [dissertation]. São Paulo: Universidade de São Paulo, Faculdade de Odontologia; 2020. Versão Corrigida.
\end{abstract}

Porosity has a great influence on bone strength, as people age, porosity tends to increase, decreasing bone mineral density. The main objective of this work was the evaluation of bone porosity using the low-field magnetic resonance technique, comparing it with patient data such as age and the secondary objective was to compare the magnetic resonance data with the data of micro-ct and cone beam computed tomography (CBCT). Case of 14 patients that had been diagnosed for placement of at least one implant were included. The patients underwent a CBCT exam, where the regions of interest (ROIs) of $6 \mathrm{~mm}$ in length and $3 \mathrm{~mm}$ in width were measured, coinciding with the implant placement site. Using the Osirix software, pixel values (bone density) were measured. The implant sites were prepared with a trephine, obtaining bone samples of $3.0 \mathrm{~mm}$ in diameter and $7.0 \mathrm{~mm}$ in length. The bone samples were fixed and stored in a $10 \%$ formaldehyde buffer solution, to then be scanned in the MRI (Magnetic Resonance Imaging) machine. Of the 14 samples, the first 8 bone samples were analyzed with a micro-CT machine, where we analyzed the number (Tb.N), thickness (Tb.Th), trabecular spacing (Tb.Sp) and the bone volume fraction ( BV / TV). MRI scans were performed in a 0.3T sample device (NMI20, Niumag Corporation, Shanghai, China). The data of the T2 curves were converted into porosity of the bone sample, this is possible due to the different T2 times that the water molecules of each pore have, since each pore has different sizes, and consequently, the water inside them has different T2 times. Thus, T2 is proportional to the pore size. In the MRI charts, we were able to analyze the relationship between the number of large and small pores, uniformity and average pore size. In the statistical analysis, normality was assessed for continuous variables (age, porosity with MRI) using the Shapiro-Wilk test. Correlation analyzes were performed between all variables analyzed in the study. For the correlation test, Pearson's correlation test and Spearman's correlation test were used. All statistical analyzes were performed using the IBM SPSS Statistics 24 software. As a result, we found positive correlations between the bone 
volume fraction (BV/TV) and trabecular thickness, and a negative correlation between the bone volume fraction (BV/TV) and the average pore radius; and between trabecular thickness and trabecular space. The test results were considered statistically significant when $p<0.05$. In view of the results found, we were able to find a correlation in the oldest patient of 70 years, with the findings of the MRI, micro-ct and CBCT graphs and in the younger patients, of 35 and 37 years, they had the two highest pixel values in $\mathrm{CBCT}$, they had the highest density.

Keywords: Magnetic resonance imaging. Osteoporosis. Porosity. Bone density. 


\section{LISTA DE ILUSTRAÇÕES}

Figura 2.1 - Ilustração da anatomia do osso trabecular .26

Figura 2.2 - Imagem mostrando a microestrutura do osso cortical 27

Figura 2.3 - Imagem 3D de micro-ct mostrando a porosidade cortical do osso femoral.

Figura 2.4 - Imagem da anatomia do osso mandibular .29

Figura 2.5 - Imagem da anatomia do osso maxilar 29

Figura 2.6 - Imagem da máquina de Ressonância Magnética: MesoMR23-060H-I RMN.

Figura 2.7 - Parte das amostras para RMN.

Figura 2.8 - Espaço tridimensional dos poros de arenito

Figura 2.9 - Espectroscopia por RM montrando esquema de relaxação T2, mostrando os três principais sinais de RMN de $1 \mathrm{H}$ no osso. A água dos poros tem um T2> $1 \mathrm{~ms}$ em 4,7T, enquanto a água ligada do colágeno tem T2 300-400 us e uma fração de sinal de RMN de $1 \mathrm{H}$ com T2 $~ 60 \mu$ s curto de núcleos de $1 \mathrm{H}$ em colágeno de matriz óssea.

Figura 2.10 - Esquema mostrando os sinais de $1 \mathrm{H}$ com base no tempo de relaxamento T2: a água dos poros tem T2> $1 \mathrm{~ms}$, a água ligada tem T2 300-400 $\mu \mathrm{s}$ e o colágeno tem T2 $<60 \mu \mathrm{s}$. 35

Figura 2.11 - Imagens A e B: A linha sólida mostra o limite interno do osso total e a linha tracejada o limite interno para análise do osso cortical. Imagens $C$ e D: imagens de micro-CT mostrando a distribuição da porosidade.......36

Figura 2.12 - Imagens de micro-CT mostrando distribuições de poros do osso cortical. No jovem há mais presença de poros normais e grande, enquanto no mais velho, há mais presenças de poros extragrandes e gigantes.......37 
Figura 4.1 - Esquema demonstrando a seleção da amostra.

Figura 4.2 - Resultado da RM do paciente 1

Figura 4.3 - Gráfico do resultado da RM do paciente 2

Figura 4.4 - Dados do resultado da RM do paciente 2. 45

Figura 5.1 - Imagem do gráfico dos dados de RM, tempo T2.do paciente 1 .48

Figura 5.2 - Imagem do gráfico dos dados de RM, tempo T2 do paciente 2 .50

Figura 5.3 - Imagem do gráfico dos dados de RM, tempo T2 do paciente 3 51

Figura 5.4 - Imagem do gráfico dos dados de RM, tempo T2 do paciente 4 53

Figura 5.5 - Imagem do gráfico dos dados de RM, tempo T2 do paciente 5 54

Figura 5.6 - Imagem do gráfico dos dados de RM, tempo T2 do paciente 6 .56

Figura 5.7 - Imagem do gráfico dos dados de RM, tempo T2 do paciente 7 57

Figura 5.8 - Imagem do gráfico dos dados de RM, tempo T2 do paciente 8 59

Figura 5.9 - Imagem do gráfico dos dados de RM, tempo T2 do paciente 9 60

Figura 5.10 - Imagem do gráfico dos dados de RM, tempo T2 do paciente 10 62

Figura 5.11 - Imagem do gráfico dos dados de RM, tempo T2 do paciente 11 63

Figura 5.12 - Imagem do gráfico dos dados de RM, tempo T2 do paciente $12 \ldots \ldots \ldots . .65$

Figura 5.13 - Imagem do gráfico dos dados de RM, tempo T2 do paciente 13...........66

Figura 5.14 - Imagem do gráfico dos dados de RM, tempo T2 do paciente 14 68 


\section{LISTA DE TABELAS}

Tabela 5.1 - Análise descritiva das variáveis contínuas analisadas por este estudo...47

Tabela 5.2 - Tabela dos dados de RM do paciente 1

Tabela 5.3 - Tabela dos dados de RM do paciente 2

Tabela 5.4 - Tabela dos dados de RM do paciente 3.

Tabela 5.5 - Tabela dos dados de RM do paciente 4 .52

Tabela 5.6 - Tabela dos dados de RM do paciente 5 .54

Tabela 5.7- Tabela dos dados de RM do paciente 6. 55

Tabela 5.8 - Tabela dos dados de RM do paciente 7. 57

Tabela 5.9 - Tabela dos dados de RM do paciente 8 58

Tabela 5.10 - Tabela dos dados de RM do paciente 9 60

Tabela 5.11 - Tabela dos dados de RM do paciente 10 61

Tabela 5.12 - Tabela dos dados de RM do paciente 11 .63

Tabela 5.13 - Tabela dos dados de RM do paciente 12 64

Tabela 5.14 - Tabela dos dados de RM do paciente 13 .66

Tabela 5.15 - Tabela dos dados de RM do paciente 14 
Tabela 5.17 - Tabela da uniformidade de poros pequenos

.70

Tabela 5.18 - Tabela da uniformidade de poros grandes........................................70

Tabela 5.19 - Tabela do tamanho médio dos poros pequenos. .71

Tabela 5.20 - Tabela do tamanho médio dos poros grandes... . .72

Tabela 5.21 - Tabela da comparação de idade com os dados de TCFC e micro-ct.....72

Tabela 5.22 - Tabela da análise de correlação linear. .73 


\section{LISTA DE ABREVIATURAS E SIGLAS}

\begin{tabular}{ll} 
2D & Bidimensional \\
BV & Volume ósseo (Bone volume em inglês) \\
TV & Volume tecidual (Tissue volume em inglês) \\
Cbw & Concentração de água dos ossos (Bound water concentration em inglês) \\
Cpw & Concentração de água dos poros (Pore water concentration em inglês) \\
cm & Centímetro \\
Dicom & Imagem Digital e Comunicação em Medicina (Digital Imaging and \\
Communications in Medicine em inglês) \\
DMO & Densidade mineral óssea \\
DXA & Densitometria por absorção de raios-X de dupla energia \\
IMC & Índice de massa corporal \\
H2O & Água \\
IP & Índice de porosidade \\
keV & Quilo elétron-volt \\
MEV & Microscopia eletrônica de varredura \\
Micro-CT & Microtomografia computadorizada \\
Mm & Milímetro \\
mT & Militesla \\
nm & Nanômetro \\
RM & Ressonância magnética \\
RMN & Ressonância magnética nuclear \\
ROls & Regiões de interesse \\
STL & Estereolitografia (stereolithography em inglês) \\
T & Tesla \\
TC & Tomografia computadorizada \\
TCFC & Tomografia computadorizada de feixe cônico \\
UTE & Tempo de eco ultrassônico \\
& \\
\hline
\end{tabular}





\section{SUMÁRIO}

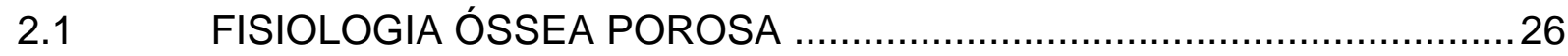

2.2 CARACTERÍSTICA DOS OSSOS MAXILARES E MANDIBULARES......28

$2.3 \quad$ ESTUDOS DE POROSIDADE NAS ROCHAS .......................................

2.4 TÉCNICAS DE IMAGENS PARA ANÁLISE DA POROSIDADE ÓSSEA.32

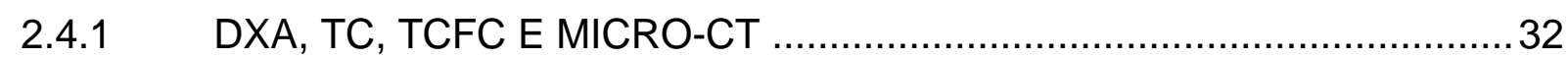

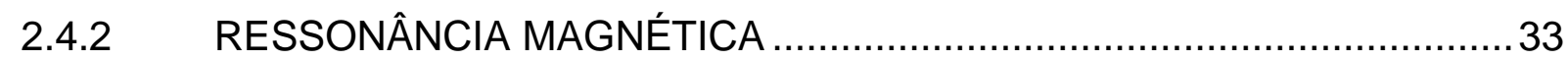

$3 \quad$ PROPOSIÇÃO

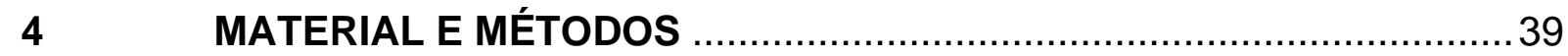

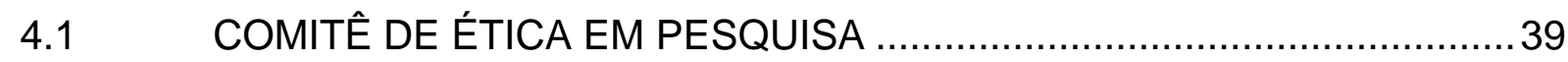

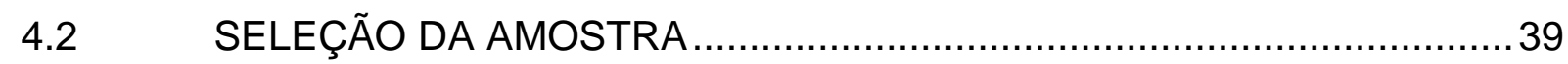

4.3 TOMOGRAFIA COMPUTADORIZADA POR FEIXE CÔNICO .................. 41

4.4 CIRURGIAS DE IMPLANTES E OBTENÇÃO DE AMOSTRAS

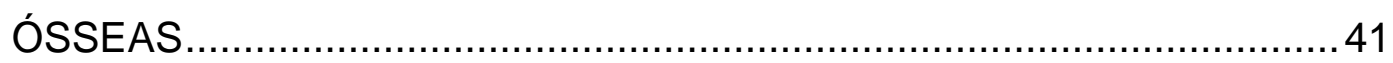

4.5 MICROTOMOGRAFIA COMPUTADORIZADA ….............................. 42

4.6 RESSONÂNCIA MAGNÉTICA DE BAIXO CAMPO …….....................42

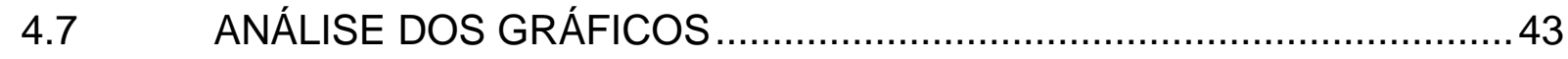

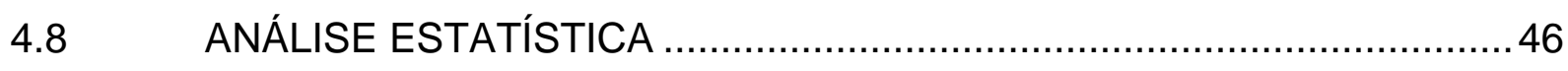

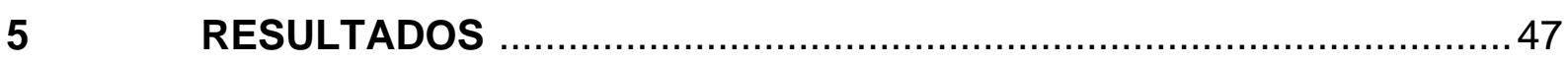

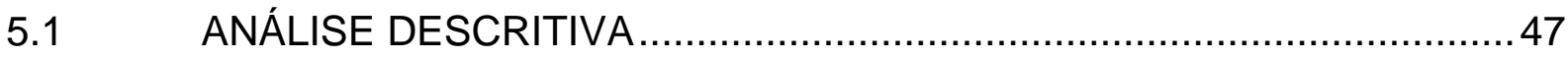

5.2 RESULTADOS INDIVIDUAIS DE RESSONÂNCIA MAGNÉTICA DE

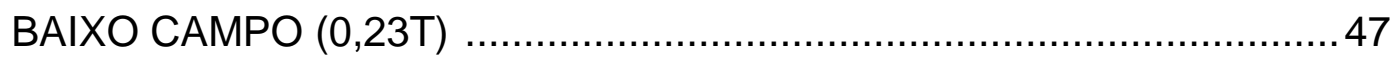

5.3 RESUMO DOS RESULTADOS INDIVIDUAIS DE RESSONÂNCIA

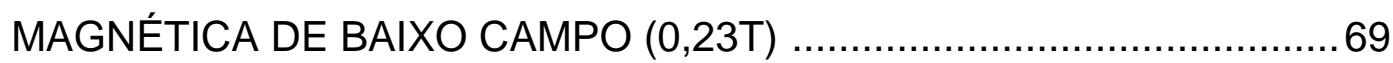

5.4 COMPARANDO IDADE COM OS DADOS DE TCFC E MICRO-CT .........72

5.5 ANÁLISE DE CORRELAÇÃO LINEAR ………...................................73

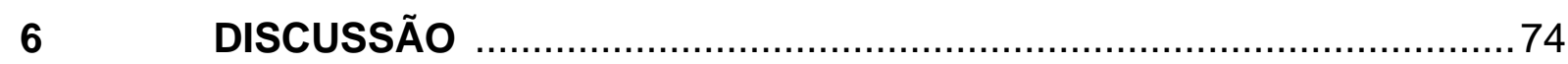

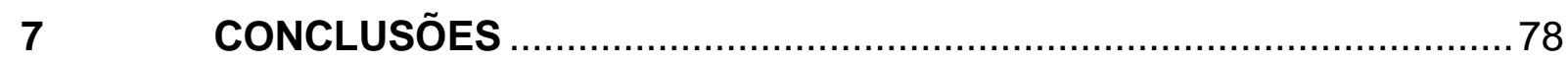




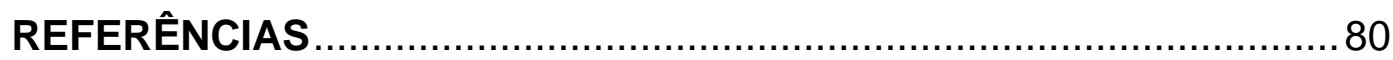

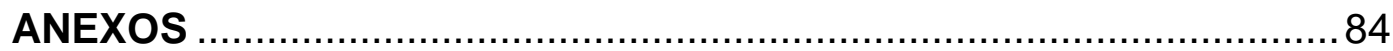




\section{INTRODUÇÃO}

A osteoporose é uma desordem óssea que geralmente ocorre com maior prevalência em mulheres com mais de 60 anos de idade, principalmente após a menopausa. É caracterizada por baixa massa óssea e deterioração microestrutural do tecido ósseo, ocorre 0 aumento da frequência do remodelamento e a reabsorção supera a deposição óssea, ocasionando o aumento do risco de fratura.

O resultado do desequilíbrio mencionado acima, é o adelgaçamento das trabéculas ósseas e o aumento do diâmetro dos poros. A porosidade, por sua vez, é um determinante crítico da força óssea no nível microestrutural $(1,2)$, e sua avaliação in vivo permite estudar a deterioração estrutural na osteoporose e com isso, ajudar no diagnóstico para identificar o risco de fraturas. A porosidade óssea pode aumentar como consequência do envelhecimento. Um aumento no volume de poros no osso normalmente mineralizado se manifesta como uma diminuição da densidade mineral óssea (DMO).

As técnicas mais utilizadas atualmente para a análise da DMO são: Tomografia Computadorizada (TC) e Densitometria por absorção de raios-X de dupla energia (DXA). Entretanto ambos possuem desvantagem: TC utiliza radiação ionizante e DXA não consegue medir a densidade volumétrica verdadeira, como a TC. Com a evolução das técnicas de Ressonância Magnética (RM), a avaliação quantitativa da porosidade óssea é viável.

A RM consiste em uma técnica que possui excelente contraste de tecido moles, é um procedimento não invasivo e o mais importante, não utiliza radiação ionizante. As imagens são formadas a partir de sinais de radiofrequência que são gerados dos núcleos de átomos de hidrogênio, que podem ser encontrados na água e proteína da matriz óssea e na água e gordura da medula óssea (3).

$\mathrm{Na}$ Odontologia, a RM é muito utilizada como um método preciso para a avaliação da imagem dos tecidos moles das estruturas craniofaciais. Como por exemplo, examinar glândulas salivares e articulação temporomandibular. Além disso, podem detectar alterações ósseas precoces, lesões no canal mandibular e terceiros molares mandibulares impactados. Recentemente, algumas pesquisas 
mostraram que a ressonância magnética também podem ser usada para planejamento de implantes, fornecendo informações mais precisas sobre avaliação óssea em relação à densidade e além disso, pesquisa da porosidade no osso alveolar (4).

Apesar da análise de porosidade em rochas ser um assunto muito estudado na área de geologia e também na medicina em ossos como fêmur e tíbia; por enquanto na área da Odontologia até o presente momento não há publicações de artigos referentes a porosidade óssea com Ressonância Magnética.

Diante disso, achamos válido um estudo a cerca da porosidade para avaliar o osso alveolar por meio da técnica de Ressonância Magnética, observar a condição da densidade mineral óssea dos pacientes, conseguir meios de prever risco de osteoporose ou não, além de obter dados com relevância importante como auxiliar no planejamento de implantes, na área de cirurgia ortognática e dentre outras aplicações nas especialidades odontológicas. 


\section{REVISÃO DA LITERATURA}

\subsection{FISIOLOGIA ÓSSEA POROSA}

O osso humano é constituído por dois tipos de ossos: osso cortical e osso trabecular. O osso cortical, também chamado de osso compacto, é denso, compõe $80 \%$ do esqueleto, é uma estrutura rigída, fornecendo resistência mecânica e proteção. O osso trabecular, também chamado de osso esponjoso, é formado por trabéculas finas dispostas entre si, com espaços livre entre elas, onde se encontra a medúla óssea, água, tecido gorduroso e células sanguineas, provém suporte estrutural e flexibilidade (Figura 2.1). Comparando o osso trabecular e cortical, o osso trabecular possui maior quantidade de água e menor teor de cálcio e tem maior atividade metabólica $(5,6)$.

Figura 2.1 - llustração mostrando a anatomia do osso trabecular

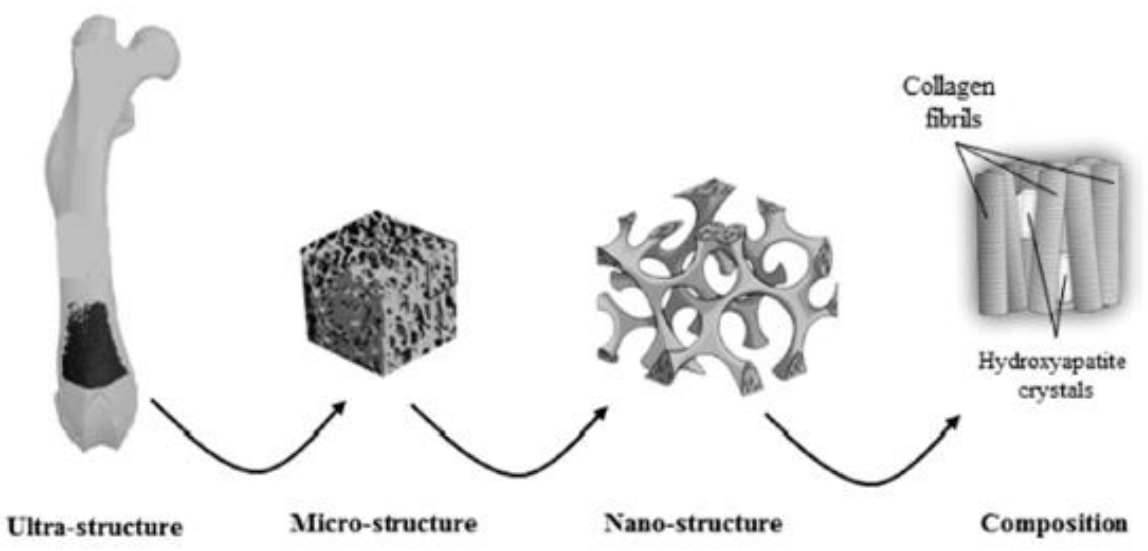

Fonte: Biomechanics and Mechanobiology of Trabecular Bone: A Review (7)

O osso cortical é de natureza porosa e contém três cavidades anatômicas: canais Haversian/Volkmann, lacunas osteocíticas e canalículos (Figura 2.2). Em pesquisa anterior foi demonstrado que os canais de Haversian/Volkmann são os principais segmentos da porosidade total, comparando com as outras cavidades (lacunas e canalículos) (8). 
Figura 2.2 - Imagem mostrando a microestrutura do osso cortical

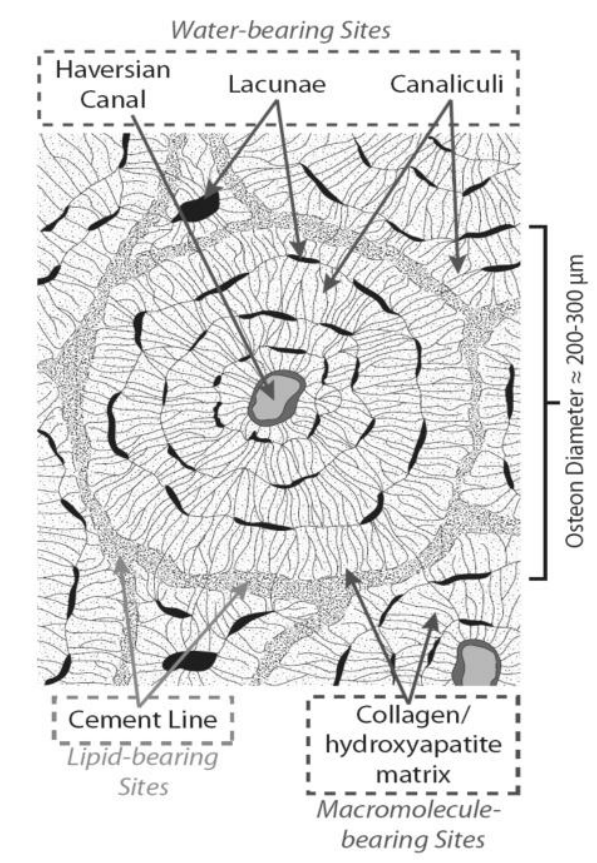

Fonte: Characterization of $1 \mathrm{H} \mathrm{NMR} \mathrm{Signal} \mathrm{in} \mathrm{Human} \mathrm{Cortical} \mathrm{Bone} \mathrm{for} \mathrm{Magnetic} \mathrm{Resonance}$ Imaging (9)

O osso cortical contém cerca de $20 \%$ de água por volume, que divide-se em água livre em poros e água ligada conectada à matriz de colágeno (10). A água livre se encontra nos canais de Havers (diâmetros entre 50-200 $\mu \mathrm{m}$ ), em lacunas osteocíticas $(\sim 5 \mu \mathrm{m})$ e canalículos $(\sim 0,1 \mu \mathrm{m})(11-16)$. E a água ligada conectada a matriz de colágeno incide na densidade da matriz orgânica (DMO) $(14,17)$. A função da água no osso consiste no transporte de oxigênio, nutrientes e sais mineirais, certificando ao osso suas propriedades viscoelásticas e regulando a formação óssea (18).

Conforme a substância óssea é perdida, os espaços dos poros se expandem (17-19). À medida que as pessoas envelhecem, a porosidade do osso cortical aumenta devido ao aumento do tamanho dos poros. Quando em um osso normalmente mineralizado há um aumento no volume de poros, isso se expressa como diminuição da densidade mineral óssea (DMO) (20).

Várias pesquisas demonstraram que a porosidade cortical afeta a microarquitetura do osso cortical, diminuindo a resistência mecânica, como em tração e à compressão $(18,21,22)$ (Figura 2.3). Em um estudo observou-se por testes mecânicos que a porosidade cortical justificou $76 \%$ da variância na resistência à 
tração do osso cortical (23). Além disso, a porosidade cortical tem sido associada negativamente com a rigidez óssea, tenacidade, elasticidade e capacidade de absorver impacto (24). Devido a presença de grandes poros e o córtex delgado (15), o risco de propagação de trinca e fratura pode aumentar, principalmente sob carga de tração. Isto é demonstrado em um estudo (25) onde observou que microfissuras grandes perto de grandes poros corticais diminuem a resistência óssea à fratura.

Figura 2.3 - Imagem 3D de micro-ct mostrando a porosidade cortical do osso femoral

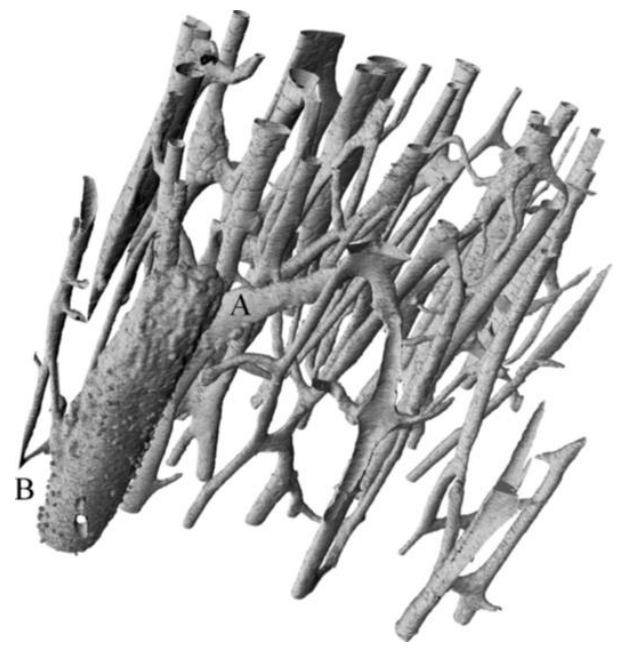

Fonte: Cooper. et al. (22)

\subsection{CARACTERÍSTICA DOS OSSOS MAXILARES E MANDIBULARES}

A maxila e mandíbula se diferem significativamente em relação ao tipo ósseo. A maxila apresenta predominantemente osso com espaços medulares amplos e com pouca espessura cortical, esses espaços são interligados por uma rede de trabéculas, sendo então um osso compacto fino e com pouca resistência, comparadas com as corticais mandibulares (26). Na mandíbula há a predominância de osso com espaços medulares pequenos e com espessa cortical. llustração do osso mandibular e maxilar (Figura 2.4 e 2.5): 
Figura 2.4 - Imagem do osso mandibular

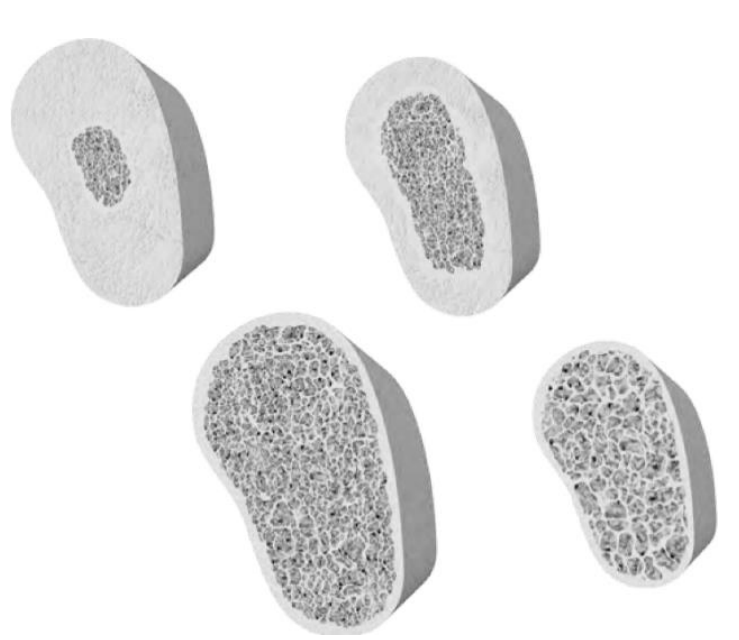

Fonte: Mazzonetto et al. (27)

Figura 2.5 - Imagem do osso da maxila

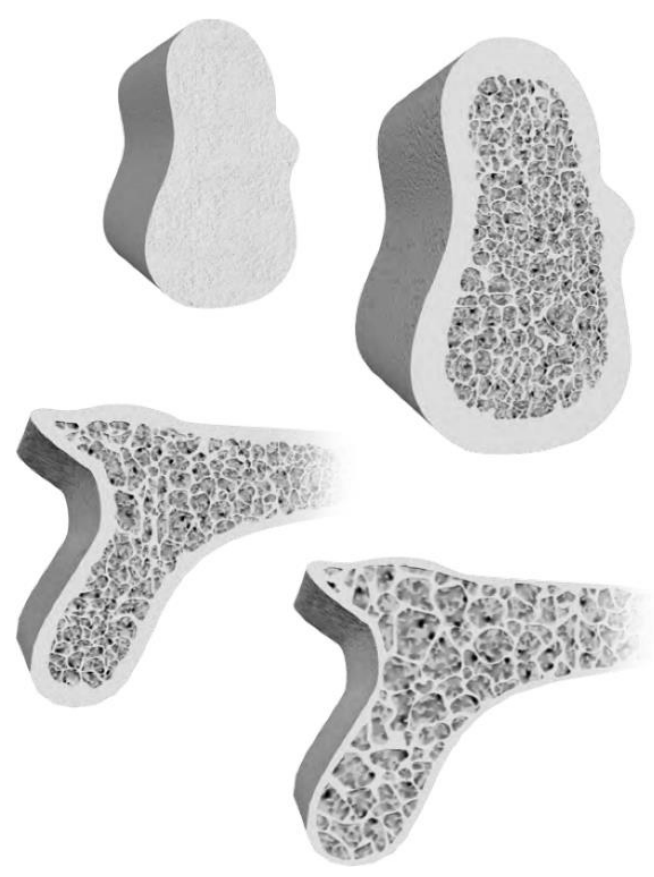

Fonte: Mazzonetto et al. (27) 


\subsection{ESTUDOS DE POROSIDADE NAS ROCHAS}

Nesse estudo, com base em estudos feitos na área de geologia utilizamos como base a mesma metodologia de RMN para análise de poros nas rochas. Nas rochas demonstraram que os picos de T2 médio das moléculas de água são proporcionais a porosidade. Por isso, foi considerado a hipótese de que poderia ser utilizado essa mesma lógica para análise de poros em amostras ósseas humanas.

A porosidade controla o movimento e armazenamento de fluidos e possui um impacto sobre o desgaste nas rochas. Pode ser entendido como a relação entre a razão entre o volume dos espaços vazios e o volume total da rocha (28). Há diferença da quantidade de porosidade de acordo com o tipo de cada rocha, ajudando a determinar suas propriedades físicas, por exemplo, permeabilidade, propriedades de adsorção, resistência mecânica e durabilidade. A porosidade total é o espaço vazio total na rocha, que contribui ou não para o fluxo de fluidos (29).

As técnicas mais utilizadas para analisar as estruturas dos poros são divididas em: análises de imagens, métodos não invasivos e métodos invasivos. Análises de imagens como microscopia eletrônica de transmissão e microscopia eletrônica de varredura (MEV). Métodos não invasivos, como micro-CT (30) e espalhamento de nêutrons de pequeno ângulo (31). Os métodos invasivos são os mais convencionais para quantificar a distribuição do tamanho dos poros, a adsorção de gás e a porosimetria por intrusão de mercúrio. E por último, a ressonância magnética nuclear (RMN), que não é invasivo (32).

A RMN consegue obter o valor da porosidade e distribuição do tamanho dos poros, calculando o volume de poros medindo a massa e densidade de água.

O valor T2 de um poro, que é um índice do tamanho do poro, é proporcional à sua relação superfície-volume $(\mathrm{S} / \mathrm{V})$. A distribuição do tempo de relaxamento tranversal $(\mathrm{T})$ calcula o tamanho dos poros:

$$
1 / T_{2}=\rho_{2} S / V
$$

T2 é o tempo de relaxamento da água no poro; S/V é relação da área da superfície do poro em relação ao volume. 
Em um estudo por Zhang et al. utilizaram 10 amostras de concreto com diferentes relações água-aglomerante e aditivos, para analisar a relação entre permeabilidade e microestrutura do concreto. Devido a característica porosa do concreto leva à maior permeabilidade. Como metodologia, as porosidades e distribuição do tamanho dos poros, foram analisados por porosimetria por intrusão de mercúrio (MIP) e por RMN. Utilizaram neste estudo RMN de baixo campo, MesoMR23060H-I; A Niumag Electric Corporation, com um campo magnético constante de 0,5T (Figura 2.6). Os sinais magnéticos nucleares foram colocados em curvas para observar as relações água-aglomerante e aditivos, nas curvas T2 do concreto (Figura 2.7) (33).

Figura 2.6 - MesoMR23-060H-I RMN

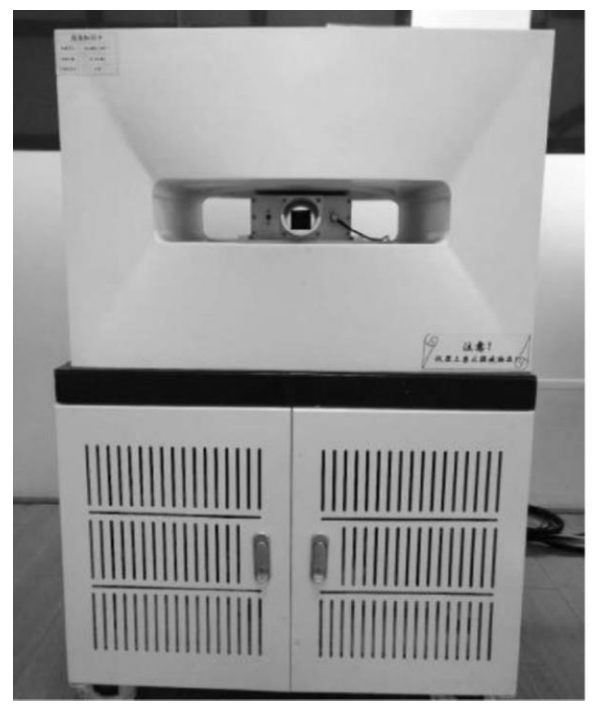

Fonte: Zhang FB et al. (33)
Figura 2.7 - Parte das amostras para RMN

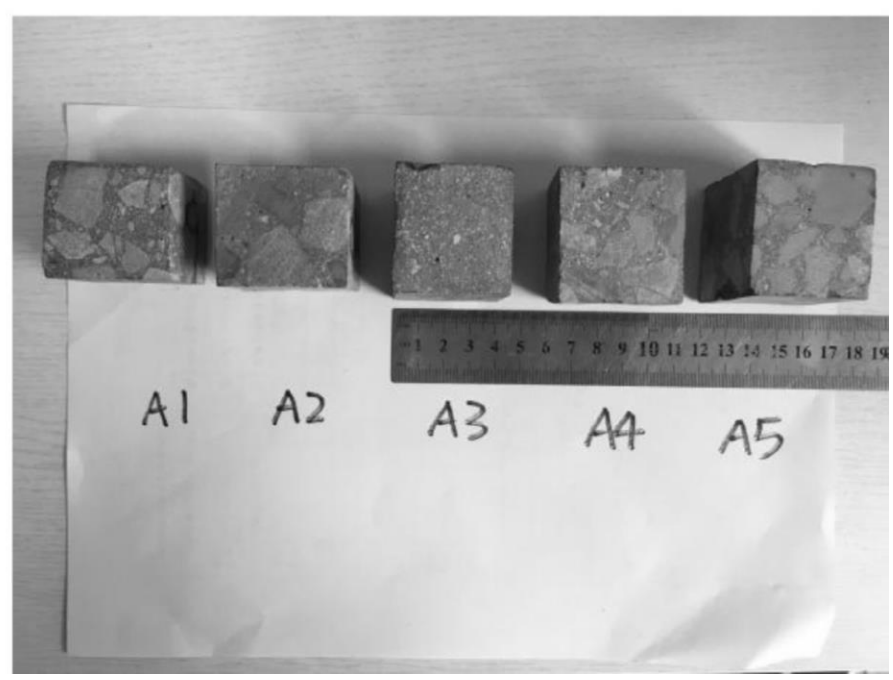

Fonte: Zhang FB et al. (33)

Outro estudo por Biswal et al., realizou uma comparação quantitativa da geometria do espaço poroso em três arenitos naturais e obteve como exemplo a seguinte imagem com micro-CT (Figura 2.8)(34): 
Figura 2.8 - Espaço tridimensional dos poros de arenito

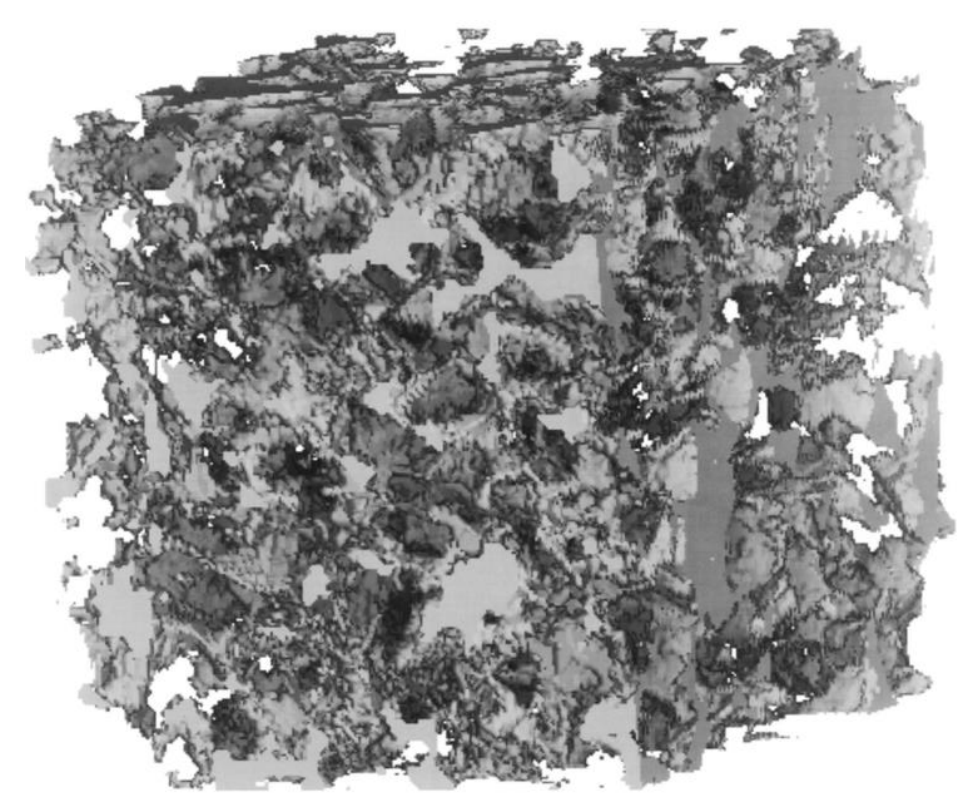

Fonte: Biswal et al. (34)

\subsection{TÉCNICAS DE IMAGENS PARA ANÁLISE DA POROSIDADE ÓSSEA}

\subsubsection{DXA, TC, TCFC E MICRO-CT}

A técnica padrão para avaliação óssea, principalmente para o diagnóstico de osteoporose, é por meio da absorciometria por raios $X$ de dupla energia (DXA). DXA mede a densidade mineral óssea (DMO) bidimensional, ou seja, ela não é capaz de medir diretamente a arquitetura tridimensional (3D), incluindo a morfologia e a porosidade do osso.

A tomografia computadorizada (TC) e a tomografia computadorizada quantitativa (TCQ) possuem uma vantagem sobre a DXA: elas conseguem analisar a estrutura óssea em três dimensões, utizando a escala de Hounsfield. Porém, a TCQ consegue analisar densidade e a porosidade do osso, contudo também tem suas limitações: o uso de radiação ionizante e a incapacidade de detectar pequenos poros, pela sua resolução limitada, não consegue avaliar a matriz orgânica dos ossos e o conteúdo de água (14). Apenas poros relativamente grandes que estão perto do 
endósteo podem ser observados devido sua resolução espacial limitada de aproximadamente $130 \mathrm{~mm}$ (35).

A tomografia computadorizada de feixe cônico (TCFC) em estudos mais recentes comprovaram ser um método eficaz para análise de densidade óssea, alguns estudos utilizaram por meio da análise de valores de pixels, descrita como proporcional à densidade mineral óssea do osso alveolar (36-38). Algumas vantagens da TCFC em relação com a TC são as doses de radiação potencialmente mais baixas e menores custos (39).

A micro-CT é um método 2D e 3D padrão ouro para visualização da microestrutura do tecido ósseo, consegue observar os poros, analisar e quantificar até mesmo os de tamanho pequeno (40). Entretanto, é um método laboratorial, por meio de uma biópsia (ex vivo) e não pode ser utilizado clinicamente.

\subsubsection{RESSONÂNCIA MAGNÉTICA}

A ressonância magnética possui uma vantagem principal em relação às técnicas citadas anteriormente: não expõem o paciente à radiação ionizante. Entretanto, para análise óssea a RM possui uma desvantagem: não consegue reproduzir a imagem diretamente do conteúdo mineral do osso, e sim de imagens de fluidos dentro ou ao redor do osso (água, gordura e tecidos hematopoiéticos), pois o osso na RM mostra pouco ou nenhum sinal. Isso ocorre porque o osso é composto principalmente de hidroxiapatita de cálcio, que possui apenas um próton que não se move. Na RM o osso aparece como uma imagem hipossinal (preta), devido ao tempo de decaimento ser muito curto e com um sinal mínimo, enquanto os fluídos aparecem hipersinal (branco) (22).

Estudos recentes com RM e espectroscopia de RMN avaliaram a porosidade cortical medindo a água livre dentro desses poros e associaram RMN com histomorfometria e medidas de micro-CT da porosidade cortical $(10,11,41)$. Como resultado indicaram que concentrações de água do poro cortical podem ser utilizadas como uma medida de porosidade e concluiram que ossos com poros corticais grandes possuem maiores tempos de relaxamento T2 (>1 ms), enquanto ossos com poros pequenos possuem tempos T2 mais curtos ( $\leq 10 \mathrm{~ms}$ ). Outro estudo observou forte 
correlação entre a porosidade analisada de RM de T2 longo e a porosidade avaliada pela histomorfometria em $\operatorname{RM}(8,14)$.

Outros estudos mostraram que os sinais de RMN com T2 curto correspondem principalmente à água ligada ao colágeno e com componentes T2 mais longos correspondem à água do poro $(9,18)$. Um trabalho sobre espectroscopia de relaxamento transversal de RMN de prótons em ossos corticais observou que aproximadamente dois terços do sinal total da água do osso provêm da água ligada ao colágeno e um terço surge da água dos poros (9). Outro estudo observou que à medida que a porosidade aumenta, há um aumento de T2, pois há uma menor relação superfície-volume dos poros (Figura 2.9 e 2.10) (19).

Figura 2.9 - Espectroscopia por RM montrando esquema de relaxação T2, mostrando os três principais sinais de RMN de $1 \mathrm{H}$ no osso. A água dos poros tem um T2> $1 \mathrm{~ms}$ em 4,7T, enquanto a água ligada do colágeno tem T2 300-400 $\mu$ s e uma fração de sinal de RMN de $1 \mathrm{H}$ com T2 $60 \mu$ s curto de núcleos de $1 \mathrm{H}$ em colágeno de matriz óssea

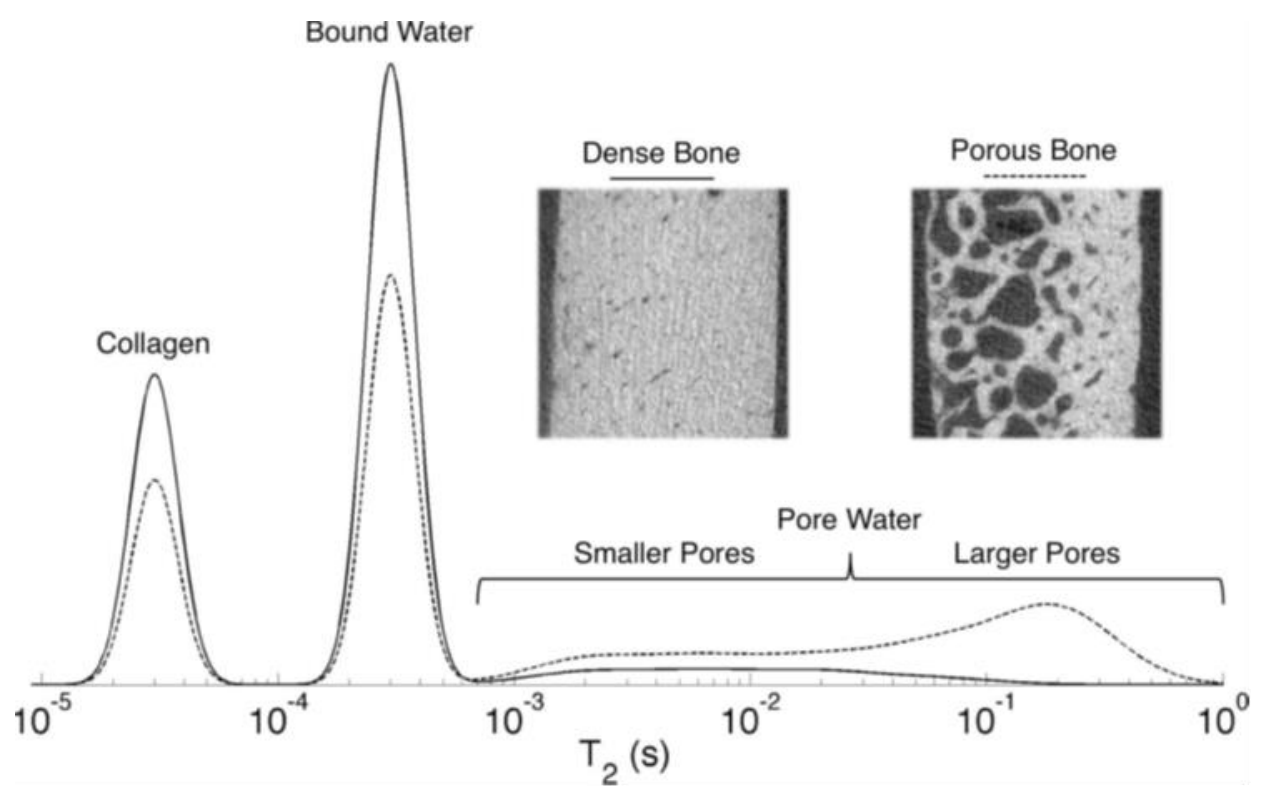

Fonte: Seifert et al. (19) 
Figura 2.10 - Esquema mostrando os sinais de 1H com base no tempo de relaxamento T2: a água dos poros tem T2> $1 \mathrm{~ms}$, a água ligada tem T2 300-400 $\mu$ s e o colágeno tem T2 <60 $\mu \mathrm{s}$

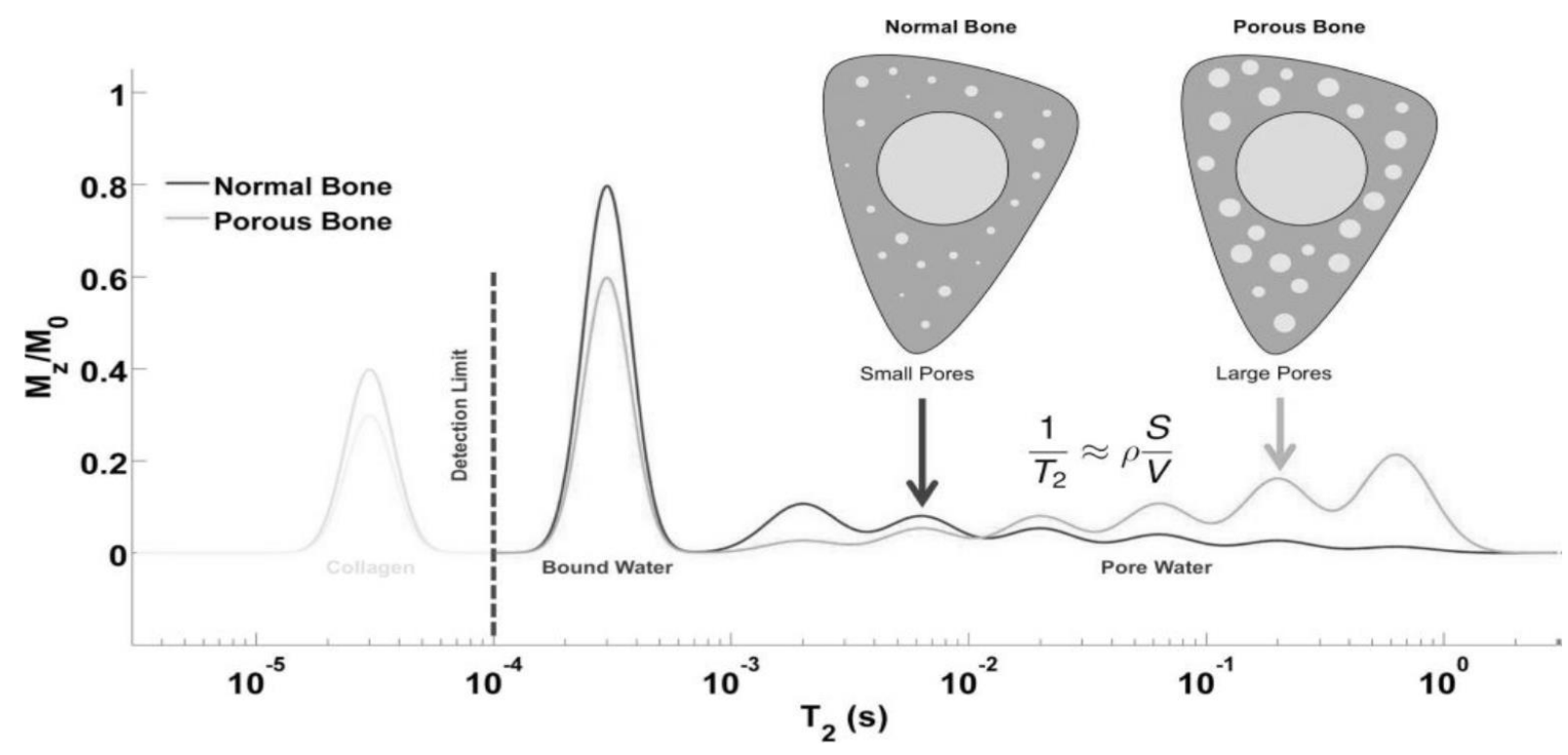

Fonte: Seifert et al. (42)

Uma outra pesquisa também observou que, com o aumento da porosidade, os poros aumentam de tamanho, causando tempos prolongados de relaxamento T2 da água (como resultado da diminuição da relação superfície-volume, que é a relação da área da superfície do poro em relação ao volume) (20). Outro estudo também analisou imagens de espectroscopia de prótons nucleares de osso cortical humano e sugeriram que a fração de água ligada com T2 curto e fração de água porosa com valores T2 mais longos estão positivamente e negativamente associados a força óssea, respectivamente (43).

Um estudo com UTE (tempo de eco ultrassônico) investigou concentrações de água do osso e de água dos poros (Cbw e $\mathrm{Cpw}$ ) para preditar o risco de fratura. As propriedades estruturais e materiais do osso foram comparados com os valores de DXA e micro-CT (44). Como resultado, as medidas de Cbw e Cpw tiveram uma capacidade preditiva similar de força do material. Cbw foi o único a correlacionar-se com a tenacidade óssea. Com isso concluiram que as medidas derivadas da RM de Cbw e Cpw no osso cortical podem serem úteis para avaliar o risco de fraturas.

Um estudo recente mediu o índice de porosidade (IP) por RM UTE do colo do fêmur e tíbia e correlacionaram com idade, sexo, pré e pós-menopausa, e índice de massa corporal (IMC). O IP foi calculado como a razão entre as intensidades de imagem do segundo eco (sinais principalmente da água do poro) e o primeiro eco 
(sinais de toda a água), que representou a fração poro-água e foi correlacionada positivamente com porosidade cortical medida por micro-CT in vitro. Como resultado, os IPs apresentaram correlações com idade, pré e pós-menopausa, gênero e IMC, porém não houve correlação entre eles (45).

No estudo feito por Rajapakse et al., tinha por objetivo desenvolver um método clinicamente prático para avaliar a porosidade cortical óssea medindo o decaimento do sinal em dois TEs (50 ms- TE curto e $2000 \mathrm{~ms}$ - TE longo) em um exame de RM de UTE. Para analisar a porosidade também utilizaram o IP: (TE longa intensidade/TE baixa intensidade) $x 100$, e os resultados foram comparados com a análise biexponencial. O IP foi realizado em amostras de osso cortical da tíbia obtidas de 16 doadores e foi comparado com a porosidade usando imagens de micro-CT e densidade mineral óssea por meio de tomografia computadorizada periférica quantitativa. E com os mesmos métodos realizaram a reprodutibilidade do índice de porosidade em 5 pacientes saudáveis e analisaram a viabilidade clínica em 34 mulheres na pós-menopausa. Como resultado, o índice de porosidade foi correlacionado com a porosidade de imagem do micro-CT e tamanho do poro; idade; densidade periférica de tomografia computadorizada quantitativa; e fração de água porosa e T2 (Figuras 2.11 e 2.12) (41).

Figura 2.11 - Imagens A e B: A linha sólida mostra o limite interno do osso total e a linha tracejada o limite interno para análise do osso cortical. Imagens $C$ e D: imagens de micro-CT mostrando a distribuição da porosidade

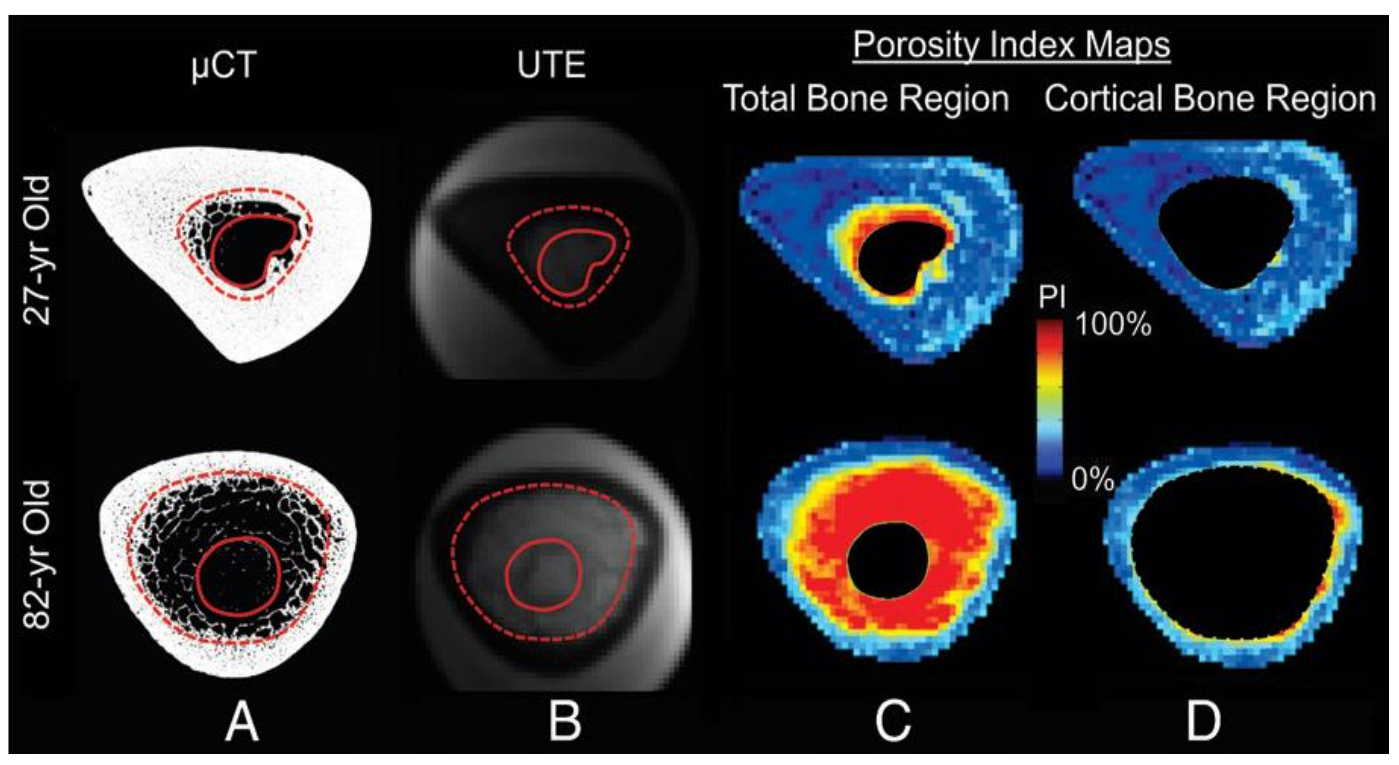

Fonte: Rajapakse et al. (41) 
Figura 2.12 - Imagens de micro-CT mostrando distribuições de poros do osso cortical. No jovem há mais presença de poros normais e grande, enquanto no mais velho, há mais presenças de poros extragrandes e gigantes

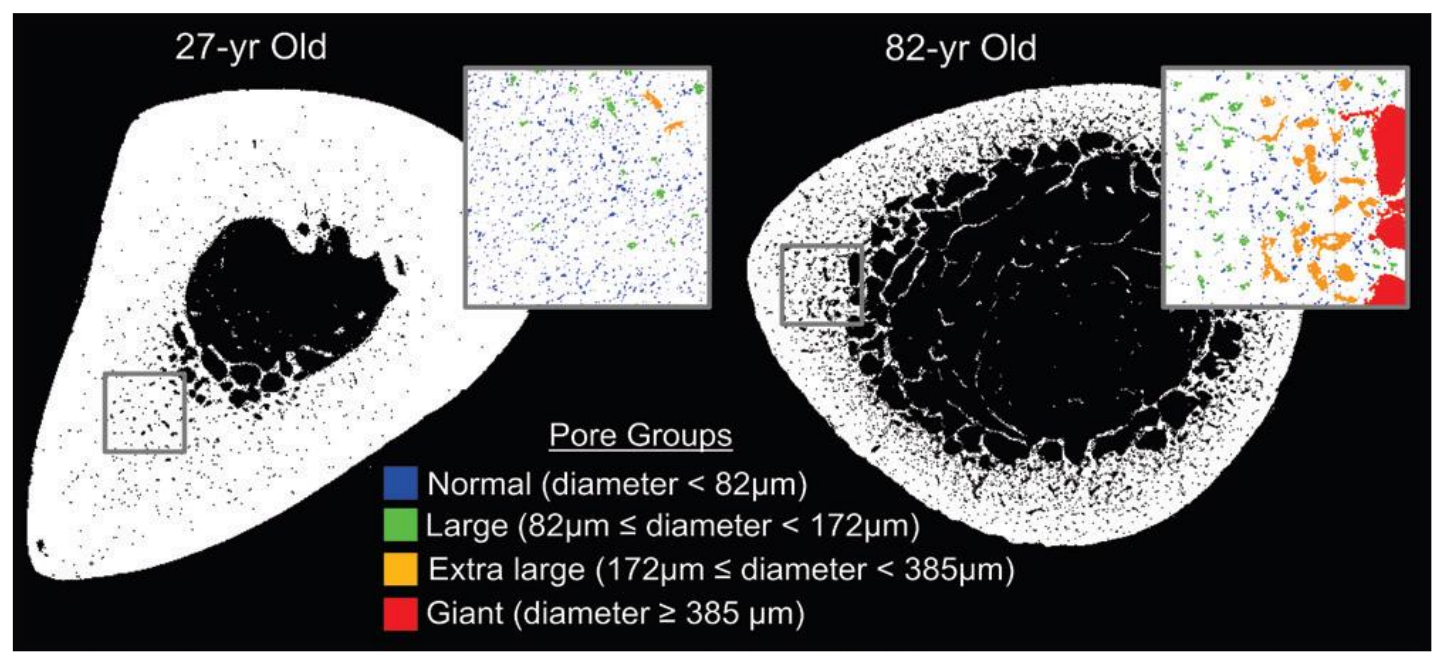

Fonte: Rajapakse et al. (41) 


\section{PROPOSIÇÃO}

O objetivo principal nesse trabalho consiste na avaliação da porosidade óssea, no osso alveolar, com a utilização da técnica de Ressonância Magnética de baixo campo, comparando com dados do paciente, levando em conta a idade.

O objetivo secundário consiste em comparar os dados de RM de baixo campo com os dados de micro-ct e TCFC. 


\section{MATERIAL E MÉTODOS}

\subsection{COMITÊ DE ÉTICA EM PESQUISA}

O presente estudo retrospectivo foi enviado ao Comitê de Ética em Pesquisa da Universidade de São Paulo e aprovado sob o número: 2.865.434 (Anexo A). Foram utilizados apenas resultados dados de escaneamento de Ressonância Magnética do Hospital Geral de Massachusetts, da universidade de Harvard. As diretrizes STARD para estudos de diagnóstico e as diretrizes da Declaração de Helsinque também foram cuidadosamente respeitadas durante a pesquisa (Anexo B).

\subsection{SELEÇÃO DA AMOSTRA}

Foram incluídos 14 casos de paciente parcialmente edêntulos, e que já haviam sido diagnosticados para colocação de ao menos um implante. Sítios implantares com extração dentária recente (menos de 6 meses de acompanhamento) foram excluídos para evitar o período de cicatrização alveolar.

Dos 14 casos, 13 são do sexo feminino e 1 do sexo masculino. A faixa etária era entre 35 a 70 anos de idade. $E$ a amostra óssea retirada pela trefina, eram 8 da região da maxila e 6 da região da mandíbula (Figura 4.1). 
Figura 4.1 - Esquema demonstrando a seleção da amostra

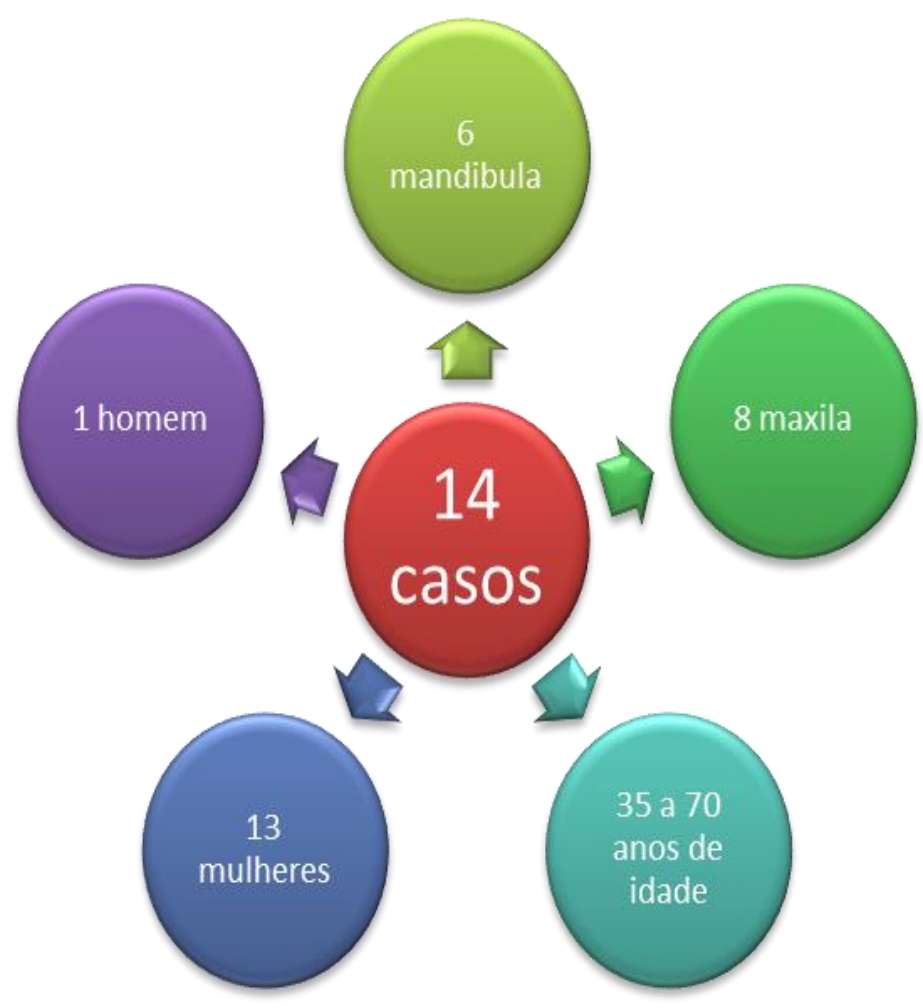

Também foram excluídos os pacientes com distúrbios metabólicos, como diabetes e deficiência de vitamina $D$, com volume ósseo alveolar insuficiente para a colocação do implante, grávidas ou com suspeita de gravidez, e menores de idade.

\subsection{TOMOGRAFIA COMPUTADORIZADA POR FEIXE CÔNICO}

Todos os pacientes foram submetidos a um exame de TCFC, indicado para planejamento cirúrgico virtual, utilizando o mesmo dispositivo (i-CAT Classic, Imagem Sciences International, Hatfield, PA, EUA), com um protocolo de diagnóstico utilizado para implantes dentários $(0,25 \mathrm{~mm}$ de voxel, $120 \mathrm{kVp}, 8 \mathrm{~mA}$, tempo de exposição de 8,5 segundos, e campo de visão de $16 \mathrm{~cm}$ de diâmetro e $6 \mathrm{~cm}$ de altura) (46). O campo de visão mencionado incluiu apenas um arco dentário completo em resolução padrão, permitindo uma dose de radiação efetiva baixa (aproximadamente 35 microsieverts), 
como relatado por um estudo utilizando o mesmo dispositivo de TCFC (47). Imagens DICOM (digital Imaging communication in medicine) foram avaliadas com o software OsiriX (versão 3.9.4 OsiriX, Pixmeo, Genebra, Suíça). As áreas edêntulas do rebordo, planejadas para receber implantes dentários, foram delimitadas em cortes parassagitais de TCFC, e identificadas como regiões de interesse (ROIs) de $6 \mathrm{~mm}$ de comprimento e $3 \mathrm{~mm}$ de largura, coincidindo com o local de colocação do implante. Os valores de pixel (densidade óssea radiográfica) foram medidos nas imagens das ROls, por meio de dois observadores cirurgiões dentistas radiologistas treinados, com as ferramentas específicas do software Osirix, em escala 12 Bit. Em seguida, as imagens DICOM e de ROls foram exportadas para o formato STL (arquivo referente a estereolitografia), e utilizadas para fazer um guia cirúrgico personalizado utilizando uma máquina de prototipagem rápida (Bioparts, São Paulo, Brasil). Os guias cirúrgicos possuíam perfurações compatíveis com as brocas e trefinas utilizadas, no intuito de evitar desvios angulares durante o processo de preparação do sitio, garantindo assim a colocação do implante no mesmo ROI de TCFC utilizado para as medidas radiográficas.

\subsection{CIRURGIAS DE IMPLANTES E OBTENÇÃO DE AMOSTRAS ÓSSEAS}

A coleta de amostras ósseas foi realizada em todos os casos imediatamente antes de serem então submetidos ao procedimento de colocação de implantes. Uma hora antes das cirurgias, todos os pacientes receberam antibioticoterapia profilática com amoxicilina $(2,0 \mathrm{~g})$, e foram tratados pelo mesmo cirurgião, utilizando o mesmo procedimento cirúrgico. Após anestesia local, uma incisão foi realizada na crista óssea do rebordo (ligeiramente palatal à linha média), e o retalho mucogengival foi elevado. Utilizando guia cirúrgico, os sítios implantares foram preparados com uma trefina, utilizada para obter amostras ósseas de 3,0 milímetros de diâmetro e 7,0 milímetros de comprimento (tal osso sempre é normalmente removido para colocar os implantes). As amostras de osso foram fixadas e armazenadas em solução tampão de formaldeído a 10\%, de acordo com metodologias descritas anteriormente para a avaliação óssea trabecular com ressonância magnética $(48,49)$. 
Uma broca cirúrgica adicional de 3,5 milímetros de diâmetro interno foi utilizada para completar a preparação do local do implante. Em seguida, implantes dentários (SLA, Straumann AG, Basiléia, Suíça) com 4,1 mm de diâmetro e 10,0 mm de comprimento, foram colocados usando uma catraca adaptada ao torquímetro do sistema de implante. Todos os implantes foram colocados com a plataforma permanecendo ao nível do tecido gengival, e restaurados após dois meses de cicatrização.

\subsection{MICROTOMOGRAFIA COMPUTADORIZADA}

Das 14 amostras, as 8 primeiras amostras ósseas foram analisadas com uma máquina de micro-ct (SkyScan1172 @; SkyScan; Kontich, Bélgica) no laboratório de imagem da Universidade McGill, Montreal, Canadá. Devido á um problema técnico, não foi possível realizar a análise de micro-ct com todas as amostras. O protocolo de imagem utilizado foi de $100 \mathrm{KeV}$ e 100 micro-amperes, e uma resolução de $6,0 \mathrm{mM}$, com um filtro de Al de $0,5 \mathrm{~mm}$. O tempo de exposição por quadro foi de $450 \mathrm{~ms}$, e as imagens de raios- $X$ foram reconstruídas com o software Nrecon $\AA^{\circledR}$ (Sky-Scan, Kontich, Bélgica), para que então pudessem ser analisadas quanto a número (Tb.N), espessura (Tb.Th) e espaçamento trabecular (Tb.Sp), assim como para fração volumétrica óssea (BV/TV) usando uma ferramenta do mesmo software de análise quantitativa tridimensional morfométrica. BV/TV é uma variável que se refere à quantidade total de osso presente dentro da biópsia, incluindo osso cortical e trabecular $(38,50)$.

\subsection{RESSONÂNCIA MAGNÉTICA DE BAIXO CAMPO}

Todos os escaneamentos de RM foram realizados em um aparelho pequeno de 0,3T para amostras (NMI20, Niumag Corporation, Shanghai, China) com um gradiente máximo de 2370 mT (militesla), com interface Siemens (Siemens Medical Systems, Erlangen, Alemanha), disponível no departamento de Radiologia 
(Universidade de Harvard, Boston, EUA). Todos os exames foram obtidos usando a orientação coronal.

Uma sequência de pulso 2D específica e experimental foi utilizada para avaliar curva de distribuição de T2 (tempo de relaxamento da magnetização vertical) de prótons presentes em moléculas de $\mathrm{H} 2 \mathrm{O}$. Um software do próprio aparelho (NMI Analyzing system Versão 4, Niumag Corporation) foi utilizado para converter os dados das curvas de T2 em porosidade da amostra óssea. Isso é possível devido aos diferentes tempos T2 que as moléculas de água de cada poro possuem, uma vez que cada poro (espaço entre trabéculas) tem tamanhos diferentes, e por consequência, a água dentro deles tem diferentes tempos T2. Assim, T2 é proporcional ao tamanho do poro.

\subsection{ANÁLISE DOS GRÁFICOS}

Pelos gráficos obtidos nos escaneamentos de RM, conseguimos analisar:

- A razão de volume de grandes e pequenos poros, que pode ser derivada da razão da área de pico. Por exemplo, no paciente 1 (Figura 4.2) a proporção de poros grandes e poros pequenos é $4376 \div 2264=1,93 \quad 0,659 \div 0,341=1,93$.

- A uniformidade do tamanho dos poros, que pode ser derivada da largura do pico (igual ao tempo final do pico - tempo do pico). Para o paciente 1, a uniformidade dos poros pequenos é igual a $(2.407-0.010) \div 1.016=2$; e a uniformidade de poros grandes é igual a $(1955.9-2.355) \div 29.292=66.7$. 
Figura 4.2 - Resultado da RM do paciente 1

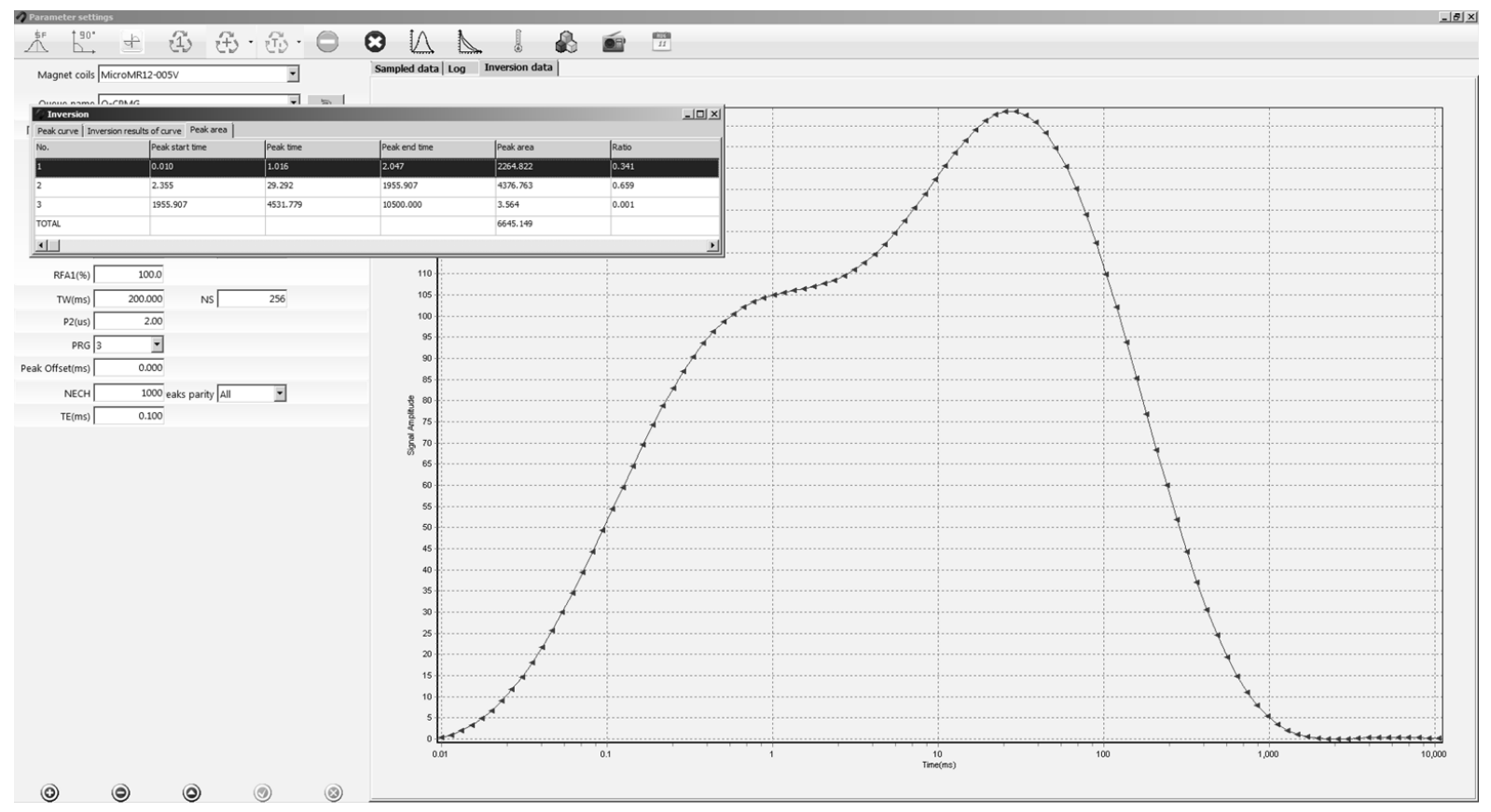

Fonte: A autora

Em outro gráfico, como exemplo o Paciente 2 (Figura 4.3), conseguimos observar que:

- Para os dados do espectro T2, há apenas dois picos principais, um dos picos representa pequenos poros e o segundo consiste nos grandes poros. Se a razão de pico for igual a 0 , esse é um pico falso que causado pelo ruído podemos ignorá-lo (pico número 1). Em alguns pacientes, há um pico muito longo em que o tempo de pico é igual a 2000ms ou ainda maior, que podemos ignorá-lo também por razão similar.

- Diante disso, os picos verdadeiros são nำ e nํ 3, representados por poros pequenos e grandes, respectivamente. Para ํㅜㄴ, 4 e 5 a área é 0, por isso pode-se desconsiderar, são picos falsos. 
Figura 4.3 - Gráfico do resultado da RM do paciente 2

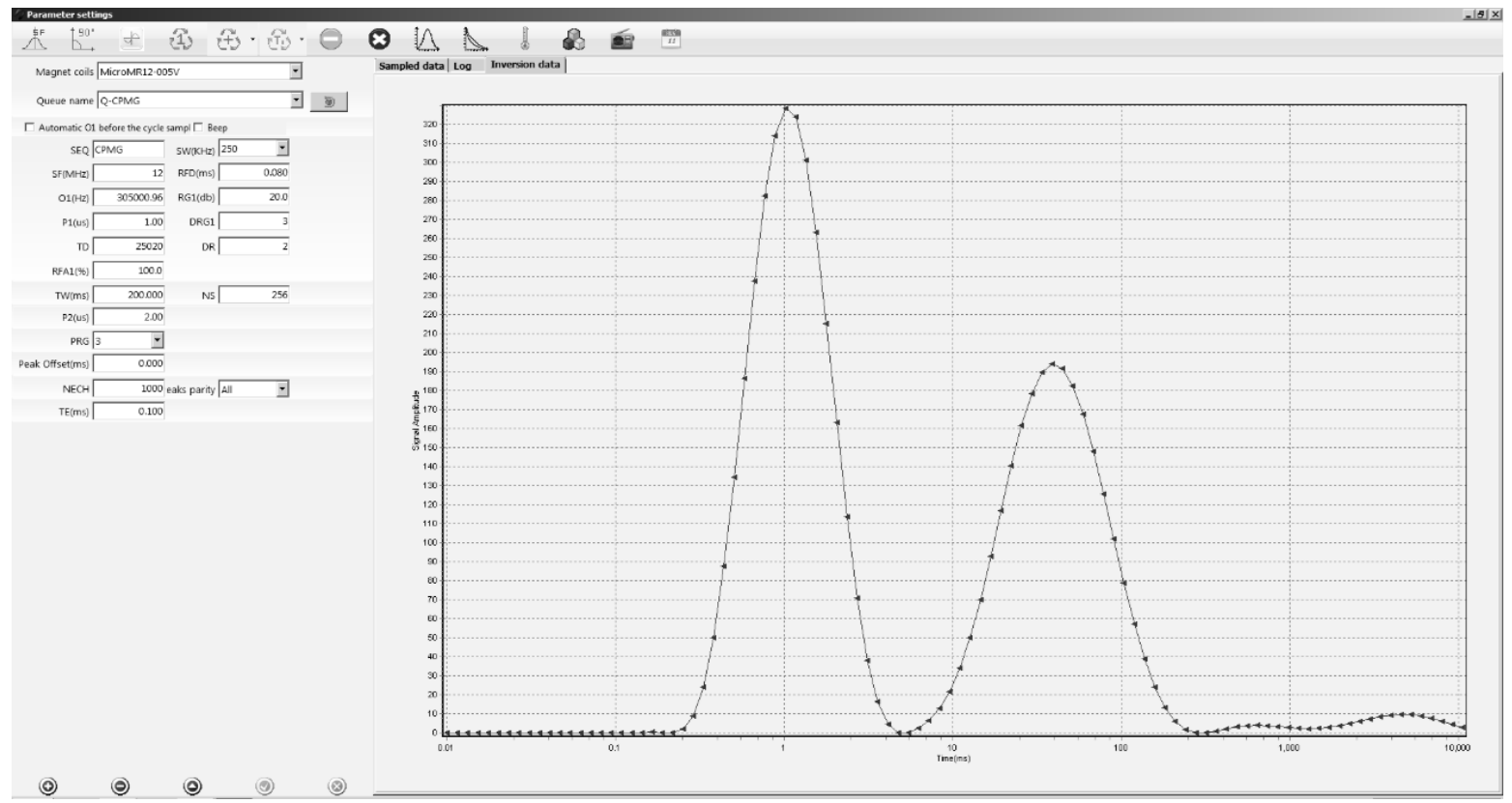

Fonte: A autora

Figura 4.4 - Dados do resultado da RM do paciente 2

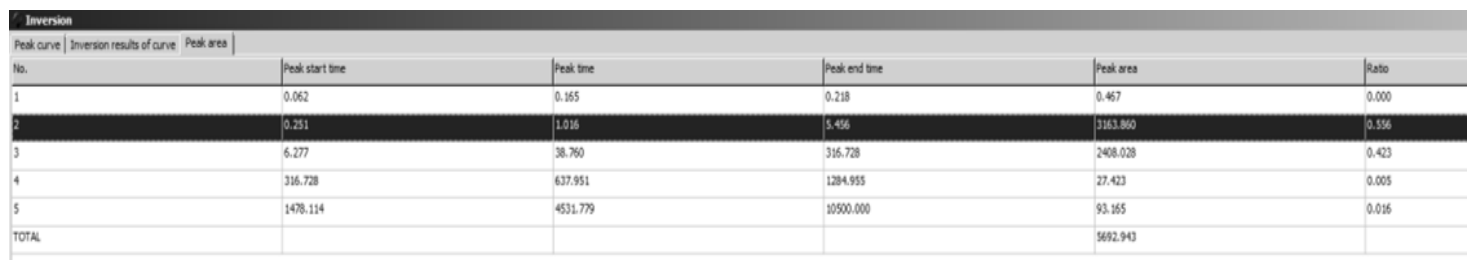

Fonte: A autora

Em resumo:

1. No paciente 1, no longo T2 (grandes poros) tem um tamanho de poro pouco menor (29.292ms) do que o longo T2 do paciente 2 (38.76ms). O tempo mais longo de pico mostra maior tamanho de poro.

2. No paciente 1, a amostra tem uma variabilidade maior do tamanho do poro (tempo final do pico - tempo de início do pico=1955.907ms-2.355ms) do que o paciente 2 (316.728ms-6.277ms).

3. O aparelho NIUMAG também consegue analisar o tamanho médio dos poros pequenos e grandes. 


\subsection{ANÁLISE ESTATÍSTICA}

Uma vez que correlações diretas são esperadas, o tamanho da amostra foi previamente determinado para correlações numéricas mínimas de valor $r=0.8$, dando ao estudo um poder estatístico de $80 \%$, ao nível de significância de 5\% ( $n=14$ pacientes). Considerando que a amostra era um número menor que 100, a normalidade foi avaliada para as variáveis contínuas (idade, porosidade com RM) através do teste de Shapiro-Wilk. Análises de correlação foram realizadas entre todas as variáveis analisadas no estudo. Assim, o teste de correlação de Pearson foi utilizado para correlações que envolvem apenas variáveis contínuas normais, enquanto as correlações envolvendo ao menos uma das variáveis categóricas, foram analisadas com o teste de correlação de Spearman.

Todas as análises estatísticas foram realizadas utilizando o software IBM SPSS Statistics 24 (SPSS, Inc, Chicago, IL). Para todos os testes foram estabelecido um erro $\alpha=5 \%$, isto é, os resultados dos testes foram considerados estatisticamente significativos somente quando $p<0,05$. 


\section{RESULTADOS}

\subsection{ANÁLISE DESCRITIVA}

Um total de 14 pacientes (13 do sexo feminino, 1 do sexo masculino; idade média de $55.86 \pm 9.47$ ) foram avaliados nesse estudo. Não houve complicações relacionadas aos procedimentos cirúrgicos nos quais as respectivas amostras foram retiradas. De maneira similar, todos os implantes colocados nos sítios de rebordo alveolar analisados obtiveram satisfatória osseointegração e foram posteriormente reabilitados com um tempo mínimo de 3 anos de acompanhamento. Todas as variáveis apresentaram curva de normalidade, confirmada ao teste de Shapiro-Wilk ( $p>0,05)$. As análises descritivas das variáveis estão disponíveis na tabela 5.1.

Tabela 5.1 - Análise descritiva das variáveis contínuas analisadas por este estudo

\begin{tabular}{|c|c|c|c|}
\hline Método & Variável & $\begin{array}{c}\text { Média } \pm \\
\text { Desvio padrão }\end{array}$ & Unidade \\
\hline \multirow{2}{*}{ TCFC } & Valores de pixel & $482,38 \pm 153,41$ & Valor de pixel: 12bit \\
\hline \multirow{2}{*}{ Micro-TC } & BV/TV & $82,46 \pm 11,59$ & porcentagem \\
\cline { 2 - 4 } & Espessura trabecular & $0,46 \pm 0,10$ & $\mu \mathrm{m}$ \\
\cline { 2 - 4 } & Espaçamento trabecular & $0,19 \pm 0,10$ & $\mu \mathrm{m}$ \\
\cline { 2 - 4 } & Número de trabéculas & $1,82 \pm 0,23$ & $1 / \mu \mathrm{m}$ \\
\hline \multirow{2}{*}{ RM } & Tempo do pico de T2 & $1,46 \pm 0,46$ & $\mathrm{~ms}$ \\
& Tamanho médio dos poros & $8,79 \pm 2,80$ & $\mathrm{~nm}$ \\
\hline
\end{tabular}

\subsection{RESULTADOS INDIVIDUAIS DE RESSONÂNCIA MAGNÉTICA DE BAIXO CAMPO $(0,23 T)$}

Paciente 1:

- 70 anos de idade,

- sexo feminino, 
- região da amostra óssea: maxila (região do dente 12)

Tabela 5.2 - Tabela dos dados de RM do paciente 1

\begin{tabular}{llllll}
\hline$N^{\circ}$ & $\begin{array}{l}\text { Início tempo } \\
\text { de pico }\end{array}$ & $\begin{array}{l}\text { Tempo de } \\
\text { pico }\end{array}$ & $\begin{array}{l}\text { Final tempo } \\
\text { de pico }\end{array}$ & $\begin{array}{l}\text { Área de } \\
\text { Pico }\end{array}$ & Razão \\
\hline 1 & 0.010 & 1.016 & 2.047 & 2264.822 & 0.341 \\
\hline 2 & 2.355 & 29.292 & 1955.907 & 4376.763 & 0.659 \\
\hline 3 & 1955.907 & 4531.779 & 10500.00 & 3.564 & 0.001 \\
\hline
\end{tabular}

Fonte: A autora

Figura 5.1 - Imagem do gráfico dos dados de RM, tempo T2.do paciente 1

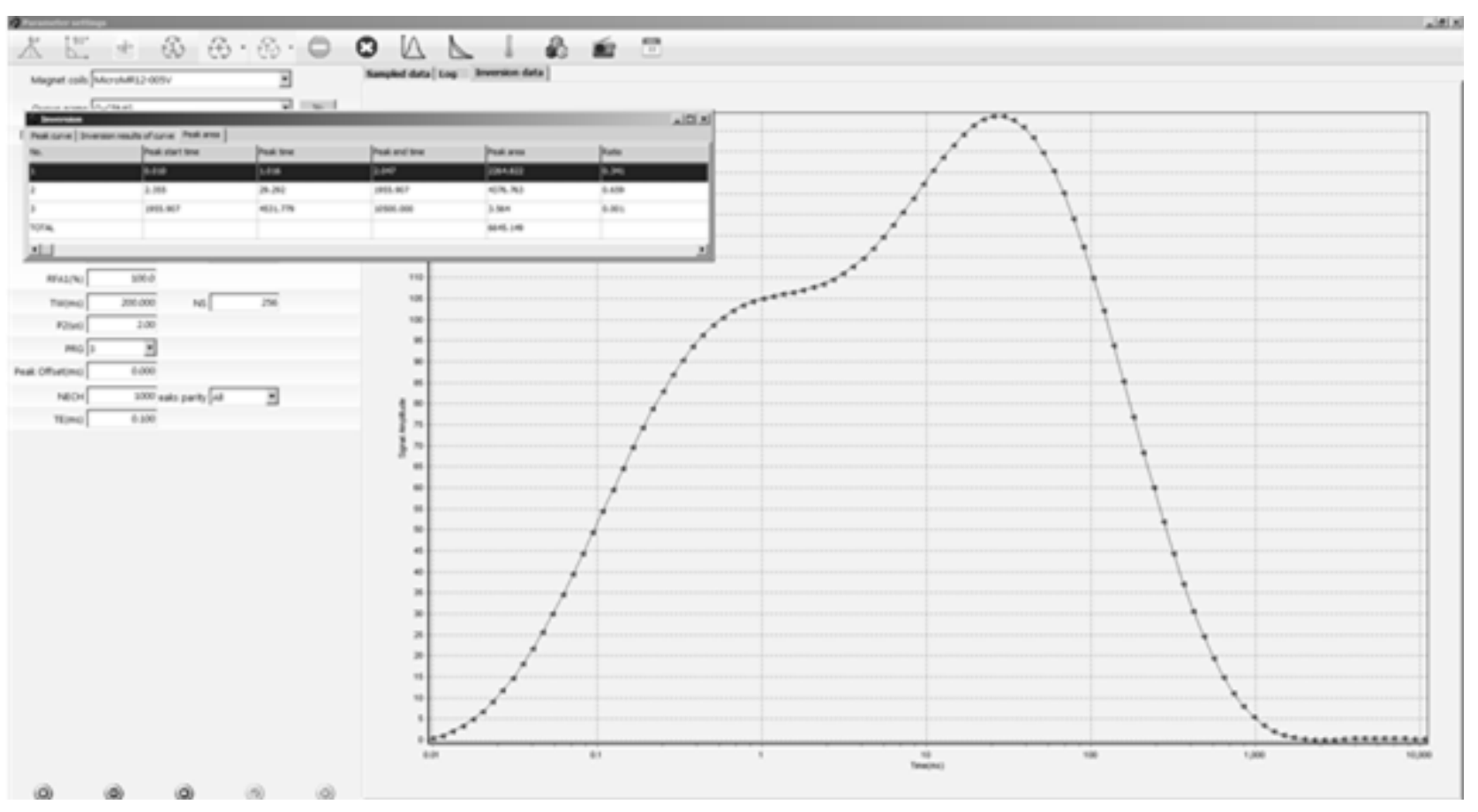

Fonte: A autora

Pico ํㅜ $1=$ poros pequenos

Pico $\mathrm{n} \cong 2=$ poros grandes

Razão do pico ํㅜ=ㅇ, ignorar.

A razão de volume de grandes e pequenos poros:

A proporção da razão de poros grandes e poros pequenos é:

$4376 \div 2264=1,93 \quad 0,659 \div 0,341=1,93$

$\checkmark$ Ou seja, há maior quantidade de poros grandes do que poros pequenos. 
$>$ A uniformidade do tamanho dos poros:

Derivada da largura do pico (igual ao tempo final do pico - tempo inicial do pico/ tempo de pico).

A uniformidade dos poros pequenos é igual a $2.407-0.010 \div 1.016=2$;

A uniformidade de poros grandes é igual a 1955.9-2.355 $\div 29.292=66.69$.

$\checkmark$ Ou seja, os poros pequenos são mais uniformes que os poros grandes.

Paciente 2:

- 55 anos de idade

- Sexo femino

- Região da amostra óssea: maxila (região do dente 25)

Tabela 5.3 - Tabela dos dados de RM do paciente 2

\begin{tabular}{llllll}
\hline $\mathrm{N}^{\circ}$ & $\begin{array}{l}\text { Início tempo } \\
\text { de pico }\end{array}$ & $\begin{array}{l}\text { Tempo de } \\
\text { pico }\end{array}$ & $\begin{array}{l}\text { Final tempo } \\
\text { de pico }\end{array}$ & $\begin{array}{l}\text { Área tempo } \\
\text { de pico }\end{array}$ & Razão \\
\hline 1 & 0.062 & 0.165 & 0.218 & 0.467 & 0.000 \\
\hline 2 & 0.251 & 1.016 & 5.456 & 3163.860 & 0.556 \\
\hline 3 & 6.277 & 38.760 & 316.728 & 2408.028 & 0.423 \\
\hline 4 & 316.728 & 637.951 & 1284.955 & 27.423 & 0.005 \\
\hline 5 & 1478.114 & 4531.779 & 10500.000 & 93.165 & 0.016 \\
\hline
\end{tabular}

Fonte: A autora 
Figura 5.2- Imagem do gráfico dos dados de RM, tempo T2 do paciente 2

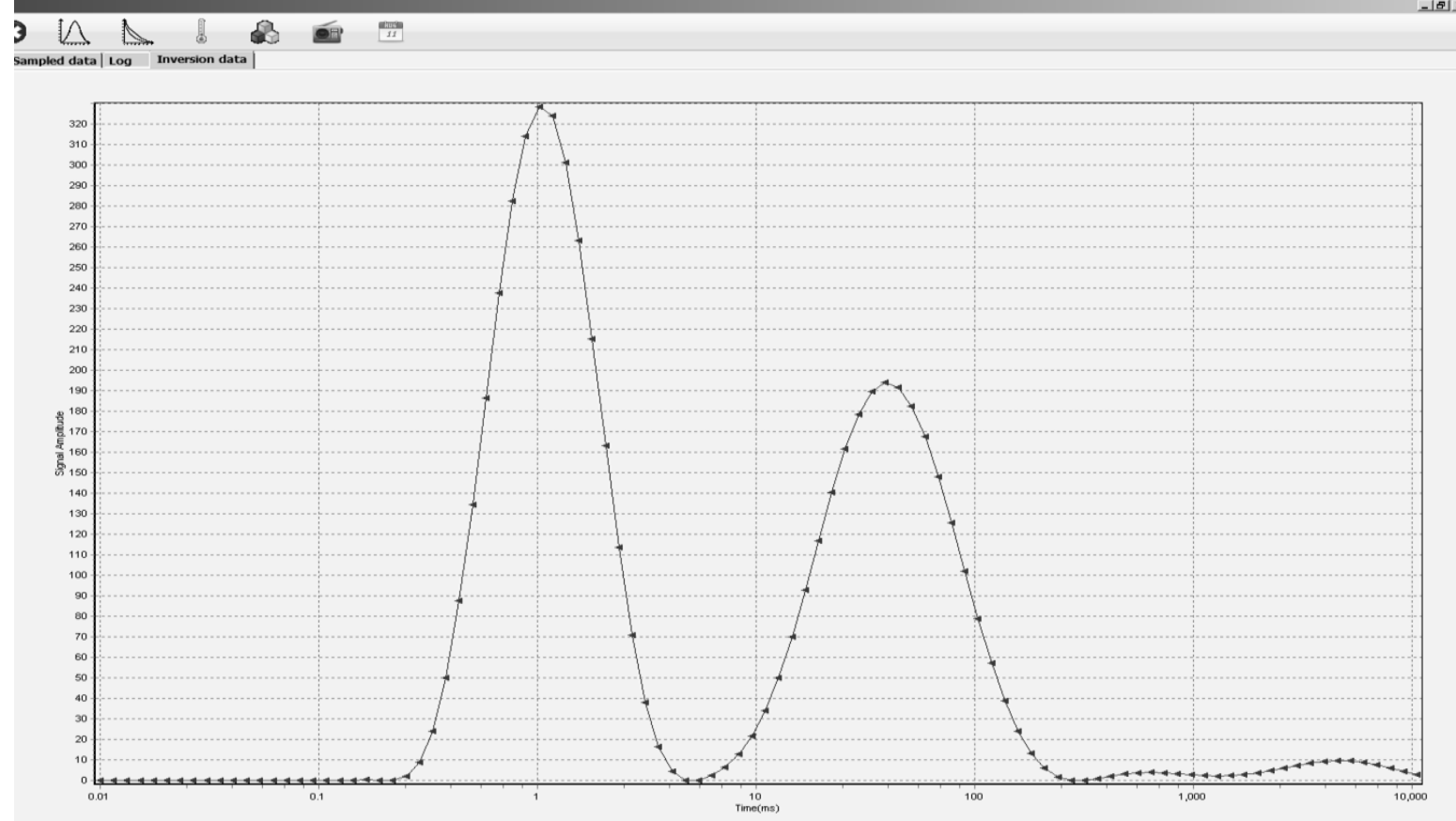

Fonte: A autora

Pico $n \div 2=$ poros pequenos

Pico $\mathrm{n}^{\circ} 3=$ poros grandes

Pico $\mathrm{n}^{0} 1$, 4 e 5 podemos ignorar

$>$ Razão de volume de grandes e pequenos poros:

Razão da área de pico.

$2408.028 \div 3163.860=0,76 \quad 0.423 \div 0.556=0,76$

Ou seja, há maior quantidade de poros pequenos do que grandes.

$>$ Uniformidade do tamanho dos poros:

- Derivada da largura do pico (tempo final do pico - tempo inicial do pico/tempo de pico).

- Poros pequenos: $5.456-0.251 \div 1.016=5,36$

- $\quad$ Poros grandes: $316.728-6.277 \div 38.760=8$

Ou seja, os poros pequenos são mais uniformes que os poros grandes. 
Paciente 3:

- 63 anos de idade

- Sexo feminino

- Região da amostra óssea: mandíbula (região do dente 31)

Tabela 5.4 - Tabela dos dados de RM do paciente 3

\begin{tabular}{cccccc}
\hline$N^{\circ}$ & $\begin{array}{c}\text { Início tempo } \\
\text { de pico }\end{array}$ & $\begin{array}{c}\text { Tempo de } \\
\text { pico }\end{array}$ & $\begin{array}{c}\text { Final tempo } \\
\text { de pico }\end{array}$ & $\begin{array}{c}\text { Área de } \\
\text { Pico }\end{array}$ & Razão \\
\hline 1 & 0.288 & 1.345 & 3.585 & 5129.007 & 0.762 \\
\hline 2 & 25.464 & 67.868 & 180.887 & 1602.191 & 0.238 \\
\hline 3 & 208.078 & 239.357 & 275.338 & 0.008 & 0.000 \\
\hline
\end{tabular}

Fonte: A autora

Figura 5.3 - Imagem do gráfico dos dados de RM, tempo T2 do paciente 3

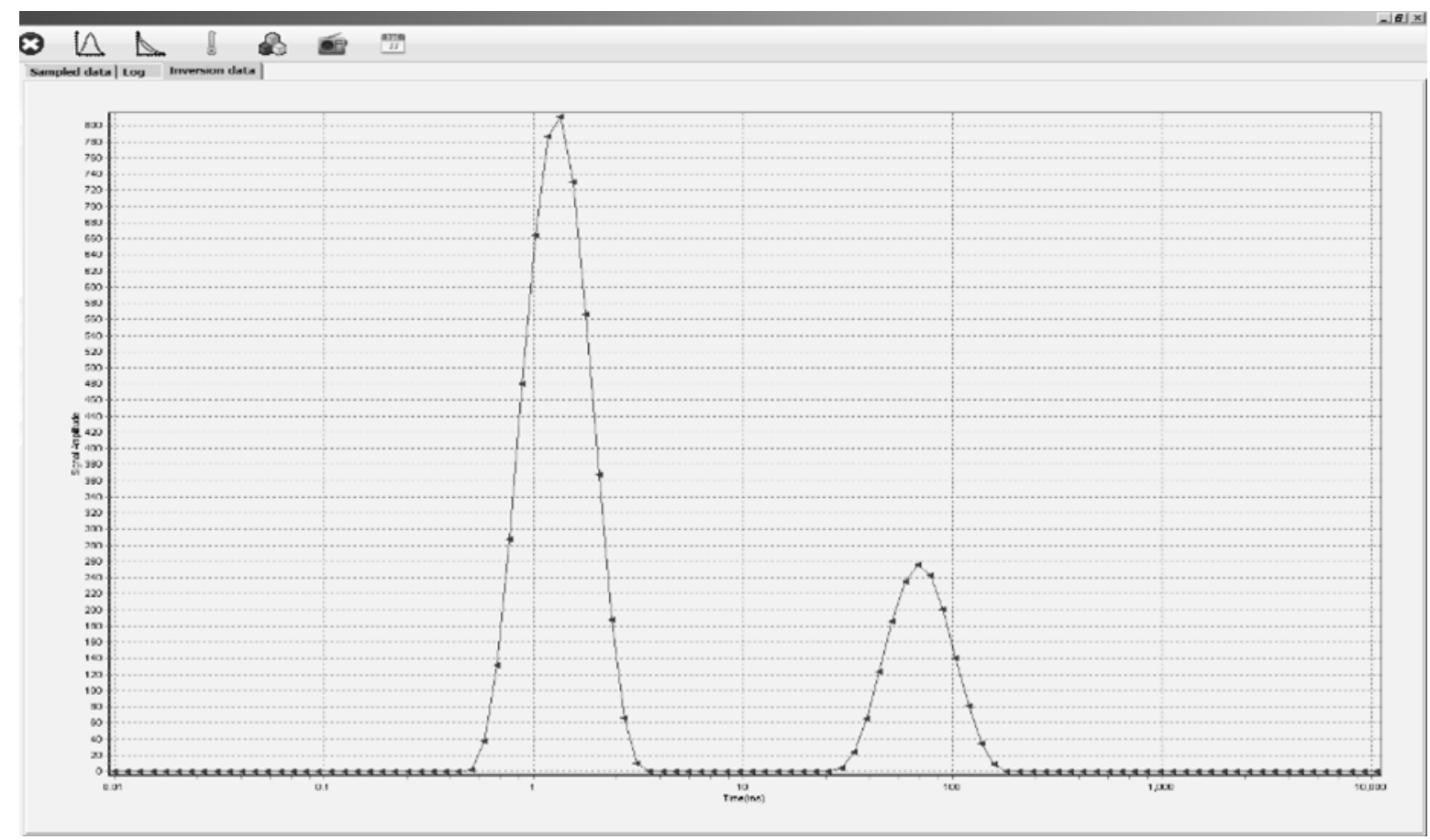

Fonte: A autora

Pico $\mathrm{n}^{0} \mathbf{1}=$ poros pequenos

Pico no 2= poros grandes

Razão do pico $\mathrm{n}^{\circ} 3=0$, ignorar.

A razão de volume de grandes e pequenos poros:

A proporção da razão de poros grandes e poros pequenos é: 
$0.238 \div 0.762=0,312 \quad 1602 \cdot 191 \div 5129.007=0,312$

$\checkmark$ Ou seja, há maior quantidade de poros pequenos do que grandes.

$>$ A uniformidade do tamanho dos poros:

Derivada da largura do pico (igual ao tempo final do pico - tempo inicial do pico/ tempo de pico).

A uniformidade dos poros pequenos é igual a 3,585-0.288 $\div 1.345=2.45130112$ A uniformidade de poros grandes é igual a $180.887-25.464 \div 67.868=2.2900778$

$\checkmark$ Ou seja, os poros grandes são mais uniformes que os poros pequenos.

Paciente 4:

- 56 anos de idade

- Sexo feminino

- Região da amostra óssea: maxila (região do dente 14)

Tabela 5.5 - Tabela dos dados de RM do paciente 4

\begin{tabular}{cccccc}
\hline № & $\begin{array}{c}\text { Início tempo de } \\
\text { pico }\end{array}$ & $\begin{array}{c}\text { Tempo de } \\
\text { pico }\end{array}$ & $\begin{array}{c}\text { Final tempo } \\
\text { de pico }\end{array}$ & Área de Pico & Razão \\
\hline 1 & 0.094 & 1.169 & 4.123 & 3996.247 & 0.549 \\
\hline 2 & 4.743 & 6.277 & 9.554 & 2.027 & 0.000 \\
\hline 3 & 9.554 & 33.695 & 180.887 & 3057.815 & 0.420 \\
\hline 4 & 180.887 & 239.357 & 419.109 & 3.550 & 0.000 \\
\hline 5 & 482.111 & 554.584 & 637.951 & 0.003 & 0.000 \\
\hline 6 & 733.850 & 971.064 & 1117.038 & 0.028 & 0.000 \\
\hline 7 & 1284.955 & 5996.653 & 10500.000 & 218.252 & 0.030
\end{tabular}

Fonte: A autora 
Figura 5.4 - Imagem do gráfico dos dados de RM, tempo T2 do paciente 4

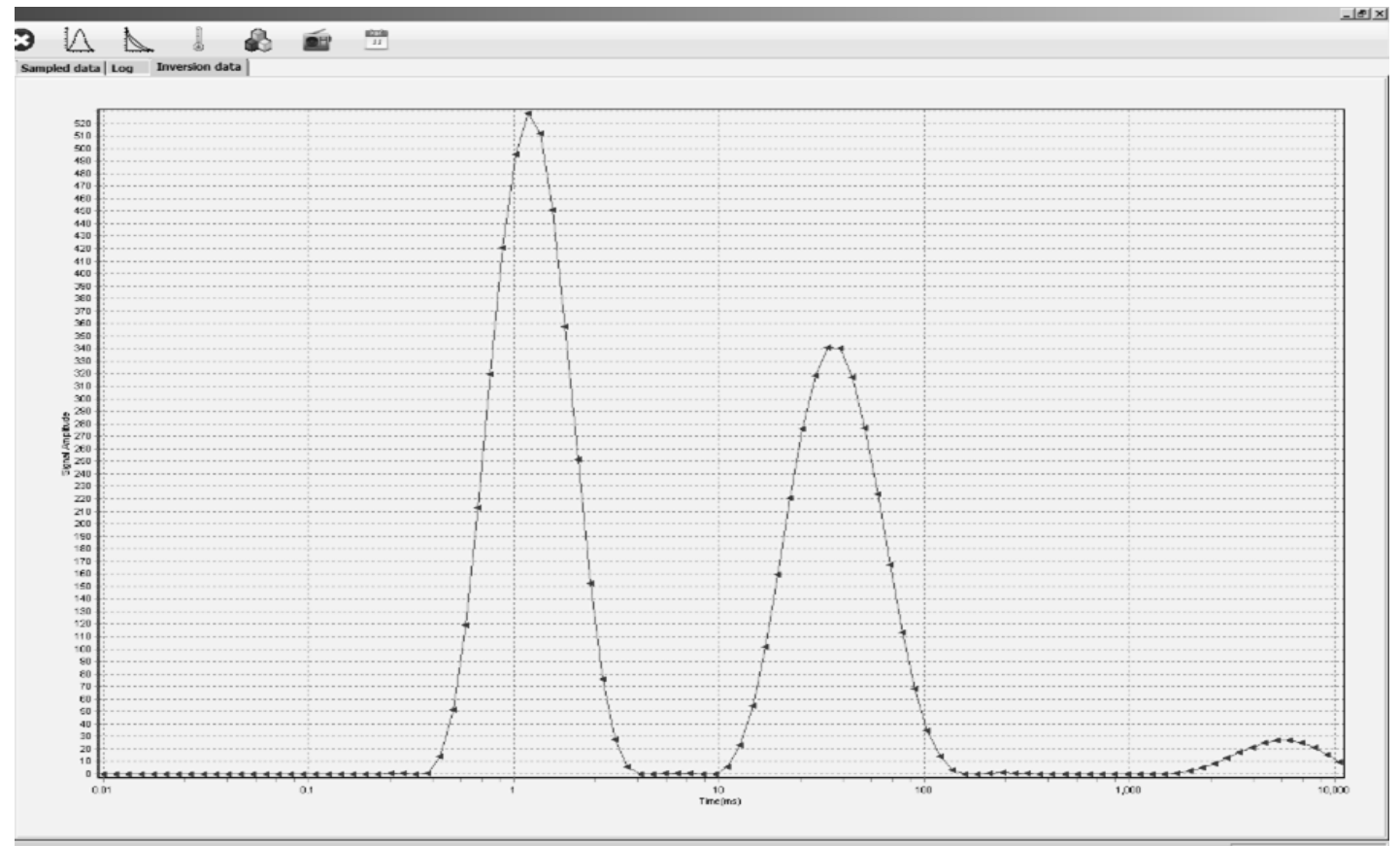

Fonte: A autora

Pico $\mathrm{n}^{0} 1=$ poros pequenos

Pico $\mathrm{n}^{\circ} \mathrm{3}=$ poros grandes

Pico nํ2, 4, 6 e 7 ignorar, razão=0.

A razão de volume de grandes e pequenos poros:

A proporção da razão de poros grandes e poros pequenos é:

$0.420 \div 0.549=0.7650 \quad 3057.815 \div 3996.247=0.7650$

$\checkmark$ Ou seja, há maior quantidade de poros pequenos do que grandes.

$>$ A uniformidade do tamanho dos poros:

Derivada da largura do pico (igual ao tempo final do pico - tempo inicial do pico/ tempo de pico).

A uniformidade dos poros pequenos é igual a 4.123-0.094 $\div 1.169=3.4465355$

A uniformidade de poros grandes é igual a $180.887-9.554 \div 33.695=5.08481971$

$\checkmark$ Ou seja, os poros pequenos são mais uniformes que os poros grandes.

Paciente 5:

- 56 anos de idade 
- Sexo feminino

- Região da amostra óssea: maxila (região do dente 24)

Tabela 5.6 - Tabela dos dados de RM do paciente 5

\begin{tabular}{cccccc}
\hline № & $\begin{array}{c}\text { Início tempo } \\
\text { de pico }\end{array}$ & $\begin{array}{c}\text { Tempo de } \\
\text { pico }\end{array}$ & $\begin{array}{c}\text { Final tempo } \\
\text { de pico }\end{array}$ & $\begin{array}{c}\text { Área de } \\
\text { Pico }\end{array}$ & Razão \\
\hline 1 & 0.010 & 0.018 & 0.035 & 3.447 & 0.001 \\
\hline 2 & 0.041 & 0.082 & 0.143 & 8.921 & 0.002 \\
\hline 3 & 0.165 & 0.884 & 6.277 & 4608.654 & 0.791 \\
\hline 4 & 7.220 & 58.999 & 554.584 & 1173.724 & 0.201 \\
\hline 5 & 637.951 & 1700.310 & 10500.000 & 5828.909 & 0.006 \\
\hline
\end{tabular}

Fonte: A autora

Figura 5.5 - Imagem do gráfico dos dados de RM, tempo T2 do paciente 5

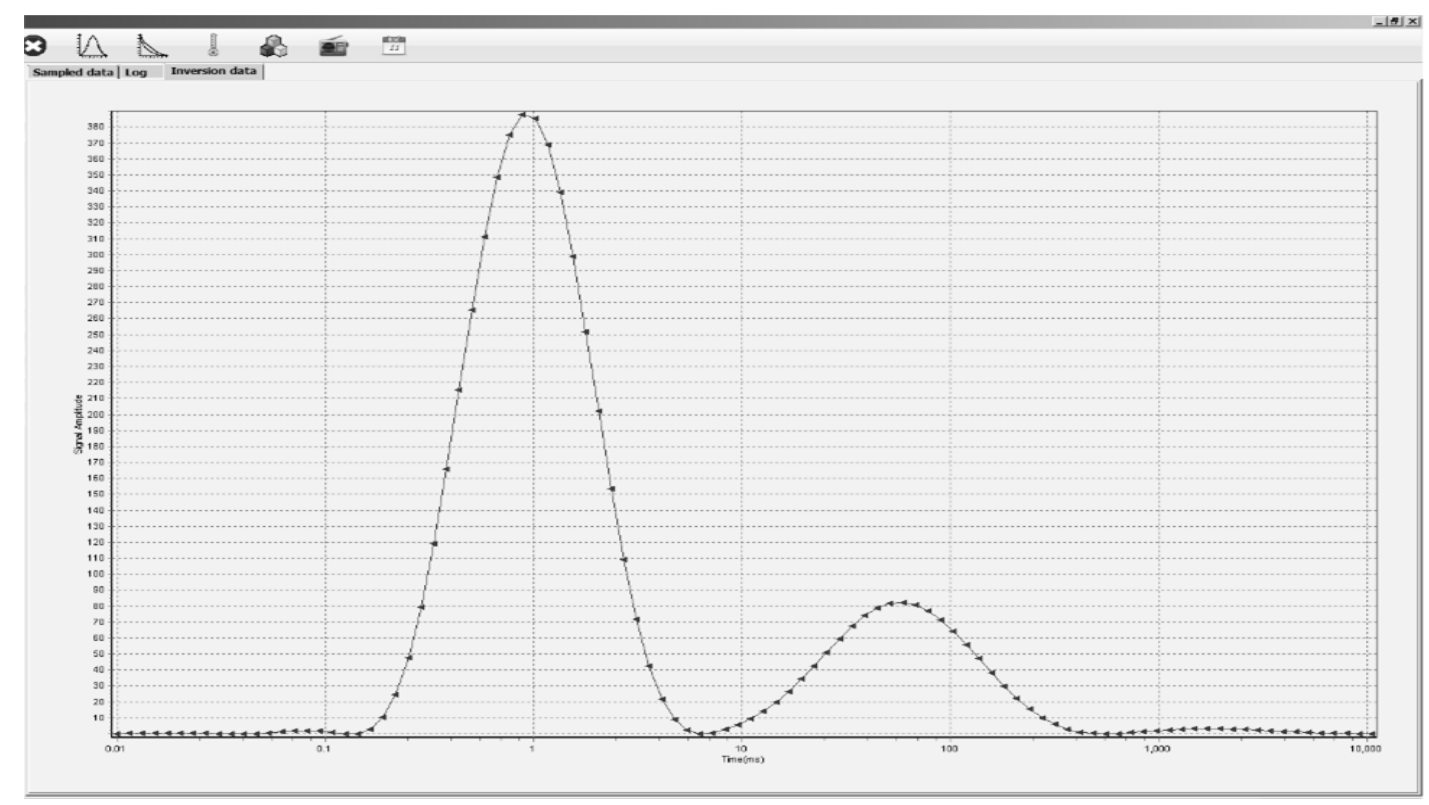

Fonte: A autora

Pico $n^{\circ} 3=$ poros pequenos

Pico no 4= poros grandes

Pico nำ 1, 2 e 5 ignorar, razão muito baixa.

$>$ A razão de volume de grandes e pequenos poros:

A proporção da razão de poros grandes e poros pequenos é: 
$0.201 \div 0.791=0.25410872 \quad 1173.724 \div 4608.654=0.25410872$

$\checkmark$ Ou seja, há maior quantidade de poros pequenos do que grandes.

A uniformidade do tamanho dos poros:

Derivada da largura do pico (igual ao tempo final do pico - tempo inicial do pico/ tempo de pico).

A uniformidade dos poros pequenos é igual a $6.277-0.165 \div 0.884=6.91402715$ A uniformidade de poros grandes é igual a $554.584-7.22 \div 58.999=9.27751318$ Ou seja, os poros pequenos são mais uniformes que os poros grandes.

Paciente 6:

- 55 anos de idade

- Sexo feminino

- Região da amostra óssea: maxila (região do dente 14)

Tabela 5.7 - Tabela dos dados de RM do paciente 6

\begin{tabular}{cccccc}
\hline № & $\begin{array}{c}\text { Início tempo } \\
\text { de pico }\end{array}$ & $\begin{array}{c}\text { Tempo de } \\
\text { pico }\end{array}$ & $\begin{array}{c}\text { Final tempo } \\
\text { de pico }\end{array}$ & $\begin{array}{c}\text { Área de } \\
\text { Pico }\end{array}$ & Razão \\
\hline 1 & 0.332 & 2.047 & 7.220 & 6339.789 & 0.601 \\
\hline 2 & 8.305 & 9.554 & 12.642 & 11.610 & 0.001 \\
\hline 3 & 14.543 & 51.289 & 239.357 & 4039.330 & 0.383 \\
\hline 4 & 275.338 & 419.109 & 844.166 & 8.727 & 0.001 \\
\hline 5 & 971.064 & 1117.038 & 1284.955 & 0.088 & 0.000 \\
\hline 6 & 1478.114 & 5996.653 & 10500.000 & 143.817 & 0.014
\end{tabular}

Fonte: A autora 
Figura 5.6 - Imagem do gráfico dos dados de RM, tempo T2 do paciente 6

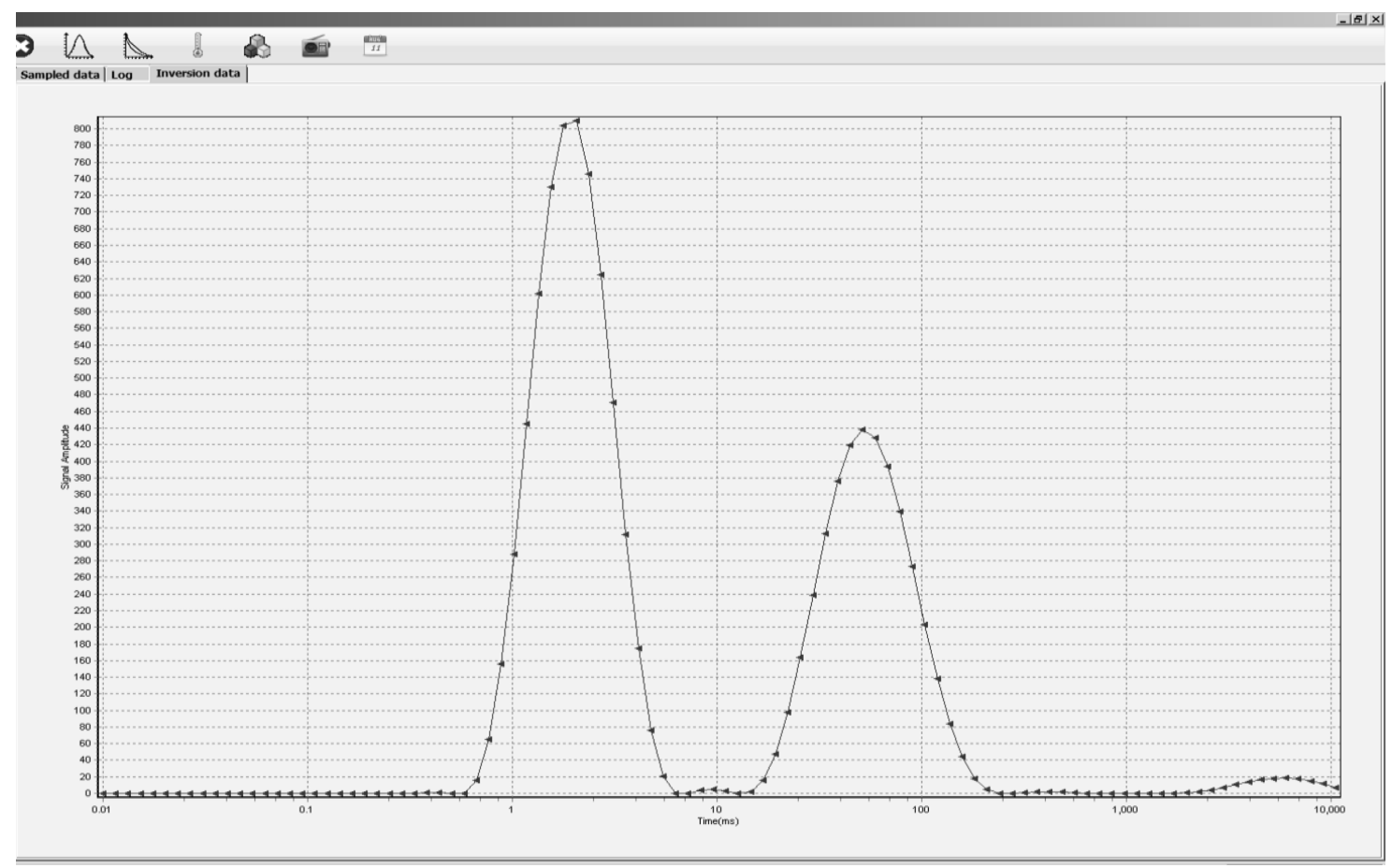

Fonte: A autora

Pico $\mathrm{n}^{-} \mathbf{1}=$ poros pequenos

Pico no $3=$ poros grandes.

Pico № 2, 4 e 5 ignorar, razão muito baixa.

A razão de volume de grandes e pequenos poros:

A proporção da razão de poros grandes e poros pequenos é:

$0.383 \div 0.601=0.63727121 \quad 4039.330 \div 6339.789=0.63727121$

$\checkmark$ Ou seja, há maior quantidade de poros pequenos do que grandes.

$>$ A uniformidade do tamanho dos poros:

Derivada da largura do pico (igual ao tempo final do pico - tempo inicial do pico/ tempo de pico).

A uniformidade dos poros pequenos é igual a 7.22-0.332 $\div 2.047=3.36492428$

A uniformidade de poros grandes é igual a $239.357-14.543 \div 51.289=4.38327907$

$\checkmark$ Ou seja, os poros pequenos são mais uniformes que os poros grandes. 
Paciente 7:

- 64 anos de idade

- Sexo feminino

- Região da amostra óssea: mandibula (região do dente 34)

Tabela 5.8 - Tabela dos dados de RM do paciente 7

\begin{tabular}{cccccc}
\hline № & $\begin{array}{c}\text { Início tempo de } \\
\text { pico }\end{array}$ & $\begin{array}{c}\text { Tempo de } \\
\text { pico }\end{array}$ & $\begin{array}{c}\text { Final tempo } \\
\text { de pico }\end{array}$ & $\begin{array}{c}\text { Área de } \\
\text { Pico }\end{array}$ & Razão \\
\hline 1 & 0.381 & 0.439 & 0.505 & 0.235 & 0.000 \\
\hline 2 & 0.580 & 1.547 & 4.123 & 6157.735 & 0.701 \\
\hline 3 & 44.587 & 103.306 & 316.728 & 2630.240 & 0.299 \\
\hline
\end{tabular}

Fonte: A autora

Figura 5.7 - Imagem do gráfico dos dados de RM, tempo T2 do paciente 7

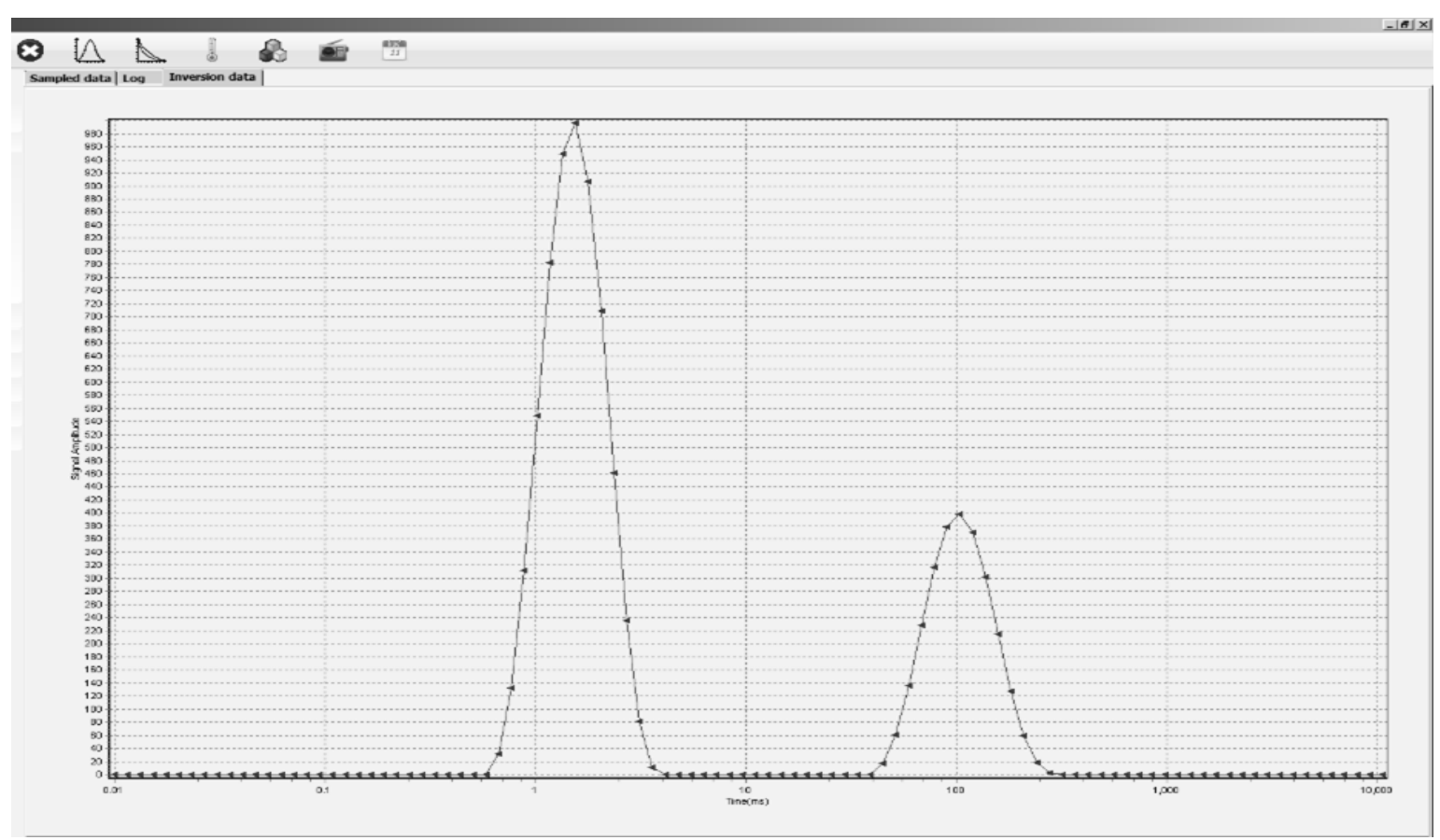

Fonte: A autora

Pico ํㅡ $2=$ poros pequenos

Pico no $3=$ poros grandes.

Pico oํ 1 ignorar, razão muito baixa. 
> A razão de volume de grandes e pequenos poros:

A proporção da razão de poros grandes e poros pequenos é:

$0.299 \div 0.701=0.42653352 \quad 2630.240 \div 6157.735=0.42653352$

$\checkmark$ Ou seja, há maior quantidade de poros pequenos do que grandes.

A uniformidade do tamanho dos poros:

Derivada da largura do pico (igual ao tempo final do pico - tempo inicial do pico/ tempo de pico).

A uniformidade dos poros pequenos é igual a $4.123-0.58 \div 1.547=2.29023917$ A uniformidade de poros grandes é igual a $316.728-44.587 \div 103.306=2.6343194$

$\checkmark$ Ou seja, os poros pequenos são mais uniformes que os poros grandes.

Paciente 8:

- 37 anos de idade

- Sexo feminino

- Região da amostra óssea: maxila (região do dente 11)

Tabela 5.9 - Tabela dos dados de RM do paciente 8

\begin{tabular}{cccccc}
\hline № & $\begin{array}{c}\text { Início tempo de } \\
\text { pico }\end{array}$ & $\begin{array}{c}\text { Tempo de } \\
\text { pico }\end{array}$ & $\begin{array}{c}\text { Final tempo } \\
\text { de pico }\end{array}$ & $\begin{array}{c}\text { Área de } \\
\text { Pico }\end{array}$ & Razão \\
\hline 1 & 0.071 & 0.251 & 0.332 & 0.674 & 0.000 \\
\hline 2 & 0.381 & 1.345 & 7.220 & 2783.342 & 0.587 \\
\hline 3 & 8.305 & 9.554 & 12.642 & 1.637 & 0.000 \\
\hline 4 & 14.543 & 103.306 & 844.166 & 1951.080 & 0.412 \\
\hline 5 & 971.064 & 1478.114 & 2977.203 & 1.631 & 0.000 \\
\hline 6 & 3424.747 & 3939.568 & 10500.000 & 0.003 & 0.000
\end{tabular}

Fonte: A autora 
Figura 5.8 - Imagem do gráfico dos dados de RM, tempo T2 do paciente 8

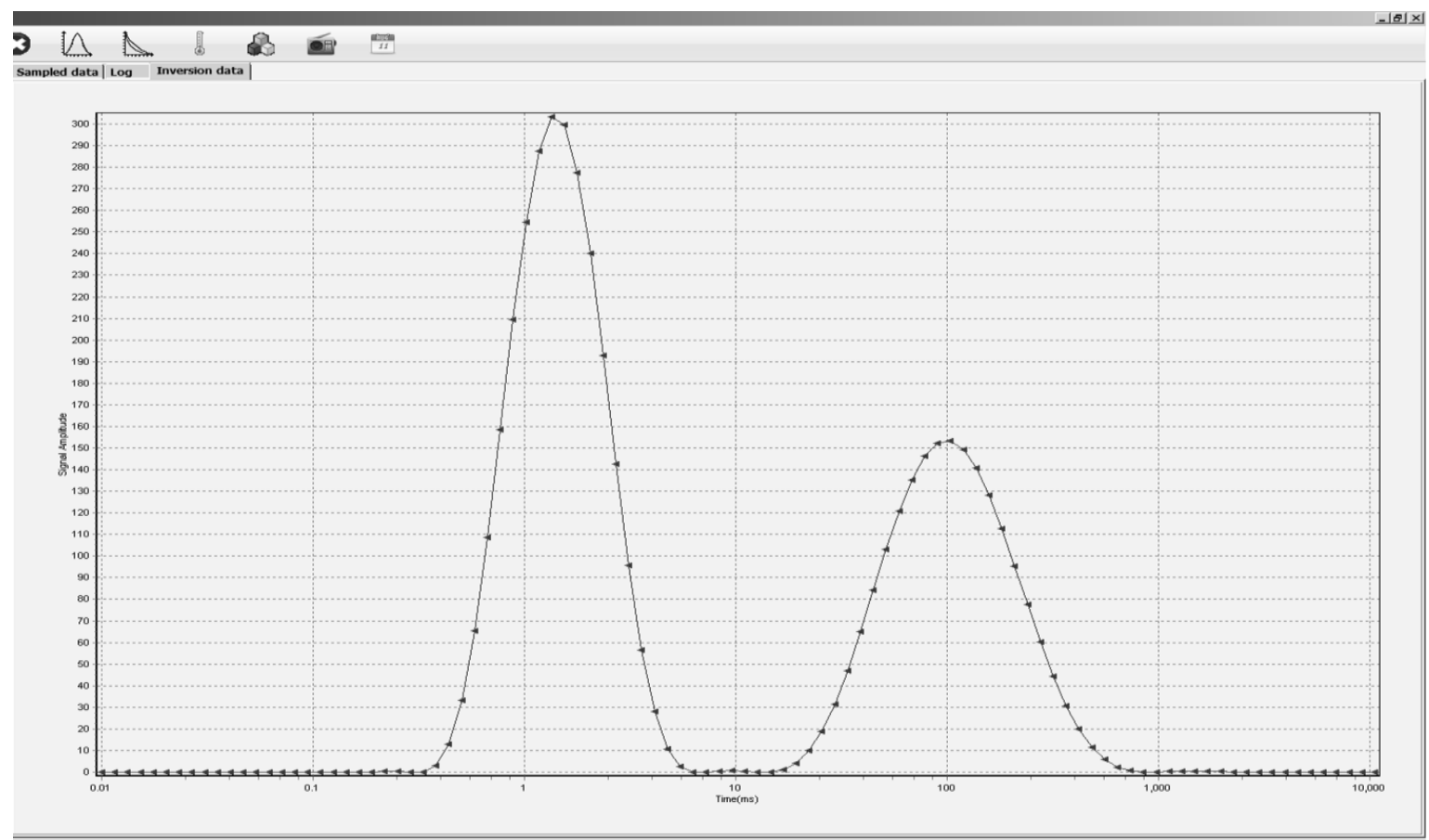

Fonte: A autora

Pico no 2= poros pequenos

Pico $\mathrm{n}^{\circ} 4=$ poros grandes.

Pico no 1, 5 e 6 ignorar, razão muito baixa.

A razão de volume de grandes e pequenos poros:

A proporção da razão de poros grandes e poros pequenos é:

$0.412 \div 0.587=0.70187394 \quad 1951.080 \div 2783.342=0.70187394$

Ou seja, há maior quantidade de poros pequenos do que grandes.

A uniformidade do tamanho dos poros:

Derivada da largura do pico (igual ao tempo final do pico - tempo inicial do pico/ tempo de pico).

A uniformidade dos poros pequenos é igual a $7.22-0.381 \div 1.345=5.08475836$

A uniformidade de poros grandes é igual a $844.166-14.543 \div 103.306=8.03073394$

$\checkmark$ Ou seja, os poros pequenos são mais uniformes que os poros grandes. 
Paciente 9:

- 35 anos de idade

- Sexo masculino

- Região da amostra óssea: maxila (região do dente 21)

Tabela 5.10 - Tabela dos dados de RM do paciente 9

\begin{tabular}{cccccc}
\hline № & $\begin{array}{c}\text { Início tempo } \\
\text { de pico }\end{array}$ & $\begin{array}{c}\text { Tempo de } \\
\text { pico }\end{array}$ & $\begin{array}{c}\text { Final tempo } \\
\text { de pico }\end{array}$ & $\begin{array}{c}\text { Área de } \\
\text { Pico }\end{array}$ & Razão \\
\hline 1 & 0.251 & 0.332 & 0.439 & 1.923 & 0.000 \\
\hline 2 & 0.439 & 2.047 & 9.554 & 4309.077 & 0.512 \\
\hline 3 & 10.990 & 67.868 & 482.111 & 4101.743 & 0.487 \\
\hline 4 & 482.111 & 637.951 & 1284.955 & 4.146 & 0.000 \\
\hline 5 & 1478.114 & 3424.747 & 10500.000 & 0.002 & 0.000 \\
\hline
\end{tabular}

Fonte: A autora

Figura 5.9 - Imagem do gráfico dos dados de RM, tempo T2 do paciente 9

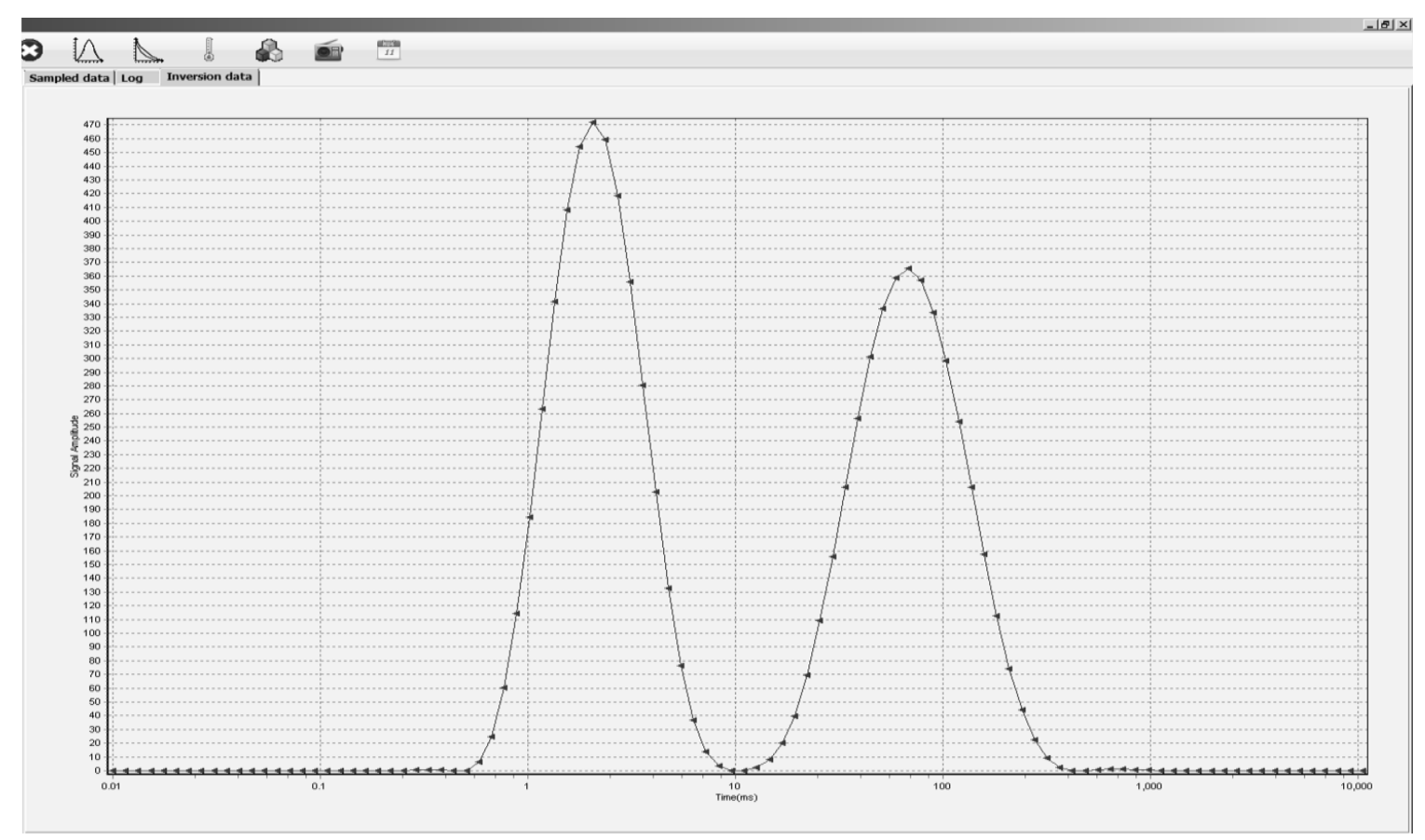

Fonte: A autora

Pico $\mathrm{n}^{\circ} 2=$ poros pequenos

Pico $\mathrm{n}^{\circ} 3=$ poros grandes.

Pico no 1 , 4 e 5 ignorar, razão muito baixa. 
$>$ A razão de volume de grandes e pequenos poros:

A proporção da razão de poros grandes e poros pequenos é:

$0.487 \div 0.512=0.95117188 \quad 4101.743 \div 4309.077=0.95117188$

$\checkmark$ Ou seja, há maior quantidade de poros pequenos do que grandes.

A uniformidade do tamanho dos poros:

Derivada da largura do pico (igual ao tempo final do pico - tempo inicial do pico/ tempo de pico).

A uniformidade dos poros pequenos é igual a $9.554-0.439 \div 2.047=4.45285784$

A uniformidade de poros grandes é igual a $482.111-10.99 \div 67.868=6.94172511$

$\checkmark$ Ou seja, os poros pequenos são mais uniformes que os poros grandes.

Paciente 10:

- 56 anos de idade

- Sexo feminino

- Região da amostra óssea: maxila (região do dente 25)

Tabela 5.11 - Tabela dos dados de RM do paciente 10

\begin{tabular}{cccccc}
\hline № & $\begin{array}{c}\text { Início tempo de } \\
\text { pico }\end{array}$ & $\begin{array}{c}\text { Tempo de } \\
\text { pico }\end{array}$ & $\begin{array}{c}\text { Final tempo de } \\
\text { pico }\end{array}$ & Área de Pico & Razão \\
\hline 1 & 0.439 & 0.505 & 0.580 & 0.069 & 0.000 \\
\hline 2 & 0.668 & 1.780 & 4.743 & 3782.869 & 0.607 \\
\hline 3 & 38.760 & 103.306 & 364.340 & 2448.869 & 0.393 \\
\hline 4 & 419.109 & 482.111 & 1955.907 & 0.464 & 0.000
\end{tabular}

Fonte: A autora 
Figura 5.10 - Imagem do gráfico dos dados de RM, tempo T2 do paciente 10

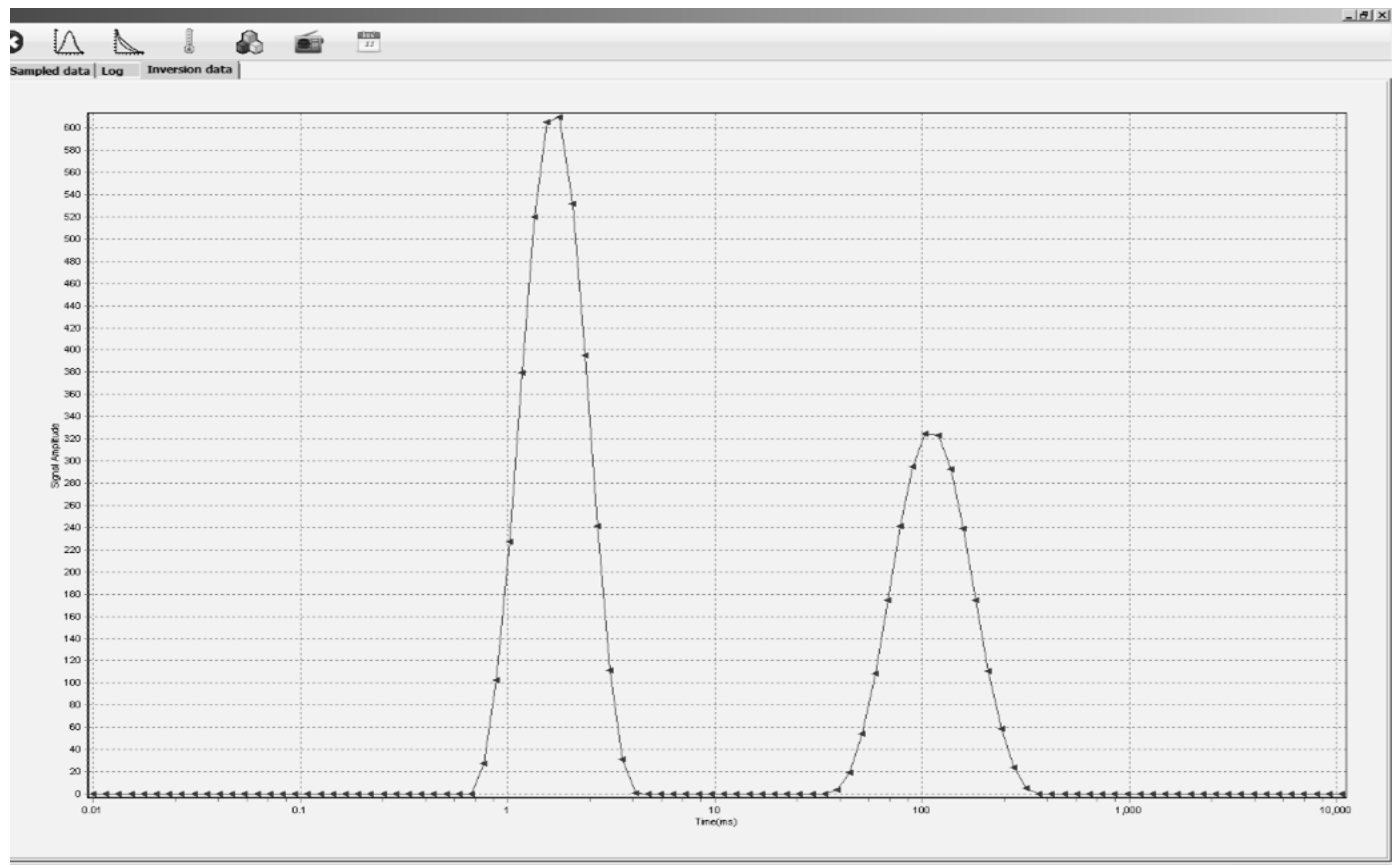

Fonte: A autora

Pico $\mathrm{n}^{\circ} \mathbf{2}=$ poros pequenos

Pico $n^{\circ} 3=$ poros grandes.

Pico no 1 e 4 ignorar, razão muito baixa.

A razão de volume de grandes e pequenos poros:

A proporção da razão de poros grandes e poros pequenos é:

$0.393 \div 0.607=0.6474464 \quad 2448.869 \div 3782.869=0.6474464$

$\checkmark$ Ou seja, há maior quantidade de poros pequenos do que grandes.

$>$ A uniformidade do tamanho dos poros:

Derivada da largura do pico (igual ao tempo final do pico - tempo inicial do pico/ tempo de pico).

A uniformidade dos poros pequenos é igual a $4.743-0.668 \div 1.78=2.28932584$

A uniformidade de poros grandes é igual a 364.34-38.76 $\div 103.36=3.1499613$ $\checkmark$ Ou seja, os poros pequenos são mais uniformes que os poros grandes.

Paciente 11:

- 63 anos de idade

- Sexo feminino 
- Região da amostra óssea: mandibula (região do dente 41)

Tabela 5.12 - Tabela dos dados de RM do paciente 11

\begin{tabular}{cccccc}
\hline № & $\begin{array}{c}\text { Início tempo de } \\
\text { pico }\end{array}$ & $\begin{array}{c}\text { Tempo de } \\
\text { pico }\end{array}$ & $\begin{array}{c}\text { Final tempo de } \\
\text { pico }\end{array}$ & Área de Pico & Razão \\
\hline 1 & 0.010 & 0.020 & 0.047 & 22.406 & 0.003 \\
\hline 2 & 0.054 & 1.016 & 9.554 & 4785.656 & 0.557 \\
\hline 3 & 10.990 & 78.070 & 2588.144 & 3787.251 & 0.440 \\
\hline 4 & 2977.203 & 5996.653 & 10500.000 & 4.093 & 0.000
\end{tabular}

Fonte: A autora

Figura 5.11 - Imagem do gráfico dos dados de RM, tempo T2 do paciente 11

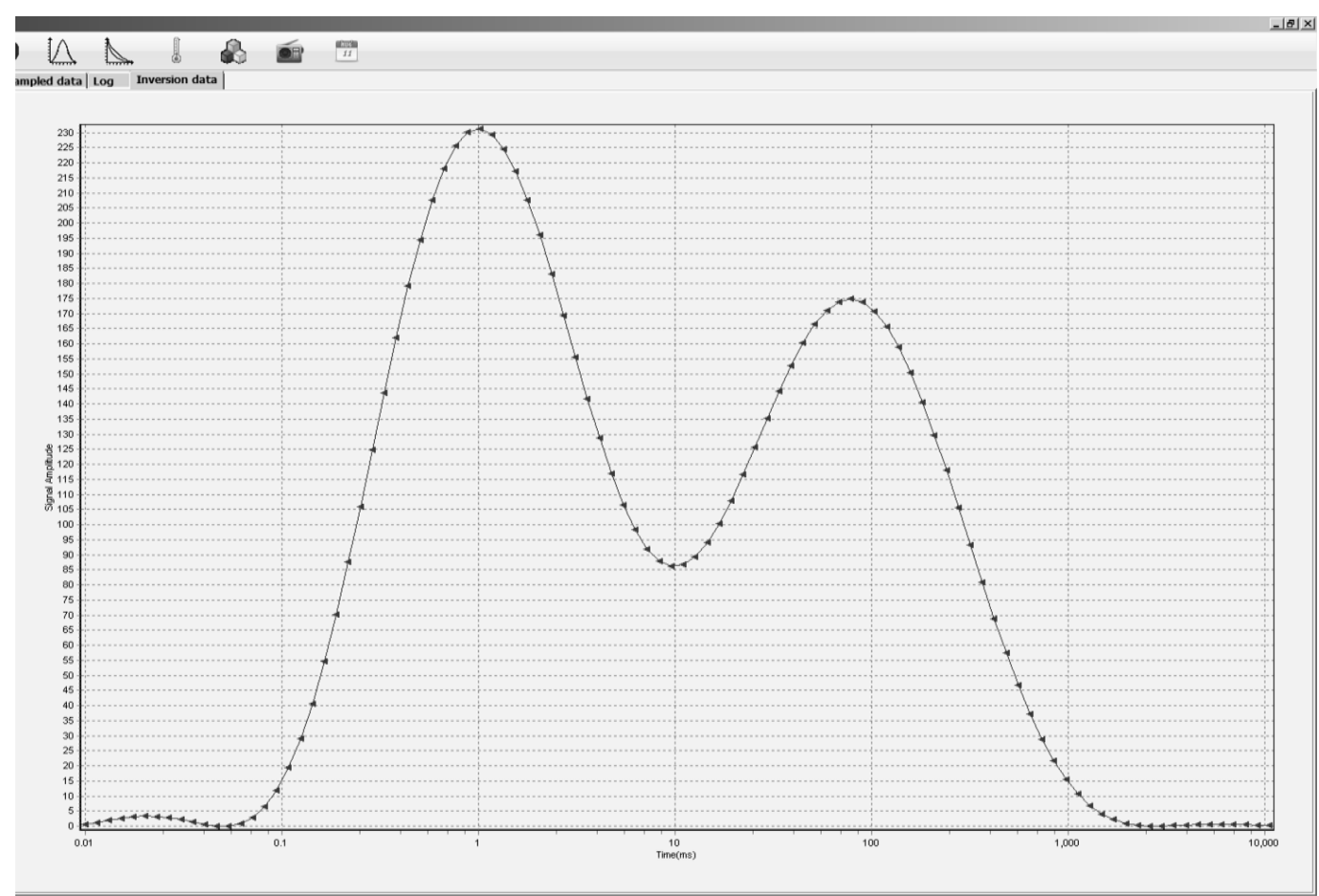

Fonte: A autora

Pico $\mathrm{n}^{\circ} \mathbf{2}=$ poros pequenos

Pico $n^{\circ} 3=$ poros grandes.

Pico oํ 1 e 4 ignorar, razão muito baixa.

A razão de volume de grandes e pequenos poros:

A proporção da razão de poros grandes e poros pequenos é: 
$0.440 \div 0.557=0.78994614 \quad 3787.251 \div 4785.656=0.78994614$

$\checkmark$ Ou seja, há maior quantidade de poros pequenos do que grandes.

A uniformidade do tamanho dos poros:

Derivada da largura do pico (igual ao tempo final do pico - tempo inicial do pico/ tempo de pico).

A uniformidade dos poros pequenos é igual a 9.554-0.054 $\div 1.016=9.3503937$

A uniformidade de poros grandes é igual a $2588.144-10.99 \div 78.07=33.0108108$

Ou seja, os poros pequenos são mais uniformes que os poros grandes.

Paciente 12:

- 57 anos de idade

- Sexo feminino

- Região da amostra óssea: mandíbula (região do dente 46)

Tabela 5.13 - Tabela dos dados de RM do paciente 12

\begin{tabular}{cccccc}
\hline № & $\begin{array}{c}\text { Início tempo de } \\
\text { pico }\end{array}$ & $\begin{array}{c}\text { Tempo de } \\
\text { pico }\end{array}$ & $\begin{array}{c}\text { Final tempo } \\
\text { de pico }\end{array}$ & $\begin{array}{c}\text { Área de } \\
\text { Pico }\end{array}$ & Razão \\
\hline 1 & 0.668 & 1.780 & 4.743 & 6070.069 & 0.659 \\
\hline 2 & 51.289 & 157.248 & 482.111 & 3145.879 & 0.341 \\
\hline 3 & 554.584 & 637.951 & 1955.907 & 0.189 & 0.000 \\
\hline
\end{tabular}

Fonte: A autora 
Figura 5.12 - Imagem do gráfico dos dados de RM, tempo T2 do paciente 12

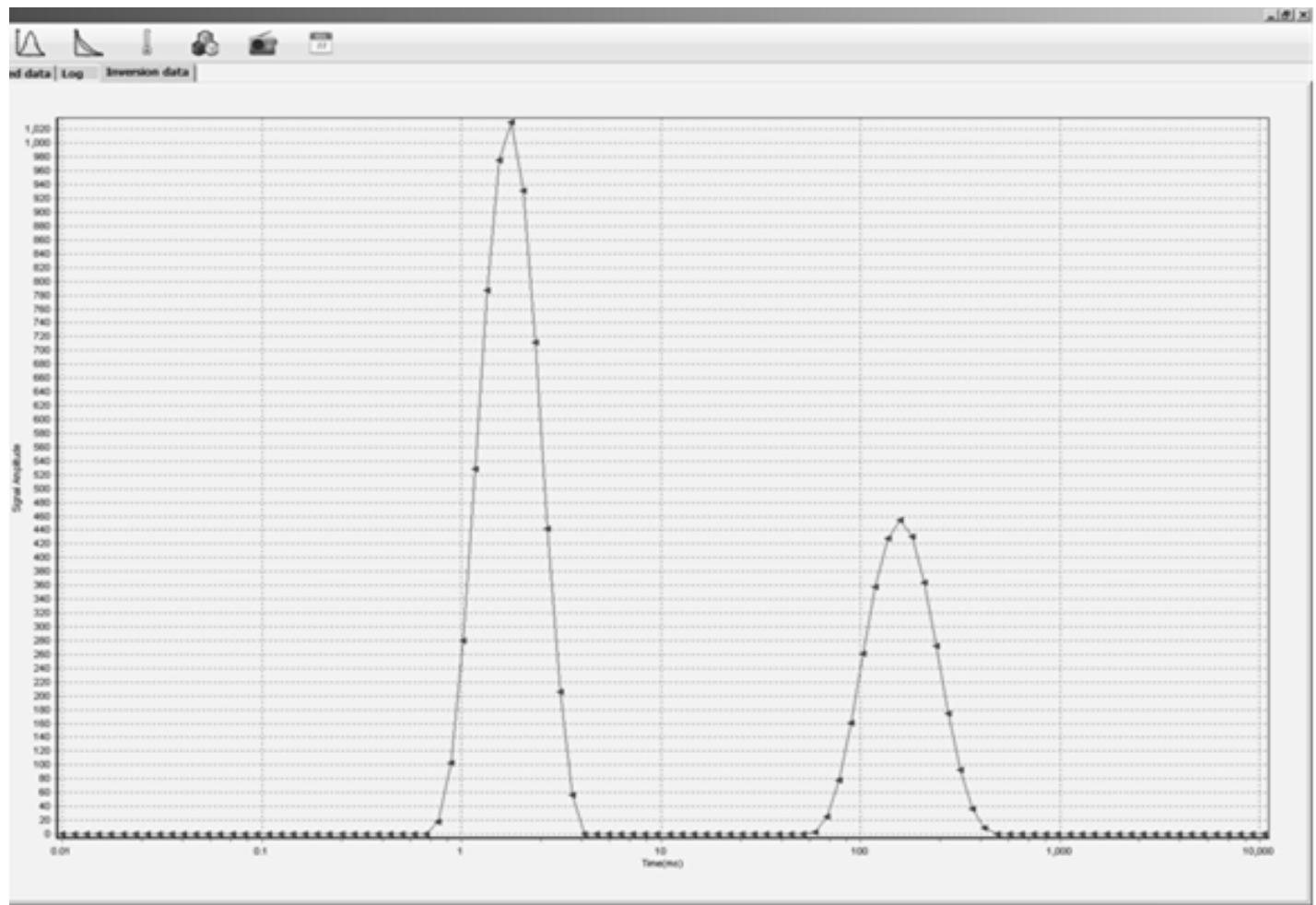

Fonte: A autora

Pico $\mathrm{n}^{0} \mathbf{1}=$ poros pequenos

Pico $\mathrm{n}^{\circ} 2=$ poros grandes .

Pico ํo 3 ignorar, razão muito baixa.

$>$ A razão de volume de grandes e pequenos poros:

A proporção da razão de poros grandes e poros pequenos é:

$0.341 \div 0.659=0.51745068 \quad 3145.879 \div 6070.069=0.51745068$

$\checkmark$ Ou seja, há maior quantidade de poros pequenos do que grandes.

$>$ A uniformidade do tamanho dos poros:

Derivada da largura do pico (igual ao tempo final do pico - tempo inicial do pico/ tempo de pico).

A uniformidade dos poros pequenos é igual a $4.743-0.668 \div 1.78=2.28932584$

A uniformidade de poros grandes é igual a $482.111-51.289 \div 157.248=2.7397614$

$\checkmark$ Ou seja, os poros pequenos são mais uniformes que os poros grandes. 
Paciente 13:

- 58 anos de idade

- Sexo feminino

- Região da amostra óssea: mandíbula (região do dente 45)

Tabela 5.14 - Tabela dos dados de RM do paciente 13

\begin{tabular}{cccccc}
\hline № & $\begin{array}{c}\text { Início tempo de } \\
\text { pico }\end{array}$ & $\begin{array}{c}\text { Tempo de } \\
\text { pico }\end{array}$ & $\begin{array}{c}\text { Final tempo } \\
\text { de pico }\end{array}$ & $\begin{array}{c}\text { Área de } \\
\text { Pico }\end{array}$ & Razão \\
\hline 1 & 0.054 & 0.062 & 0.082 & 0.006 & 0.000 \\
\hline 2 & 0.094 & 0.143 & 0.189 & 1.817 & 0.000 \\
\hline 3 & 0.218 & 1.169 & 6.277 & 3320.997 & 0.451 \\
\hline 4 & 6.277 & 7.220 & 8.305 & 0.050 & 0.000 \\
\hline 5 & 8.305 & 58.999 & 419.109 & 3702.439 & 0.503 \\
\hline 6 & 482.111 & 2249.926 & 10500.000 & 332.070 & 0.045
\end{tabular}

Fonte: A autora

Figura 5.13 - Imagem do gráfico dos dados de RM, tempo T2 do paciente 13

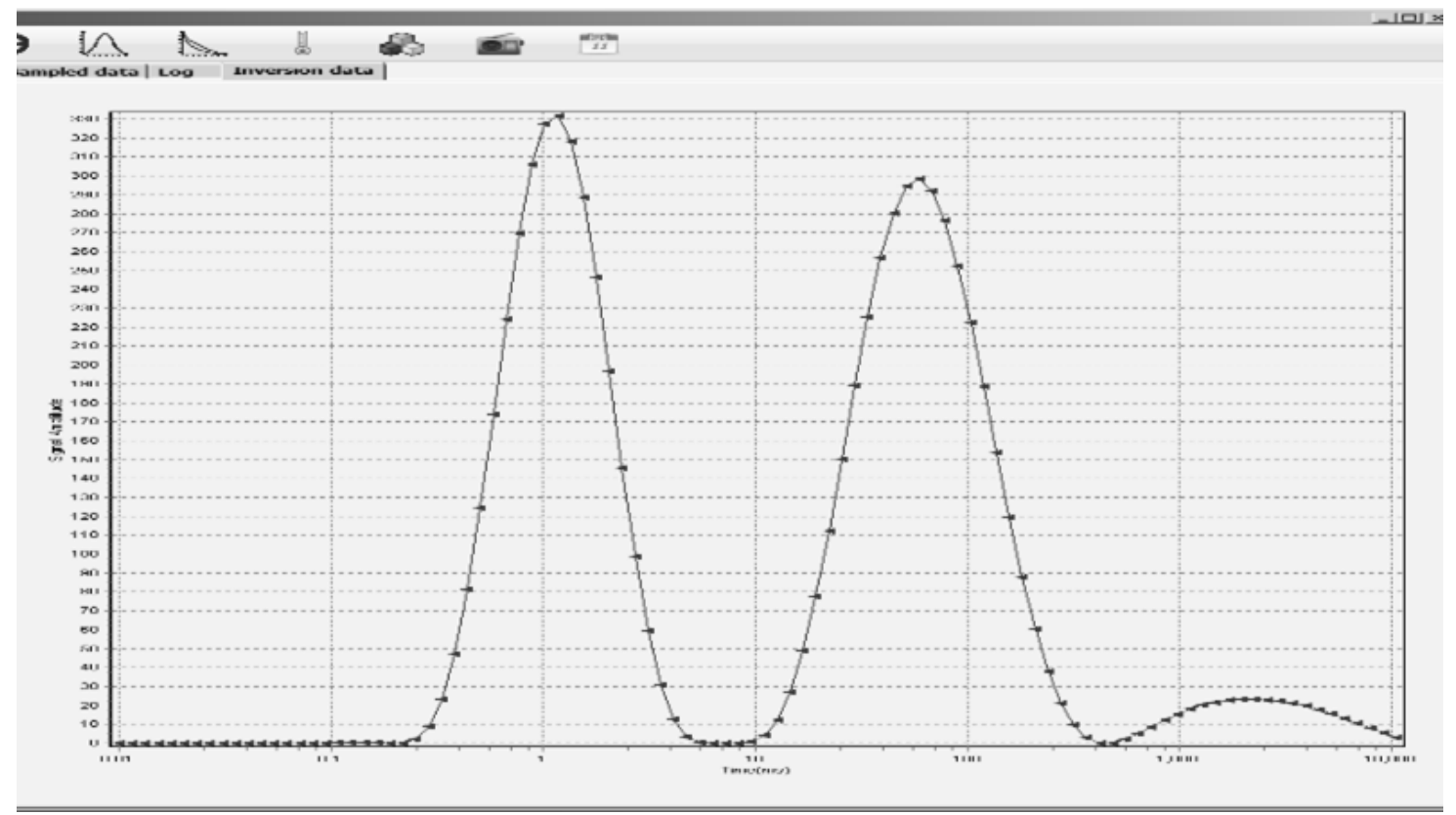

Fonte: A autora

Pico $n^{\circ} 3=$ poros pequenos

Pico $\mathrm{n}^{\circ} 5=$ poros grandes.

Picos nำ 1,2,4 e 6 ignorar, razão muito baixa. 
$>$ A razão de volume de grandes e pequenos poros:

A proporção da razão de poros grandes e poros pequenos é:

$0.503 \div 0.451=1.11529933 \quad 3702.439 \div 3320.997=1.11529933$

$\checkmark$ Ou seja, há maior quantidade de poros grandes do que pequenos.

A uniformidade do tamanho dos poros:

Derivada da largura do pico (igual ao tempo final do pico - tempo inicial do pico/ tempo de pico).

A uniformidade dos poros pequenos é igual a $6.2777-0.218 \div 1.169=5.18366125$ A uniformidade de poros grandes é igual a $419.019-8.305 \div 58.999=6.96137223$

$\checkmark$ Ou seja, os poros pequenos são mais uniformes que os poros grandes.

Paciente 14:

- 57 anos de idade

- Sexo feminino

- Região da amostra óssea: mandíbula (região do dente 46)

Tabela 5.15 - Tabela dos dados de RM do paciente 14

\begin{tabular}{cccccc}
\hline № & $\begin{array}{c}\text { Início tempo de } \\
\text { pico }\end{array}$ & $\begin{array}{c}\text { Tempo de } \\
\text { pico }\end{array}$ & $\begin{array}{c}\text { Final tempo } \\
\text { de pico }\end{array}$ & $\begin{array}{c}\text { Área de } \\
\text { Pico }\end{array}$ & Razão \\
\hline 1 & 0.884 & 2.355 & 5.456 & 10644.453 & 0.815 \\
\hline 2 & 103.306 & 316.728 & 1284.955 & 2409.895 & 0.185 \\
\hline 3 & 1478.114 & 1478.114 & 2249.926 & 0.068 & 0.000 \\
\hline
\end{tabular}

Fonte: A autora 
Figura 5.14 - Imagem do gráfico dos dados de RM, tempo T2 do paciente 14

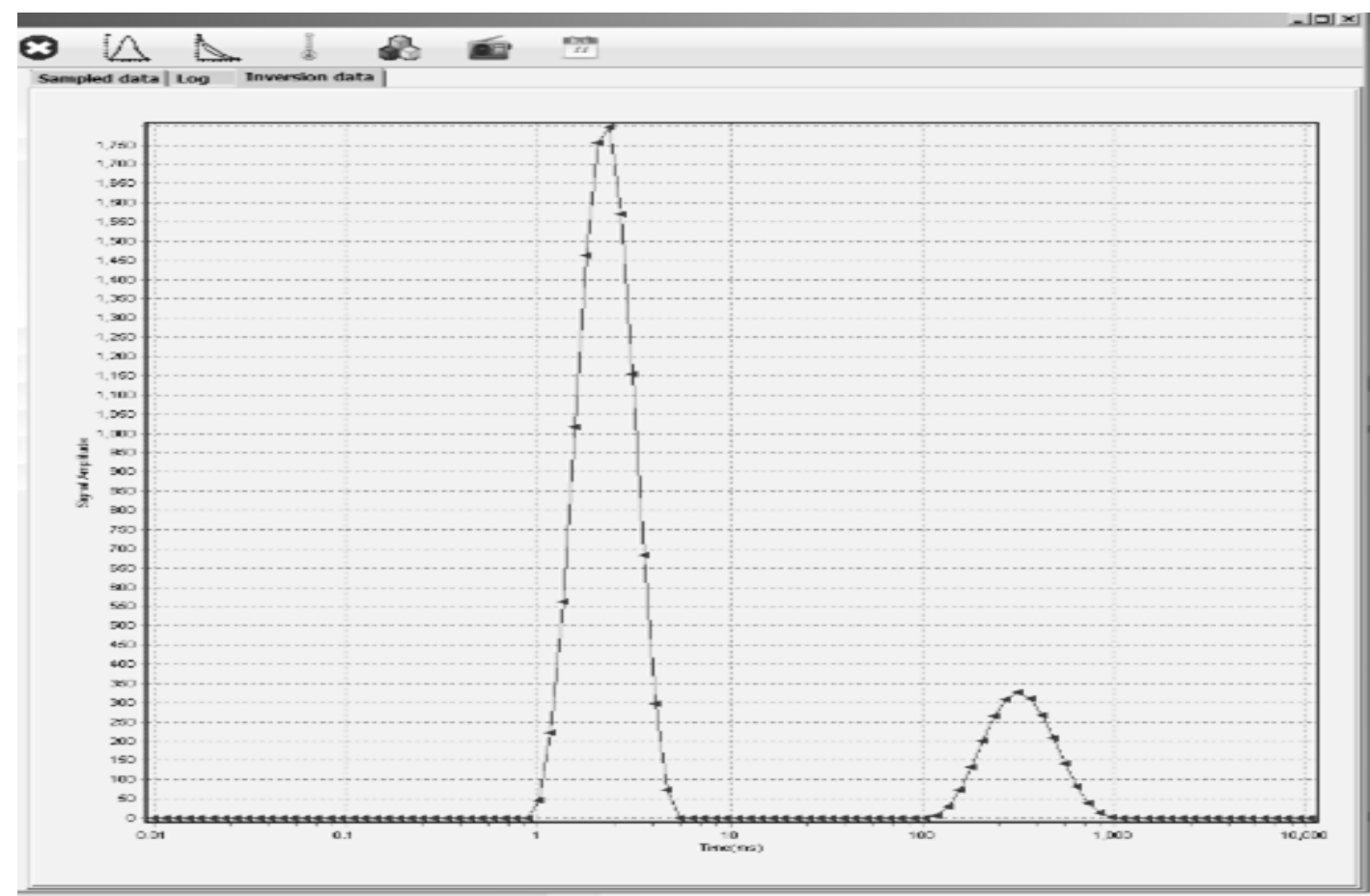

Fonte: A autora

Pico $\mathrm{n}^{0} 1=$ poros pequenos

Pico $\mathrm{n}^{\circ} 2=$ poros grandes .

Pico oㅜ 3 ignorar, razão muito baixa.

A razão de volume de grandes e pequenos poros:

A proporção da razão de poros grandes e poros pequenos é:

$0.185 \div 0.815=0.22699387 \quad 2409.895 \div 10644.453=0.22699387$

$\checkmark$ Ou seja, há maior quantidade de poros pequenos do que grandes.

> A uniformidade do tamanho dos poros:

Derivada da largura do pico (igual ao tempo final do pico - tempo inicial do pico/ tempo de pico).

A uniformidade dos poros pequenos é igual a $5.456-0.844 \div 2.355=1.95838641$

A uniformidade de poros grandes é igual a 1284.955- 103.306 $\div 316.728=3.73080056$

$\checkmark$ Ou seja, os poros pequenos são mais uniformes que os poros grandes. 


\subsection{RESUMO DOS RESULTADOS INDIVIDUAIS DE RESSONÂNCIA MAGNÉTICA DE BAIXO CAMPO $(0,23 T)$}

Das 14 amostras:

$>$ Em relação a quantidade de poros grandes $\mathrm{x}$ pequenos:

Tabela 5.16 - Tabela razão de volume de poros grandes e pequenos

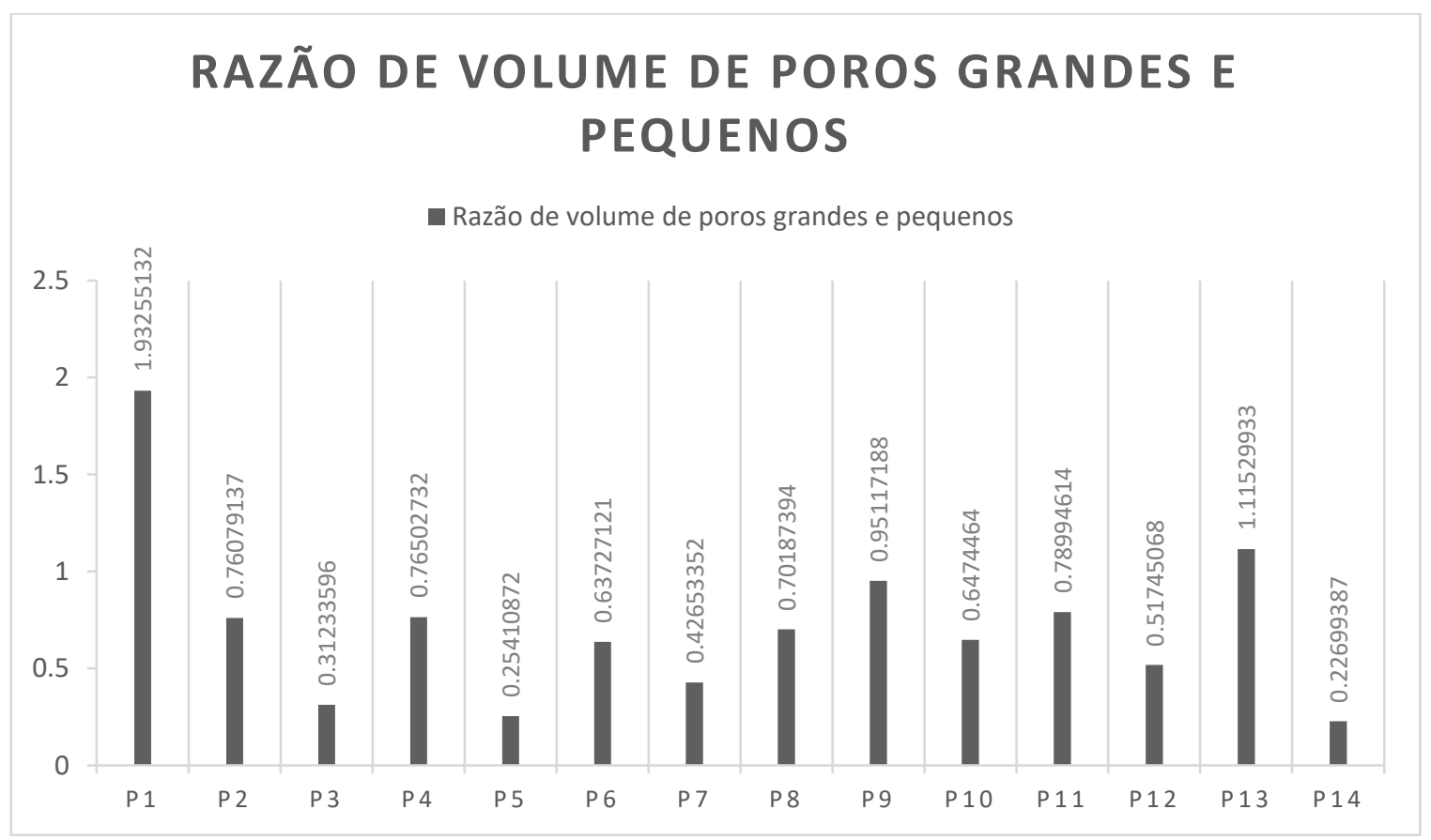

Fonte: A autora

- Apenas 2 amostras tiveram maior quantidade de poros grandes do que pequenos, que foram o paciente 1 e paciente 13 .

$>$ Em relação a uniformidade:

- O paciente 14 teve a maior uniformidade de poros pequenos.

- O paciente 11 teve a menor uniformidade de poros pequenos. 
Tabela 5.17 - Tabela da uniformidade de poros pequenos

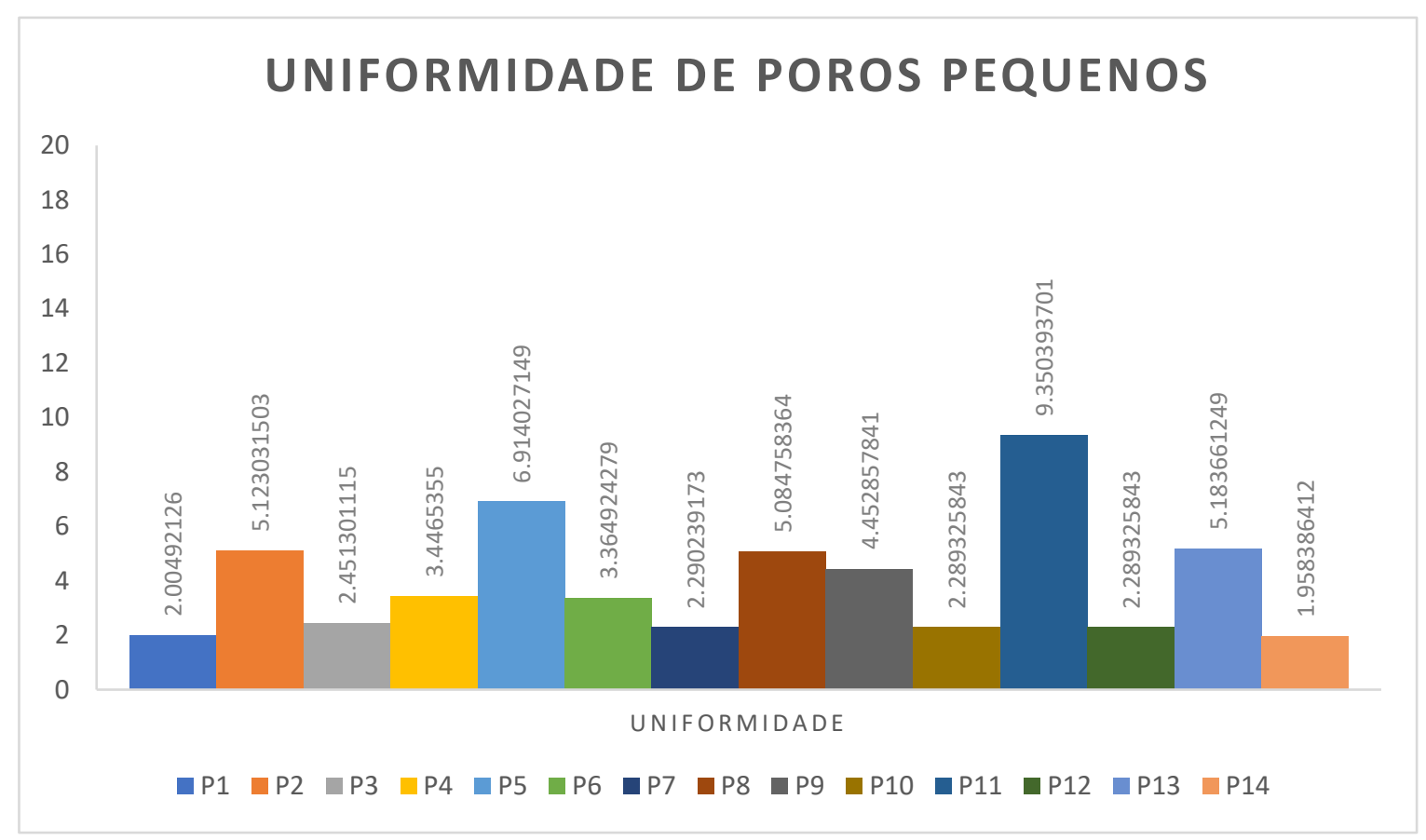

Fonte: A autora

- O paciente 3 teve a maior uniformidade de poros grandes.

- O paciente 1 teve a menor uniformidade de poros grandes.

Tabela 5.18 - Tabela da uniformidade de poros grandes

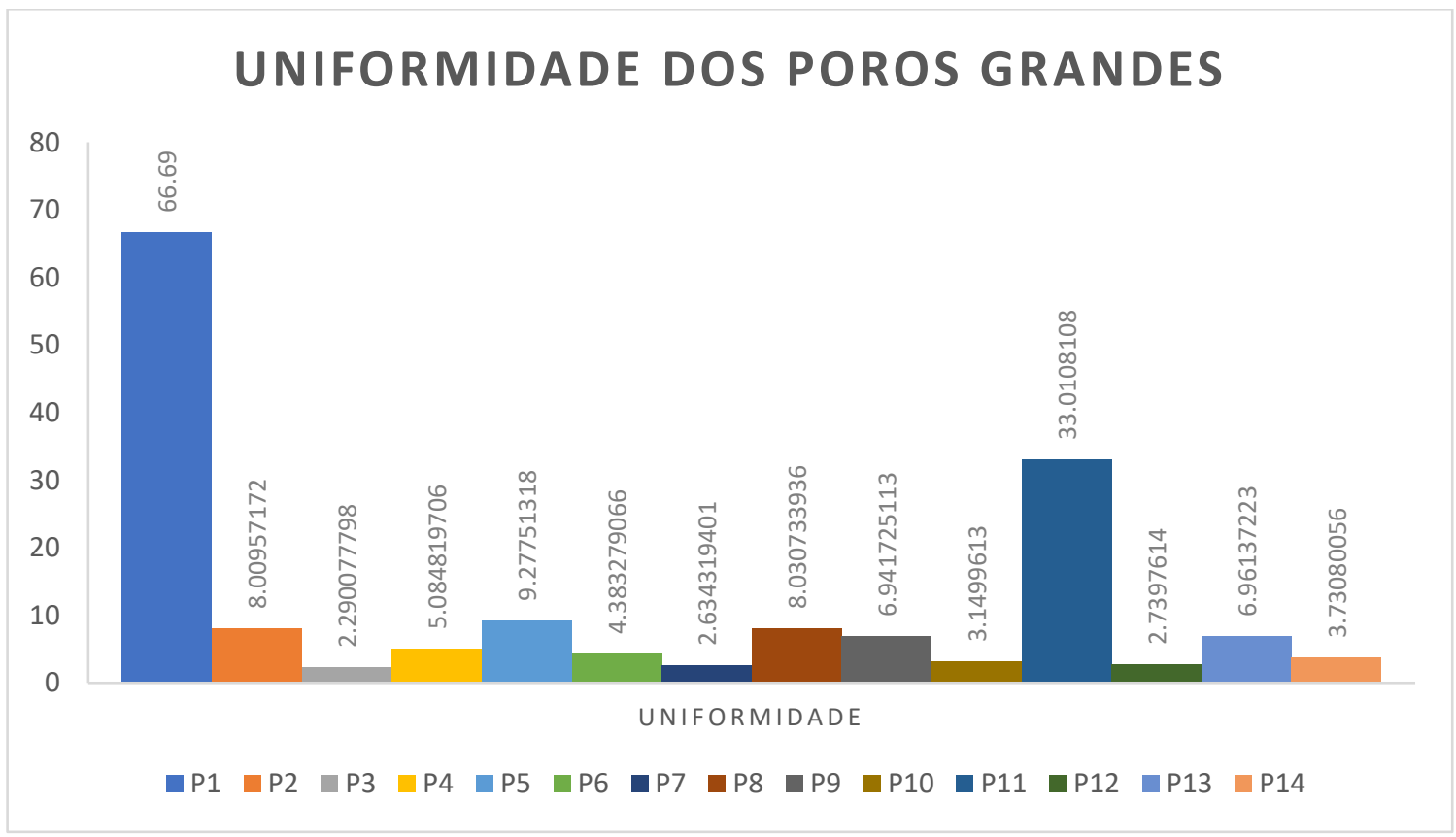

Fonte: A autora 
Em 13 amostras, os poros pequenos foram mais uniformes que os poros grandes, conseguimos observar isso comparando os dados do segundo e terceiro gráfico, o único paciente que teve o poro grande mais uniforme que o poro pequeno foi o paciente 3, poro grande (2.2900778), poro pequeno (2.45130112).

Em relação ao tamanho médio dos poros pequenos e grandes:

Tabela 5.19 - Tabela do tamanho médio dos poros pequenos

\section{TAMANHO MÉDIO DOS POROS PEQUENOS}

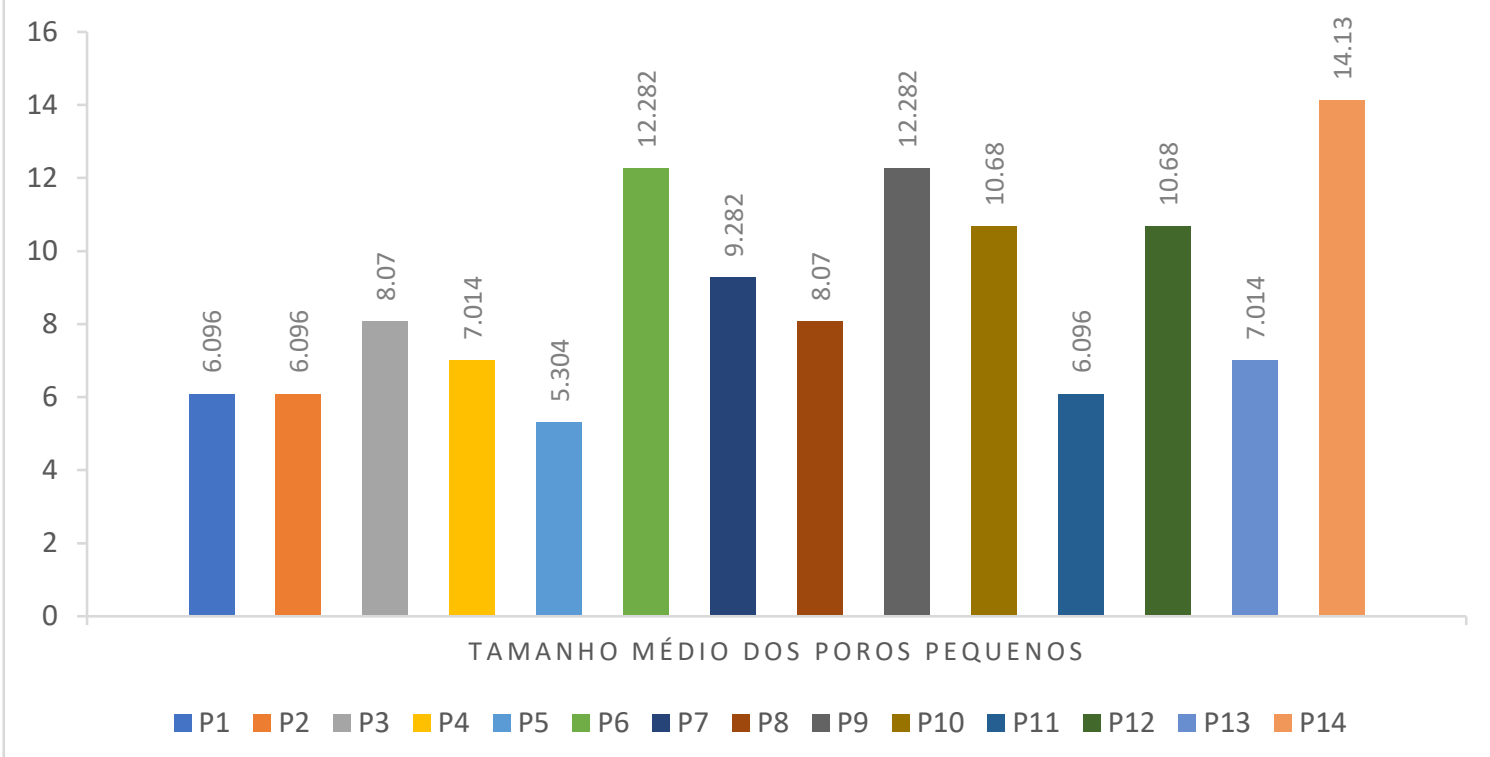

Fonte: A autora

- Paciente 5 teve o menor tamanho médio dos poros pequenos.

- Paciente 14 teve o maior tamanho médio dos poros pequenos. 
Tabela 5.20 - Tabela do tamanho médio dos poros grandes

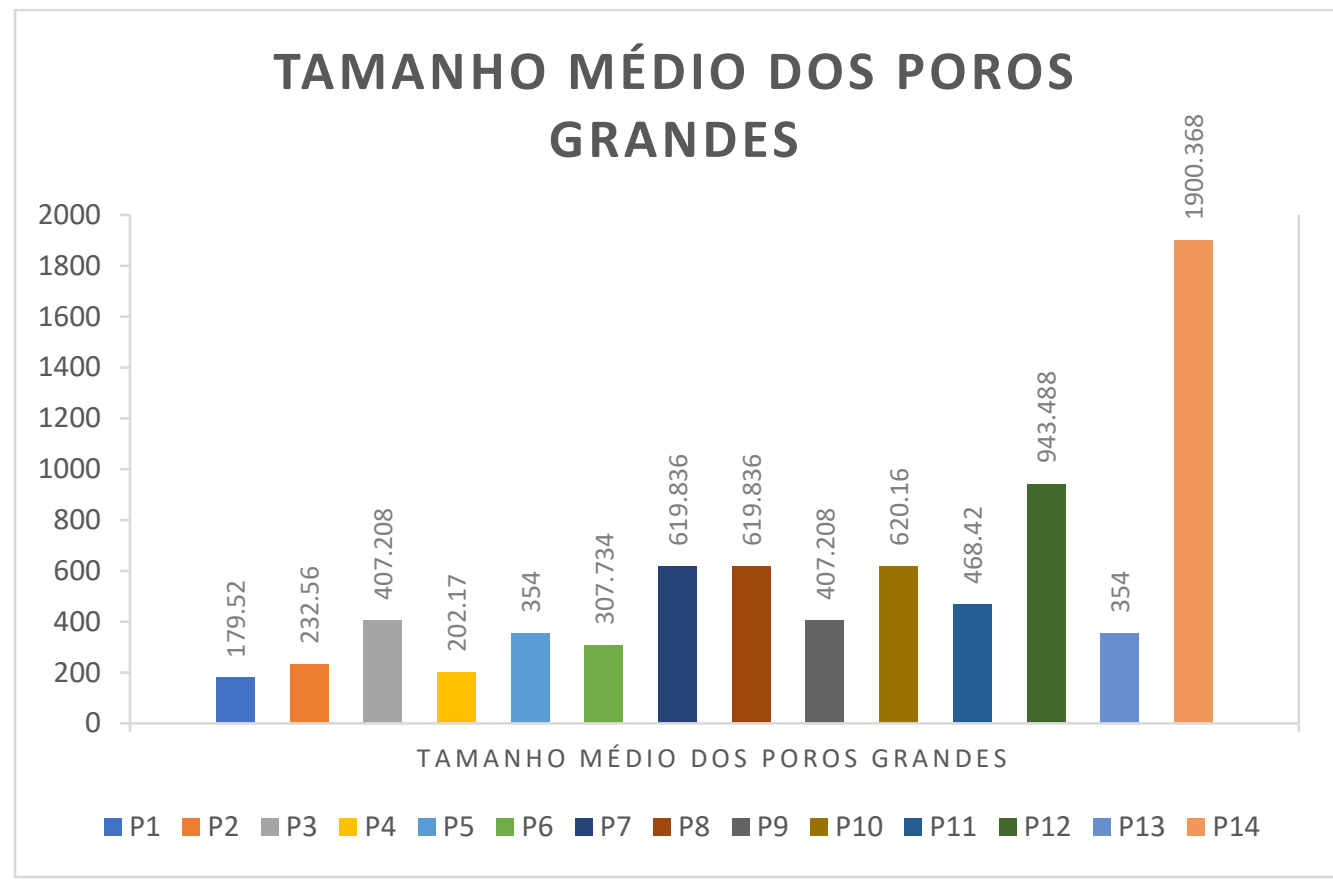

Fonte: A autora

- Paciente 1 teve o menor tamanho médio dos poros grandes.

- Paciente 14 teve o maior tamanho médios dos poros grandes.

5.4 COMPARANDO IDADE COM OS DADOS DE TCFC E MICRO-CT

TABELA 5.21 - TABELA DA COMPARAÇÃO DE IDADE COM OS DADOS DE TCFC E MICRO-CT

\begin{tabular}{|c|c|c|c|c|c|}
\hline Idade & $\begin{array}{c}\mathrm{BV} / \mathrm{TV} \\
(\%)\end{array}$ & $\begin{array}{l}\text { Tb.Th } \\
(\mathrm{mm})\end{array}$ & $\begin{array}{l}\text { Tb.Sp } \\
(\mathrm{mm})\end{array}$ & $\begin{array}{l}\text { Tb.N } \\
(1 / \mathrm{mm})\end{array}$ & $\begin{array}{l}\text { Valores de pixel } \\
\text { de TCFC }\end{array}$ \\
\hline 35 (P9) & & 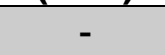 & & & 770.082 \\
\hline 37 (P8) & 85.73999 & 0.44569 & 0.20237 & 1.92374 & 672.256 \\
\hline 55 (P2) & 94.66456 & 0.66628 & 0.17196 & 1.42079 & 438.751 \\
\hline 55 (P6) & 63.22822 & 0.36513 & 0.41212 & 1.73168 & 562.773 \\
\hline 56 (P4) & 88.97492 & 0.46404 & 0.14526 & 1.91741 & 373.889 \\
\hline 56 (P5) & 84.68463 & 0.44922 & 0.12716 & 1.88514 & 351.452 \\
\hline 56 (P10) & 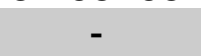 & - & & 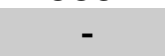 & 461.323 \\
\hline 57 (P12) & - & - & - & - & 355.29 \\
\hline 57 (P14) & - & - & - & - & 313.413 \\
\hline 58 (P13) & - & 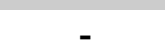 & - & - & 236.455 \\
\hline 63 (P3) & 83.10611 & 0.51948 & 0.12319 & 1.5998 & 550.304 \\
\hline 63 (P11) & . & 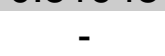 & 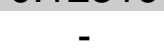 & - & 557.547 \\
\hline 64 (P7) & 92.71872 & 0.46592 & 0.08873 & 1.99001 & 663.193 \\
\hline 70 (P1) & 66.39188 & 0.31375 & 0.2602 & 2.11606 & 446.613 \\
\hline
\end{tabular}

Fonte: $\mathrm{A}$ autora 


\subsection{ANÁLISE DE CORRELAÇÃO LINEAR}

Tabela 5.22 - Tabela da análise de correlação linear

\begin{tabular}{|c|c|c|c|c|c|c|c|}
\hline $\begin{array}{l}\text { Variáveis } \\
\text { estudadas }\end{array}$ & $\begin{array}{c}\text { Fração } \\
\text { volumétric } \\
\text { a óssea, } \\
\text { BV/TV (\%) }\end{array}$ & $\begin{array}{c}\text { Espessura } \\
\text { trabecular } \\
(\mathbf{m m})\end{array}$ & $\begin{array}{c}\text { Espaça } \\
\text { mento } \\
\text { trabecul } \\
\text { ar }(\mathrm{mm})\end{array}$ & $\begin{array}{l}\text { Número } \\
\text { de } \\
\text { trabécula } \\
s(1 / \mathrm{mm})\end{array}$ & $\begin{array}{l}\text { Tamanho } \\
\text { médio } \\
\text { dos } \\
\text { poros } \\
(\mathrm{nm})\end{array}$ & Idade & $\begin{array}{l}\text { Valores } \\
\text { de pixel } \\
\text { de TCFC }\end{array}$ \\
\hline $\begin{array}{c}\text { Fração } \\
\text { volumétrica } \\
\text { óssea, } \\
\text { BV/TV (\%) } \\
\end{array}$ & $\begin{array}{l}r=1.000 \\
p=.\end{array}$ & $\begin{array}{l}r=.714 \\
p=.023\end{array}$ & $\begin{array}{l}r=-.500 \\
p=.104\end{array}$ & $\begin{array}{l}r=-.095 \\
p=.411\end{array}$ & $\begin{array}{l}r=-.690 \\
p=.029\end{array}$ & $\begin{array}{l}r=-.157 \\
p=.356\end{array}$ & $\begin{array}{l}r=-.095 \\
p=.411\end{array}$ \\
\hline $\begin{array}{c}\text { Espessura } \\
\text { trabecular } \\
(\mathrm{mm})\end{array}$ & $\begin{array}{l}r=.714 \\
p=.023\end{array}$ & $\begin{array}{l}r=1.000 \\
p=.\end{array}$ & $\begin{array}{l}r=-.690 \\
p=.029\end{array}$ & $\begin{array}{l}r=-.595 \\
p=.060\end{array}$ & $\begin{array}{l}r=-.595 \\
p=.060\end{array}$ & $\begin{array}{l}r=-.036 \\
p=.466\end{array}$ & $\begin{array}{l}r=-.167 \\
p=.347\end{array}$ \\
\hline $\begin{array}{c}\text { Espaçament } \\
\text { o trabecular } \\
(\mathrm{mm})\end{array}$ & $\begin{array}{l}r=-.500 \\
p=.104\end{array}$ & $\begin{array}{l}r=-.690 \\
p=.029\end{array}$ & $\begin{array}{l}r=1.000 \\
p=.\end{array}$ & $\begin{array}{l}r=0.48 \\
p=.455\end{array}$ & $\begin{array}{l}r=.333 \\
p=.210\end{array}$ & $\begin{array}{l}r=-.410 \\
p=.157\end{array}$ & $\begin{array}{l}r=.119 \\
p=.389\end{array}$ \\
\hline $\begin{array}{l}\text { Número de } \\
\text { trabeculas } \\
(1 / \mathrm{mm})\end{array}$ & $\begin{array}{l}r=-.095 \\
p=.411\end{array}$ & $\begin{array}{l}r=-.595 \\
p=.060\end{array}$ & $\begin{array}{l}r=.048 \\
p=.455\end{array}$ & $\begin{array}{l}r=1.000 \\
p=.\end{array}$ & $\begin{array}{l}r=.429 \\
p=.145\end{array}$ & $\begin{array}{l}r=.470 \\
p=.120\end{array}$ & $\begin{array}{l}r=.286 \\
p=.246\end{array}$ \\
\hline $\begin{array}{l}\text { Tamanho } \\
\text { médio dos } \\
\text { poros }(\mathrm{nm})\end{array}$ & $\begin{array}{l}r=-.690 \\
p=.029\end{array}$ & $\begin{array}{l}r=-.595 \\
p=.060\end{array}$ & $\begin{array}{l}r=.333 \\
p=.210\end{array}$ & $\begin{array}{l}r=.429 \\
p=.145\end{array}$ & $\begin{array}{l}r=1.000 \\
p=.\end{array}$ & $\begin{array}{l}r=-.009 \\
p=.488\end{array}$ & $\begin{array}{l}r=.221 \\
p=.224\end{array}$ \\
\hline Idade & $\begin{array}{l}r=-.157 \\
p=.356\end{array}$ & $\begin{array}{l}r=-.036 \\
p=.466\end{array}$ & $\begin{array}{l}r=-.410 \\
p=.157\end{array}$ & $\begin{array}{l}r=.470 \\
p=.120\end{array}$ & $\begin{array}{l}r=-.009 \\
p=.488\end{array}$ & $\begin{array}{l}r=1.000 \\
p=.\end{array}$ & $\begin{array}{l}r=-.259 \\
p=185\end{array}$ \\
\hline $\begin{array}{c}\text { Valores de } \\
\text { pixel de } \\
\text { TCFC }\end{array}$ & $\begin{array}{l}r=-.095 \\
p=.411\end{array}$ & $\begin{array}{l}r=-.167 \\
p=.347\end{array}$ & $\begin{array}{l}r=.119 \\
p=.389\end{array}$ & $\begin{array}{l}r=.286 \\
p=.246\end{array}$ & $\begin{array}{l}r=.221 \\
p=.224\end{array}$ & $\begin{array}{l}r=-.259 \\
p=.185\end{array}$ & $\begin{array}{l}r=1.000 \\
p=.\end{array}$ \\
\hline
\end{tabular}

Fonte: A autora

As únicas correlações encontradas foram entre:

- Correlação positiva: Fração volumétrica óssea, BV/TV (\%) e Espessura trabecular (Tb.Th) (mm)

- Correlação negativa: Fração volumétrica óssea, BV/TV (\%) e Raio médio dos poros $(\mathrm{nm})$

- Correlação negativa: Espessura trabecular (Tb.Th) (mm) e Espaçamento trabecular (Tb.Sp) (mm) 


\section{DISCUSSÃO}

O presente estudo visou demonstrar pela primeira vez na literatura, a utilização da RM de baixo campo magnético para correlacionar curvas de T2 de prótons presente em moléculas de água, com a porosidade óssea e espaçamento trabecular. A aplicação deste método para tecido ósseo foi baseada em estudos sobre a porosidade de rochas, sendo esta proporcional aos picos de T2 médio das moléculas de água. De maneira similar, foi considerada neste estudo a hipótese de que o pico médio de T2 de prótons presentes no tecido ósseo trabecular estivesse correlacionado com o espaçamento trabecular, e portanto, inversamente proporcional à fração volumétrica óssea (BV/TV), sendo que tal hipótese foi confirmada de maneira significante neste estudo, apesar do seu tamanho de amostra pequeno. Para simular prótons presentes no tecido ósseo trabecular, as amostras ósseas estavam fixadas em formol, que por sua vez possui o mesmo T2 de prótons geralmente presentes no tecido ósseo trabecular, incluindo em medulas ósseas vermelha e amarela, permitindo portanto que amostras ósseas fixadas em formol possam ser correlacionadas com medidas morfométricas do próprio tecido ósseo realizada com métodos como a microTC $(48,49)$.

Apesar de não haver outros estudos em relação a análise de porosidade por meio de RM na odontologia, outros estudos na área de medicina estudando o osso cortical por meio da RM, utilizaram a mesma metodologia analisando os valores de T2 com as moléculas de água, com a mesma lógica de quanto maior o tempo T2, maior o tamanho dos poros $(19,42)$.

Em nosso estudo foi encontrado correlação positiva $(p=.023)$ da fração volumétrica óssea, BV/TV (\%) com a espessura trabecular $(\mathrm{mm})$, ou seja, quanto menor o valor de BV/TV, menor a espessura trabecular, ou seja, há uma menor densidade óssea, ou quanto maior o valor de BV/TV, maior a espessura trabecular, há uma maior densidade óssea. Também foi achado uma correlação negativa ou inversa $(\mathrm{p}=.029)$ da fração volumétrica óssea, BV/TV $(\%)$ com o raio médio dos poros $(\mathrm{nm})$, isso foi um achado interessante pois conforme o volume ósseo diminui, há uma perda óssea, o raio do poro aumenta, ou seja o tamanho do poro aumenta. E por último foi achado correlação inversa $(p=.029)$ na espessura trabecular $(\mathrm{mm}) \mathrm{e}$ 
espaçamento trabecular ( $\mathrm{mm}$ ), ou seja, podemos entender que quanto mais fina vai ficando as trabéculas, há um aumento de espaço entre as trabéculas.

Podemos observar no resultado estatístico que quase houve uma correlação inversa $(p=.060)$ entre o número de trabéculas $(1 / \mathrm{mm})$ com a espessura trabecular $(\mathrm{mm})$ e raio médio dos poros $(\mathrm{nm})$ com a espessura trabecular $(\mathrm{mm})$. Consideramos esses resultados interessantes, pois apesar de não ter dado correlação, isso pode ter acontecido devido ao baixo número de amostra. Poderíamos analisar que quando há uma maior espessura trabecular, há um menor número de trabéculas. Se o raio médio dos poros e a espessura trabecular tivessem uma correlação inversa seria muito importante pois demonstraria que conforme há diminuição da espessura trabecular, há uma diminuição óssea, aumentando o tamanho dos poros.

Analisando a tabela que compara a idade dos pacientes com os dados de TCFC e micro-ct; e os gráficos obtidos pela relação do tamanho médio dos poros pequenos e grandes e a razão da quantidade de poros grandes $x$ pequenos; conseguimos observar que os pacientes de 70 (P1) e 58 (P13) anos podem ter osteoporose, isso porque a paciente de 70 anos teve a maior quantidade de poros grandes e pelo estudo de micro-ct, ela teve a menor espessura óssea entre as amostras e teve um dos maiores espaçamento entre as trabéculas. A paciente de 58 anos, teve o menor valor de TCFC, ou seja, uma baixa densidade óssea, e teve maior quantidade de poros grandes do que pequenos, porém infelizmente não conseguimos os valores de micro-ct, apesar de não ter uma idade tão avançada comparando com a paciente de 70 anos, não temos os dados de saúde da paciente, não sabemos se a paciente é fumante, é sedentária, tipo de hábitos alimentares, se utiliza algum medicamento, entre outros.

Os outros pacientes tiveram densidade relativamente média para baixo, menos os pacientes mais novos de 35 e 37 anos que tiveram bons resultados em geral. 0 paciente mais novo de 35 anos, apesar de ser o único homem e não teve análise por meio de micro-ct, na TCFC teve o maior valor de pixel, a maior densidade óssea comparando com os outros pacientes mais velhos. O paciente de 37 anos (P8), teve o segundo maior valor de pixel de TCFC, o esperado pela baixa idade, em relação ao tamanho médio dos PP e PG, teve valor mediano em ambos. Alguns outros resultados que observamos uma correlação foi do P14, P6 e P7. A paciente de 57 anos (P14), teve o maior tamanho de poros grandes e pequenos, não tivemos a análise de microct, mas na TCFC teve o $2^{\circ}$ menor valor de pixel, ou seja, teve uma baixa densidade 
óssea, demonstrando correlação. A paciente de 55 anos (P6), teve o $2^{\circ}$ maior tamanho médio de PP, e o $3^{\circ}$ menor tamanho médio de PG, no TCFC teve um valor mediano, então pode-se colocar como um paciente com densidade média. A paciente de 64 anos (P7), teve o terceiro maior valor de pixel de TCFC, e em relação ao tamanho médio dos PP e PG, teve valor mediano em ambos. Apesar de ter uma idade que o risco de ter osteoporose é maior, não sabemos o estado de saúde completo da paciente, a alimentação, atividades físicas, pode não possuir hábitos nocivos à saúde (como cigarro), entre outros. Os outros pacientes também tiveram resultados medianos em geral.

O estudo da uniformidade dos poros, seria importante para estudar a microestrutura dos poros e a diferença de tamanho entre os poros grandes e pequenos, acreditamos que isso influencia na resistência óssea, e se em um osso há uma uniformidade nos poros grandes, teria menor densidade óssea comparando com um osso onde há uma baixa uniformidade de poros grandes.

Comparando nosso resultado com a micro-ct, um estudo (8) analisou os poros no osso cortical por meio da histomorfometria, e também obteve o resultado que há uma diminuição do volume ósseo devido o aumento de porosidade nos canais de Harvers. Isso é de acordo com o nosso resultado: conforme o BV/TV diminui, há um aumento do tamanho dos poros.

Em dois estudos $(11,14)$ também compararam os valores de micro ct com a porosidade, e obtiveram uma correlação positiva de quanto maior o tempo T2, há poros grandes no micro-ct, e quanto menor o tempo de T2, os poros no micro-ct são menores. A diferença que ambos utilizaram uma RM de UTE, tempo de eco ultracurto, a diferença é que utilizam o tempo de eco 100 vezes mais baixo do que 0 convencional.

Nos nossos resultados da análise dos gráficos de T2, em relação ao tamanho e uniformidade dos poros, infelizmente não houve correlação, porém podemos relacionar isso com o baixo número de amostra, acreditamos que com uma amostra maior poderá ter uma melhor correlação.

Além do baixo número de amostra, uma outra limitação no nosso trabalho foi por ser um estudo retrospectivo sem dados clínicos, sem anamnese, seria importante ter um dado padrão ouro como a DXA, para analisar a densidade óssea.

Uma vez que a relevância clínica do presente estudo inclui o diagnóstico por imagem do tecido ósseo alveolar para cirurgias relacionadas com a implantodontia, 
os dados de RM e micro-ct apresentados aqui também foram correlacionados com informações da TCFC, que havia sido utilizada para avaliação pré-cirúrgica de todos os casos. Embora existirem algumas controvérsias sobre análise de escala de cinzas em valores de pixels para avaliar densidade óssea, diversos estudos laboratoriais e clínicos validaram o uso da TCFC $(37-39,51,52)$.

Em contraste com os resultados deste estudo, que não encontrou correlação significativa com aspectos morfométricos de densidade óssea por micro-ct, diversos artigos na literatura tem descrito uma correlação linear significativa entre análise de valores de pixels de TCFC, com resultados morfométricos histológicos do tecido ósseo em questão $(38,53)$. O motivo de tal discordância com a literatura, no entanto, pode ser o baixo tamanho de amostra do presente trabalho, que é consideravelmente menor aos estudos acima citados $(50,54-56)$. 


\section{CONCLUSÕES}

Diante dos achados encontrados, podemos concluir:

- Conseguimos obter uma correlação dos resultados de RM com a idade do paciente, e correlacioná-los com a micro-ct e TCFC.

- Na paciente de 70 anos: Na RM teve a maior quantidade de poros grandes, no TCFC teve valor mediano de pixels e na micro-ct teve a menor espessura óssea entre as amostras e um dos maiores espaçamento entre as trabéculas.

- Nos pacientes mais novos, 35 e 37 anos tiveram os dois maiores valores de pixel em TCFC. 


\section{REFERÊNCIAS}

1. Schaffler MB, Burr DB. Stiffness of compact bone: effects of porosity and density. J Biomech. 1988;21(1):13-6.

2. Martin RB, Ishida J. The relative effects of collagen fiber orientation, porosity, density, and mineralization on bone strength. J Biomech. 1989;22(5):419-26.

3. Bousson V, Peyrin F, Bergot C, Hausard M, Sautet A, Laredo JD. Cortical bone in the human femoral neck: three-dimensional appearance and porosity using synchrotron radiation. J Bone Min Res. 2004;19(5):794-801.

4. Celenk $\mathrm{C}$, Celenk $\mathrm{P}$. Evaluation by quantitative magnetic resonance imaging of trabecular bone quality in the dentate and edentulous mandible. Clin Oral Implant Res. 2008;19(1):15-8.

5. Toledano M, Toledano-Osorio M, Guerado E, Caso E, Osorio E, Osorio R. Assessing bone quality through mechanical properties in postmenopausal trabecular bone. Injury. 2018;49 Suppl 2:S3S10.

6. Ott SM. Cortical or Trabecular Bone: What's the Difference? Am J Nephrol. 2018;47(6):373375.

7. Oftadeh R, Perez-Viloria M, Villa-Camacho JC, Vaziri A, Nazarian A. Biomechanics and Mechanobiology of Trabecular Bone: A Review. J Biomech Eng. 2015 Jan;137(1).

8. Wang X, Ni Q. Determination of cortical bone porosity and pore size distribution using a low field pulsed NMR approach. J Orthop Res. 2003/02/06. 2003;21(2):312-9.

9. Horch RA, Nyman JS, Gochberg DF, Dortch RD, Does MD. Characterization of $1 \mathrm{H}$ NMR signal in human cortical bone for magnetic resonance imaging. Magn Reson Med. 2010/09/02. 2010;64(3):680-7.

10. Bae WC, Patil S, Biswas R, Li S, Chang EY, Statum S, et al. Magnetic resonance imaging assessed cortical porosity is highly correlated with muCT porosity. Bone. 2014;66:56-61.

11. Jun Chen Hongda Shao, Darryl D'Lima, Graeme M Bydder, Zhihong Wu, Jiang Du SPG. Evaluation of Bound and Pore Water in Cortical Bone Using Ultrashort Echo Time (UTE) Magnetic Resonance Imaging. NMR Biomed. 2015;28(12):1754-62.

12. Seeman E, Delmas PD. Bone quality--the material and structural basis of bone strength and fragility. N Engl J Med. 2006;354(21):2250-61.

13. Cowin SC. Bone poroelasticity. J Biomech. 1999;32(3):217-38.

14. Bae WC, Chen PC, Chung CB, Masuda K, D'Lima D, Du J. Quantitative ultrashort echo time (UTE) MRI of human cortical bone: correlation with porosity and biomechanical properties. J Bone Min Res. 2012;27(4):848-57.

15. Wehrli FW, Song HK, Saha PK, Wright AC. Quantitative MRI for the assessment of bone structure and function. NMR Biomed. 2006;19(7):731-64.

16. Yeni YN, Brown CU, Norman TL. Influence of bone composition and apparent density on fracture toughness of the human femur and tibia. Bone. 1998;22(1):79-84. 
17. Qingwen Ni Xiaodu Wang, Armondo De Los Santos, Daniel P Nicolella JSN. Assessment of water distribution changes in human cortical bone by nuclear magnetic resonance. Meas Sci Technol. 2007;18(3):715.

18. Ong HH, Wright AC, Wehrli FW. Deuterium nuclear magnetic resonance unambiguously quantifies pore and collagen-bound water in cortical bone. J Bone Min Res. 2012;27(12):2573-81.

19. Seifert AC, Li C, Wehrli SL, Wehrli FW. A Surrogate Measure of Cortical Bone Matrix Density by Long T2 -Suppressed MRI. J Bone Min Res. 2015;30(12):2229-38.

20. Li C, Seifert AC, Rad HS, Bhagat YA, Rajapakse CS, Sun W, et al. Cortical bone water concentration: dependence of MR imaging measures on age and pore volume fraction. Radiology. 2014;272(3):796-806.

21. Augat $\mathrm{P}$, Schorlemmer $\mathrm{S}$. The role of cortical bone and its microstructure in bone strength. Age Ageing. 2006;35 Suppl 2:ii27-31.

22. Cooper DM, Kawalilak CE, Harrison K, Johnston BD, Johnston JD. Cortical Bone Porosity: What Is It, Why Is It Important, and How Can We Detect It? Curr Osteoporos Rep. 2016;14(5):187-98.

23. McCalden RW, McGeough JA, Barker MB, Court-Brown CM. Age-related changes in the tensile properties of cortical bone. The relative importance of changes in porosity, mineralization, and microstructure. J Bone Jt Surg Am. 1993;75(8):1193-205.

24. Currey JD. The effect of porosity and mineral content on the Young's modulus of elasticity of compact bone. J Biomech. 1988;21(2):131-9.

25. Turnbull TL, Baumann AP, Roeder RK. Fatigue microcracks that initiate fracture are located near elevated intracortical porosity but not elevated mineralization. J Biomech. 2014;47(12):3135-42.

26. Tatum Jr. H. Maxillary and sinus implant reconstructions. Dent Clin North Am. 1986;30(2):20729.

27. Renato Mazzonetto HDN e FFN, Napoleão. Enxertos ósseos em implantodontia. Napoleão; 2012; 573 p.

28. Kristopher L. Kuhlman ENM. Porosity and Permeability: Literature Review and Summary. Mech Behav Salt IX. 2018;

29. Rahmouni A, Boulanouar A, Boukalouch M, Samaouali A, Géraud Y, Sebbani J. Porosity, permeability and bulk density of rocks and their relationships based on laboratory measurements. RRM. 2014;44:147-52.

30. Bai B, Zhu R, Wu S, Yang W, Gelb J, Gu A, et al. Multi-scale method of Nano(Micro)-CT study on microscopic pore structure of tight sandstone of Yanchang Formation, Ordos Basin. Petrol Explor Develop. 2013;40(3): 354-358.

31. Yang R, He S, Hu Q-H, Sun M, Hu D, Yi J. Applying SANS technique to characterize nano-scale pore structure of Longmaxi shale, Sichuan Basin (China). Fuel. 2017;197:91-99.

32. Zhu F, Hu W, Cao J, Liu B, Liu Y, Chang C. Probe material choice for nuclear magnetic resonance cryoporometry (NMRC) measurements of the nano-scale pore size distribution of unconventional reservoirs. Energ Explor Exploit. 2018;37: 014459871880247.

33. Junzhi Zhang Yurong Zhang, Zhaofeng Fang, Chuanqing Fu, Jie Guo FB. Effect of pore structures on gas permeability and chloride diffusivity of concrete. Constr Build Mater. 2018;163:40213.

34. Biswal C; Hilfer RBM. Three-dimensional local porosity analysis of porous media. Phys A Stat Mech its Appl. 1998;255(3):221-41. 
35. Fischer L, Valentinitsch A, DiFranco MD, Schueller-Weidekamm C, Kienzl D, Resch H, et al. High-resolution peripheral quantitative CT imaging: Cortical porosity, poor trabecular bone microarchitecture, and low bone strength in lung transplant recipients. Radiology. 2015;274(2):473-81 .

36. Nishimura DA, Aoki EM, Abdala R, Arita ES, Pinhata-Baptista OH, Tateno RY, et al. Comparison of pixel values of maxillary sinus grafts and adjacent native bone with cone-beam computed tomography. Implant Dent. 2018; 27(6):667-671.

37. Isoda K, Ayukawa Y, Tsukiyama Y, Sogo M, Matsushita Y, Koyano K. Relationship between the bone density estimated by cone-beam computed tomography and the primary stability of dental implants. Clin Oral Implants Res. 2012;23(7):832-6.

38. González-García R, Monje F. The reliability of cone-beam computed tomography to assess bone density at dental implant recipient sites: A histomorphometric analysis by micro-CT. Clin Oral Implants Res. 2013;24(8):871-9.

39. Salimov F, Tatli U, Kürkçü $M$, Akoğlan $M$, Öztunç $H$, Kurtoğlu C. Evaluation of relationship between preoperative bone density values derived from cone beam computed tomography and implant stability parameters: A clinical study. Clin Oral Implants Res. 2014;

40. Seifert AC, Wehrli FW. Solid-State Quantitative (1)H and (31)P MRI of Cortical Bone in Humans. Curr Osteoporos Rep. 2016;14(3):77-86.

41. Rajapakse CS, Bashoor-Zadeh M, Li C, Sun W, Wright AC, Wehrli FW. Volumetric Cortical Bone Porosity Assessment with MR Imaging: Validation and Clinical Feasibility. Radiology. 2015;276(2):526-35.

42. Alan C. Seifert Felix W. Wehrli SLW. Bi-Component T2* Analysis of Bound and Pore Bone Water Fractions Fails at High Field Strengths. NMR Biomed. 2015;28(7):861-72.

43. Kribbs PJ, Chesnut 3rd CH, Ott SM, Kilcoyne RF. Relationships between mandibular and skeletal bone in an osteoporotic population. J Prosthet Dent. 1989;62(6):703-7.

44. Manhard MK, Uppuganti S, Granke M, Gochberg DF, Nyman JS, Does MD. MRI-derived bound and pore water concentrations as predictors of fracture resistance. Bone. 2016;87:1-10.

45. Chen M, Yuan H. Assessment of porosity index of the femoral neck and tibia by 3D ultra-short echo-time MRI. J Magn Reson Imaging. 2017;47(3):820-828.

46. Cone a R, Computed B, Study T. Correction of Buccal Dehiscence at the Time of Implant Placement Without Barrier Membranes : Int J Oral Maxillofac Implants. 2013;28(6):1564-9.

47. Roberts JA, Drage NA, Davies J, Thomas DW. Effective dose from cone beam CT examinations in dentistry. Br J Radiol. 2009;82(973):35-40.

48. Baum T, Kutscher M, Muller D, Rath C, Eckstein F, Lochmuller EM, et al. Cortical and trabecular bone structure analysis at the distal radius-prediction of biomechanical strength by DXA and MRI. J Bone Min Metab. 2013;31(2):212-21.

49. Cortes ARG, Cohen O, Zhao M, Aoki EM, Ribeiro RA, Abu Nada L, et al. Assessment of alveolar bone marrow fat content using 15 T MRI. Oral Surg Oral Med Oral Pathol Oral Radiol. 2018;125(3):2449.

50. Fuster-Torres MA, Penarrocha-Diago M, Penarrocha-Oltra D, Penarrocha-Diago $M$. Relationships between bone density values from cone beam computed tomography, maximum insertion torque, and resonance frequency analysis at implant placement: a pilot study. Int $\mathrm{J}$ Oral Maxillofac Implants. 2011;26(5):1051-6. 
51. Turkyilmaz I, Tumer C, Ozbek EN, Tözüm TF. Relations between the bone density values from computerized tomography, and implant stability parameters: a clinical study of 230 regular platform implants. J Clin Periodontol. 2007;34(8):716-22.

52. Cortes ARG, Eimar H, Barbosa J de S, Costa C, Arita ES, Tamimi F. Sensitivity and Specificity of Radiographic Methods for Predicting Insertion Torque of Dental Implants. J Periodontol. 2015;86(5):646-55.

53. Monje A, Monje F, González-García R, Galindo-Moreno P, Rodriguez-Salvanes F, Wang HL. Comparison between microcomputed tomography and cone-beam computed tomography radiologic bone to assess atrophic posterior maxilla density and microarchitecture. Clin Oral Implants Res. 2014;25(6):723-8.

54. Mah P, Reeves TE, McDavid WD. Deriving Hounsfield units using grey levels in cone beam computed tomography. Dentomaxillofacial Radiol. 2010;39(6):323-35.

55. Aranyarachkul P, Caruso MSJ, Gantes MSB, Schulz MSE. Bone Density Assessments of Dental Implant Sites : Int J Oral Maxillofac Implants. 2005;20(3):416-24.

56. Cankaya AB, Erdem MA, Isler SC, Demircan S, Soluk M, Kasapoglu C, et al. Use of cone-beam computerized tomography for evaluation of bisphosphonate associated osteonecrosis of the jaws in an experimental rat model. Int J Med Sci. 2011;8(8): 667-672. 


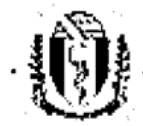
USP - FACULDADE DE
ODONTOLOGIA DA
UNIVERSIDADE DE SÃO \& Plotoforma

\section{PARECER CONSUBSTANCIADO DO CEP}

\section{DADOS DO PROJETO DE PESQUISA}

Titulo da Pesquisa: Análise de Ressonância Magnética com baixo campo para mensuraçāo da porosidade óssea alveolar

Pesquisador: Emiko Saito Arita

Área Temática:

Versão: 2

CAAE: 93572318.3 .0000 .0075

Instituição Proponente: Universidade de São Paulo - Faculdade de Odontologia

Patrocinador Principal: Financiamento Próprio

DADOS DO PARECER

Número do Parecer: 2.865 .434

Apresentação do Projeto:

De acordo com os autores, a osteoporose é uma desordem óssea que geralmente ocorre com maior prevalência em mulheres com mais de 60 anos de idade, geralmente após a menopausa. É caracterizada por baixa massa óssea e deterioração microestrutural do tecido ósseo, ocorre o aumento da frequência do remodelamento ósseo e a reabsorção óssea supera a deposição óssea, ocasionando o aumento do risco de fratura.

\section{Objetivo da Pesquisa:}

O objetivo desse trabalho consiste na avaliaçāo da porosidade óssea no osso alveolar com a utilizaçāo da técnica de Ressonância Magnética de baixo campo, comparando com dados do paciente como a idade.

Avaliação dos Riscos e Benefícios:

Os autores relatam que o risco previsto no estudo será o mínimo, pois será uma pesquisa baseados em

Endereço: Av Prof Lineu Prestes 2227

Bairro: Cidade Universitária
UF: SP $\quad$ CEP: $05.508-900$

Telefone: (11)3091-7960 Fax: (11)3091-7814 E-mail: cepfo@usp.br 


\section{USP - FACULDADE DE ODONTOLOGIA DA UNIVERSIDADE DE SÃO} Qfiacorormo

Continuaçăo do Parecer: 2.865.434

análise dos dados de arquivo e os benefícios foram relatados "Sítios implantares com extração dentária recente (menos de 6 meses de acompanhamento) serão excluídos para evitar o período de cicatrização alveolar. Também serão excluídos os pacientes com distúrbios metabólicos, como diabetes e deficiência de vitamina D, com volume ósseo alveolar insuficiente para a colocação do implante, grávidas ou com suspeita de gravidez, e menores de idade."

\section{Comentários e Considerações sobre a Pesquisa:}

Pesquisa retrospectiva, com base em estudos a partir de bancos de imagens, bem delineada e com grande potencial de contribuição para área de radiologia. EM parecer anterior, solicitou-se a inclusão de membro à equipe (Arthur Cortes), o que foi feito. Solicitou-se também esclarecimento sobre o número amostral (foi esclarecido, serão 15 tomografias provenientes dos EUA; no Plataforma, informa-se que 10 são do Brasil e 5 estrangeiras, pois o Sistema "trava" se o número amostral brasileiro for igual a zero). O cronograma foi atualizado.

\section{Considerações sobre os Termos de apresentação obrigatória:}

Foram apresentados: Folha de rosto, projeto completo e carta de autorização para uso de banco de imagens dos EUA.

\section{Recomendações:}

Tendo em vista a legislação vigente, devem ser encaminhados ao CEP-FOUSP relatórios parciais anuais referentes ao andamento da pesquisa e relatório final, utilizando-se da opção "Enviar Notificação" (descrita no Manual "Submeter Notificação", disponível na Central de Suporte - canto superior direito do site www.saude.gov.br/plataformabrasil).

Qualquer alteração no projeto original deve ser apresentada "emenda" a este CEP, de forma objetiva e com justificativas para nova apreciação.

Conclusões ou Pendências e Lista de Inadequações:

Não há.

Considerações Finais a critério do CEP:

Este parecer foi elaborado baseado nos documentos abaixo relacionados:

Endereço: Av Prof Lineu Prestes 2227
Bairro: Cidade Universitária
CEP: $\quad 05.508-900$
UF: SP Município: SAOPAULO
Telefone: (11)3091-7960 Fax: (11)3091-7814 E-mail: cepfo@usp.br 


\section{USP - FACULDADE DE ODONTOLOGIA DA UNIVERSIDADE DE SÃO

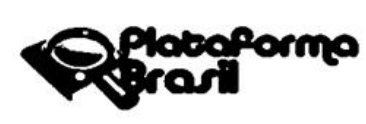

Continuaçăo do Parecer: 2.865.434

\begin{tabular}{|l|l|c|l|r|}
\hline Tipo Documento & \multicolumn{1}{|c|}{ Arquivo } & Postagem & Autor & Situação \\
\hline Informaçōes Básicas & PB_INFORMAÇŌES_BÁSICAS_DO_P & $23 / 08 / 2018$ & & Aceito \\
do Projeto & ROJETO 1174200.pdf & $01: 39: 21$ & & \\
\hline Outros & Autoriza.pdf & $23 / 08 / 2018$ & Emiko Saito Arita & Aceito \\
\hline Projeto Detalhado / & Projeto.pdf & $23 / 38: 08$ & & \\
Brochura & & $01: 36: 29$ & & Aceito \\
Investigador & & $11 / 07 / 2018$ & Emiko Saito Arita & Aceito \\
\hline Folha de Rosto & Folhaderosto.pdf & $10: 27: 29$ & & \\
\hline
\end{tabular}

Situação do Parecer:

Aprovado

Necessita Apreciação da CONEP:

Não

SAO PAULO, 31 de Agosto de 2018

Assinado por:

Maria Gabriela Haye Biazevic

(Coordenador)

Endereço: Av Prof Lineu Prestes 2227

Bairro: Cidade Universitária

UF: SP Município: SAOPAULO

CEP: $05.508-900$

Telefone: (11)3091-7960

Fax: (11)3091-7814

E-mail: cepfo@usp.br 


\section{Martinos Center}

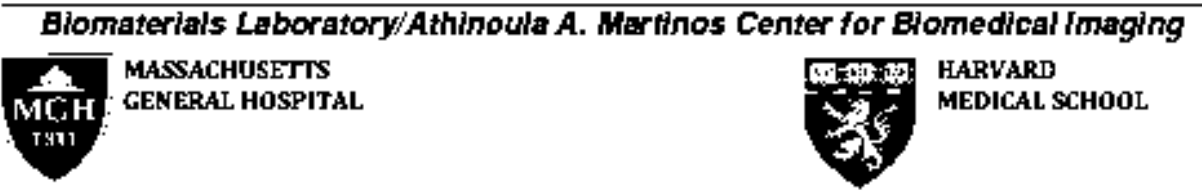

Martinos Center, Room 2320

Department of Radiolopy

Massachusetts General Hospital

I49 I 3 th Street

Charle stow' M, MA 02I39-2020 USA

Phose $+\mathrm{l}-617-726-3083$

Fax $+1-617-726-7422$

jerry@inmr.mgh.harvardedu

Juse 26. 2018

Professor Arthur Rodriguez Gonzalez Cortes

School of Dentisty

University of Sào Paulo

Sà̃o Paulo, SP

Brazil

Dear Arthw:

This letter is in regard to the data you and Protessor Hass Wang of Shanghai University of Medicine and Health Sciences collected on the Niumag low-tield MR device while you both were hosted at Massachusetts General Hospital during the 20l4-15 academic year.

You are selcome to make use of the data in you project "Evaluation of Alveolar Bose Porsity with Low-Field NMR" provided that proper acknowledgement of all organizations providing support tor the persennel, equipment, data collection and project, as well as appropriate decisions on authorship, are included in publications.

Best of luck with the project!

Regards.

renger

Jerome L Ackerman, Ph.D.

Director. Biomaterials Laboratery, Martinos Center. Massachusetts General Hospital Associate Prolessor of Radiology, Harvard Medical School

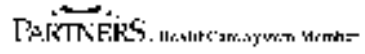

